\title{
Financial Support for Families with Children: Options for the New Integrated Child Credit
}

\author{
Mike Brewer \\ Michal Myck \\ Howard Reed \\ Institute for Fiscal Studies \\ (A n E $\cdot S \cdot R \cdot C$ Research C entre)
}

Copy-edited by Judith Payne

The Institute for Fiscal Studies

7 Ridgmount Street

London WC1E 7AE 


\section{Published by}

The Institute for Fiscal Studies

7 Ridgmount Street

London WC1E 7AE

Tel: +44-20-7291 4800

Fax: +44-20-7323 4780

Email: mailbox@ ifs.org.uk

Internet: http:/ / www.ifs.org.uk

(c) The Institute for Fiscal Studies, January 2001

ISBN 1-873357-99-0

\section{Printed by}

KK S Printing

The Printworks

12-20 Rosina Street

London E9 6JE 


\section{Preface}

An early and shortened version of this paper was submitted to the House of Commons Social Security Select Committee for its enquiry into the integrated child credit. Data from the Family Resources Survey and the Households Below Average Income datasets were made available by the Department of Social Security, data from the British Household Panel Survey were supplied by the ESRC Data Archive and data from the Programme of Research into Low-Income Families were used with the permission of the Policy Studies Institute. None of these institutions bears any responsibility for the interpretation of the data in this Commentary. The authors wish to thank James Banks, Andrew Dilnot and Alissa Goodman for useful discussion and comments on the issues and on previous drafts. Any errors that remain, though, and all opinions expressed, are those of the authors.

Mike Brewer and Howard Reed are Senior Research E conomists and Michal Mydk is a Research $\mathrm{E}$ conomist at the Institute for Fiscal Studies. 



\section{Contents}

$\begin{array}{ll}\text { Executive summary } & 1\end{array}$

1. Introduction 2

2. Creating an integrated child credit from the current systems for 4 financial support for children

2.1 The current system of financial support for children 4

2.2 Moving from the current system of financial support for children to an 6 integrated child credit

2.3 An illustrative integrated child credit based on the current structure 8

3. Why do govemments support families with children? The 10 economics of financial support for children

3.1 Why do governments support families with children? 10

3.2 What is the best way to achieve these aims? 11

3.3 Where are children in the income distribution? 18

3.4 The history of financial support for children in the UK 23

3.5 Systems for directing financial support to families with children in other 25 developed countries

4. How should we judge the success of an integrated child credit? 27

$4.1 \quad$ Objectives for the integrated child credit 27

4.2 How does the current system rate when assessed on these criteria? 28

4.3 How would an integrated child credit meet these objectives? 33

5. The structure of an integrated child credit 35

5.1 What should the maximum level of integrated child credit be for each 35 child?

5.2 How should the integrated child credit be tapered with extra income? 38

5.3 The treatment of income and capital 41

5.4 Modelling options for an integrated child credit 43

6. The administration of an integrated child credit 48

6.1 Dynamics of family structure and incomes 48

6.2 The administrative design of taxes and benefits 50

6.3 Some options for an integrated child credit 53

7. Other design issues: joint assessment, wallet-to-purse classification 59 and classifying the integrated child credit

$\begin{array}{lll}7.1 & \text { Joint assessment } & 59\end{array}$

7.2 Who should receive financial support for children? 61

7.3 Why an employment tax credit for people without children? 63

7.4 Is the integrated child credit a benefit or a tax credit? 64

$\begin{array}{ll}\text { 8. Conclusions } & 65\end{array}$

Appendix: The dynamics of family circumstances $\quad 67$

$\begin{array}{lr}\text { References } & \mathbf{8 0}\end{array}$ 



\section{Executive summary}

The government wants to bring together the different strands of financial support for children in working families' tax credit (WFTC), income support and the children's tax credit to create an integrated and seamless system of financial support for children. This new integrated child credit will be a radical reform of the tax and benefit system, affecting nearly all the 7 million families with children in the UK. The government has set broad objectives for the new credit, but few practical details have been released.

Governments all over the world direct resources to families with children to achieve equity - horizontal and vertical - and efficiency goals. The horizontal equity argument leads governments to direct resources towards poor households, taking account of their composition, whether or not they have children. The vertical equity and efficiency arguments both give rationales for directing additional resources to children. The context in the UK is that families with children are more concentrated at the bottom of the income distribution than families without children. Lone parents tend to have lower incomes than couples with children, and large families have lower average incomes even before equivalisation - than smaller families.

Designing the integrated child credit is a great opportunity to rationalise the existing mechanisms for supporting families with children that have evolved over decades. The government has set objectives for the integrated child credit; these are not met well by the current system of support. But other goals are met well at present, such as providing a safety net, reducing the hassle of applying for support for better-off families and not making large payments that have to be recovered later. The integrated child credit should also be assessed against these broader objectives.

Introducing an integrated child credit could cost around $€ 1$ billion a year, with the gains concentrated on poorer families. This is because families on income support currently receive less for each child than some families receiving WFTC, and the government wants a seamless system of support for out-of-work and low-paid families. The move to joint assessment in an integrated child credit could create losers amongst better-off families; a credit where no one lost through the full joint assessment would cost a further $£ 650$ million a year. D epending on the exact parameters, the integrated child credit could bring together around $€ 9$ billion a year of financial support and be claimed by around 6 million families.

Assessing the integrated child credit on joint family income may not represent a substantial change from the current system of financial support for children for many families: those affected are likely to be better-off families. The decision to pay the integrated child credit to the carer in couples - usually the mother - may affect more families, and may help children too. The other important parameters of an integrated child credit determine its responsiveness to changes in circumstances. The new credit is replacing three different parts of the tax and benefit system, so some parameters - such as whether the credit is cumulative or non-cumulative, the period of assessment for entitlement, the length of award, the frequency and method of payment - will have to change. It is therefore unlikely that the government can meet fully the objectives it has set without compromising on some of the desirable features of the current system. 


\section{Introduction}

The government announced in March 2000 that it wanted to '... bring together the different strands of support for children in the WFTC, Income Support and the Children's Tax Credit to create an integrated and seamless system of financial support for children' (HM Treasury, 2000b).

The integrated child credit is a potentially radical reform of the tax and benefit system that will affect almost all of the 7 million families with children in the UK. Together with the pension credit and the new employment tax credit, it represents part of a move by the current Labour Government to blur the boundaries between the tax and benefit systems, to transfer responsibilities for traditional means-tested benefits from the D epartment of Social Security to the Inland Revenue, and to extend joint assessment to a large number of families who have, since 1990, managed their financial dealings with governments as individuals. It will also mean that, after 30 years of a benefit system that treated people differently depending on whether they work or not, out-of-work families will soon be treated in the same way as low-paid families, at least in respect of the financial support for their children.

The government has set out some broad objectives for a new integrated child credit. But few practical details on how the credit will operate have been released. The most detailed publication to date on the possible structure of a credit (in HM Treasury (2000b)) contained only illustrations of how an integrated child credit would look if it were based on the current structure of financial support for families with children. No doubt this paucity of detail is partly to allow the government to seek views on the operational details; it also reflects the fact that the integrated child credit is a long-term reform: it would not be implemented until 2003 at the earliest.

But as the integrated child credit represents a radical reform of the tax and benefit system for families with children, and the government has given itself a long time to get it right, it is important to realise that there are many options for almost any of the major parameters of the integrated child credit. For example, how should the credit relate to family size and family income? what should the period of assessment and length of award be? how responsive should the credit be to changes in needs or income? should it be cumulative or non-cumulative? and how should it treat different sorts of income and capital? Few of these issues are new, but as the present tax and benefit system has evolved piecemeal, they are not often examined simultaneously from first principles, and certainly not since the Fowler reviews in the mid-1980s that led to the 1988 social security reforms. The introduction of the integrated child credit represents an ideal time to do just that.

There are many questions raised by the integrated child credit, and we only look at what we think are the most important. In this Commentary, we discuss the following:

\footnotetext{
1 Other studies of the integrated child credit include a comparative international study part-funded by the Joseph Rowntree Foundation, and an enquiry by the House of Commons Social Security Select Committee - see House of Commons Social Security Select Committee (forthcoming) and Battle and Mendelson (2001).
} 
- What the current structure of financial support for families with children looks like, and how the government could carve up the existing system to separate out the 'adult' and 'child' components of financial support (Chapter 2).

- Why governments all over the world direct extra resources to families with children (Chapter 3). We consider the economics of financial support for children, look at where children are in the income distribution and examine evidence on the cost of children. We also review the history of financial support for children in the UK and look at some recent international reforms.

- What objectives the government has set for an integrated child credit, and what other criteria we might use to evaluate options and judge its eventual success (Chapter 4).

- How the integrated child credit could be structured to meet the costs of children in different sorts of households (Chapter 5). We look at how it could vary with the number of children and family income, and what level it should be set at. We calculate the aggregate cost and analyse the distributional impact of some options.

- Issues around the administration of the integrated child credit (Chapter 6). Some of the most important design parameters for an integrated child credit will be its responsiveness to changes in income and family circumstances. As the integrated child credit is replacing three very different systems of financial support for children, some parameters will inevitably have to change. We review what is known about short-run changes in family circumstances, as any integrated child credit will need to be responsive and sensitive enough to deal with the constant changes in people's family lives and work situations, and we outline some illustrative options of how sufficient responsiveness and sensitivity might be achieved.

- The implications of other design features, such as the decision to assess the integrated child credit on joint income, why it matters to whom the integrated child credit is paid, why the government wants to have tax credits for people without children, and how the integrated child credit will score in the National Accounts (Chapter 7).

We have not covered all of the issues, omitting discussions of how to reform payments for disabled adults with children or adults with disabled children, what to do with the childcare tax credit and housing benefit, whether to pay the integrated child credit to dependent children over 16, and whether the proposed split between 'adult' and 'child' payments makes sense to people receiving financial support for children. Nor do we pretend to have all the answers to the questions we have posed. But we hope we have set out a useful framework with which to analyse the integrated child credit and provided information to help promote the debate on its future form. 


\section{Creating an integrated child credit from the current systems for financial support for children}

This chapter describes the current system of financial support for children and shows one way in which it could be restructured to form an integrated child credit. We present this simple reform before going on, in future chapters, to explore more radical alternatives.

\subsection{The current system of financial support for children}

From April 2001, there will be four ways that the government directs financial support to children:

- child benefit - a flat-rate, non-means-tested, non-taxable benefit for each child - is the core of financial support for children;

- means-tested benefits for families where no one works - income support and income-related jobseeker's allowance - contain extra child premiums for each child and a family premium for any family with children;

- in-work benefits for low-income families where one adult works 16 hours or more a week - working families' tax credit and disabled person's tax credit - contain child credits for each child;

- a new tax credit for all families who pay income tax - the children's tax credit - is worth up to $£ 442$ in 2001 , and is phased out where there is a higher-rate taxpayer in the family. It will be worth less than $£ 442$ to families who would pay less than $£ 442$ income tax a year (gross incomes of less than $€ 7,500$ ) and to families where any partner pays higher-rate tax (corresponding to gross incomes of over £33,935 or more in 2001). The credit will not vary with the number of children.

Table 2.1 shows the rates of these instruments from April 2001, assuming they are not altered in the 2001 Budget. Clearly, the actual rates will be different by 2003, when the integrated child credit is due to be introduced.

Table 2.2 shows how many families may benefit from each strand of support. But these four systems overlap: almost all families will receive simultaneous support from two systems, and some will receive three. For example:

\footnotetext{
2 Section 3.4 outlines the development of financial support for children in the UK. Battle and Mendelson (2001) contains more details on the UK's current system.

3 The Chancellor suggested in the 2000 Pre-Budget Report that it could rise to £520 in April 2001.

4 Hereafter, we use WFTC to refer to both working families' tax credit and disabled person's tax credit for parents, and income support to refer to both income support and income-related jobseeker's allowance.

5 In Chapter 6, we look at some of the dynamics of family circumstances that mean that, over the period of a year, some families may receive financial support for children from all four sources.
} 
Table 2.1. Transfer payments for families with children from April 2001

\begin{tabular}{l|c}
\hline & Weekly payments \\
\hline Child benefit & $£ 15.50$ \\
First child & $£ 10.35$ per child \\
Subsequent children & $£ 53.05$ (lone parent) \\
Inome support & $£ 83.25$ (couple) \\
Adult premium & $£ 14.50$ \\
& $£ 31.45$ \\
Family premium & \\
Child allowance & $£ 54.00$ \\
W FTC & $£ 26.00$ \\
Basic credit & \\
Child credit & $£ 8.50$ \\
Children's tax credit & \\
Maximum value & \\
\hline \hline
\end{tabular}

$N$ otes: IS and WFTC values are for children aged under 17; higher rates apply for children under 19 and in full-time education. CB rates apply for all dependent children (i.e. under 17 and under 19 and in full-time education). Families must have a child under 16 to claim the CTC.

- All families with children can receive child henefit alongside one or more of income support, WFTC and the children's tax credit.

- WFTC and income support are nearly mutually exclusive because of the conditions on the number of hours worked, but some families in transition from having some adults in work to having no adults in work could temporarily receive both income support and WFTC. Almost no family would receive income support and benefit from the children's tax credit at the same time.

- Families receiving WFTC will generally also benefit from the children's tax credit from April 2001.

Table 2.2. Families receiving financial support for children, 1999-2000

\begin{tabular}{l|cc}
\hline \hline & Number of families & Number of children \\
\hline Child benefit & $7,025,000$ & $12,700,000$ \\
Income support & $1,230,000$ & $2,400,000$ \\
Jobseeker's allowance & 136,000 & 286,000 \\
(income-related) & & \\
WFTC & 989,000 & $2,010,000$ \\
Children's tax credit & about 5 million & about 8 million \\
\hline \hline
\end{tabular}

N otes: CB, IS and JSA estimates are for Great Britain, WFTC and CTC for the UK. JSA and WFTC estimates relate to February 2000.

Sources: CB, IS, JSA and WFTC figures from appropriate Quarterly Statistical Enquiries (D epartment of Social Security and Inland Revenue). CTC estimate from HM Treasury (2000b).

${ }^{6}$ Families on income support do not see any increase in their income from receiving child benefit, but they still have to claim it. 


\subsection{Moving from the current system of financial support for children to an integrated child credit}

The government has said that it will '... bring together the different strands of support for children in the Working Families' Tax Credit (WFTC), Income Support (IS) or Job Seekers Allowance (Income Related) and the Children's Tax Credit to create an integrated and seamless system of financial support for children paid direct to the main carer, building upon the foundation of universal Child Benefit' (HM Treasury, 2000b). Figure 2.1 shows the transfer payments from these four transfer mechanisms from April 2001, when the children's tax credit is introduced. The figure shows the total value of income support and WFTC awards, not just the amount payable in respect of having a child. The figure assumes a couple family with one child and one earner; the equivalent picture for a lone parent would be identical apart from a lower total income support payment.

Figure 2.1. Financial support for a family with one child from April 2001 (f p.w.)

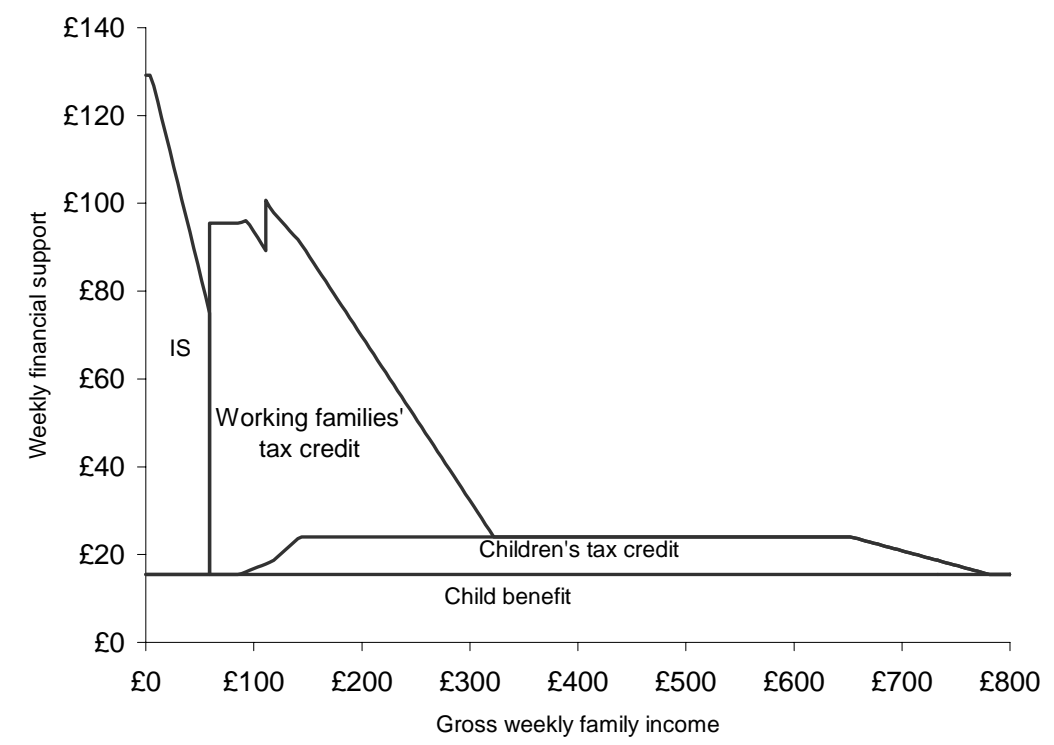

Souro: Authors' calculations from the IFS tax and benefit model, TAXBEN. The figure assumes that the family qualifies for WFTC at a weekly wage of $£ 59.20$, corresponding to 16 hours of work at the national minimum wage.

The first step in constructing a possible integrated child credit is to consider how to split the current transfer payments for families with children into 'child-related payments' the extra transfer payments made to families because they have a child - and 'adultrelated payments' - whatever is left. This is relatively straightforward except for WFTC. WFTC consists of a 'basic credit' plus 'child credits', and it is unclear how to treat the basic credit. It could be viewed in a similar way to the family premium in income support: it is a payment made only to families with children and it does not vary with the number of children, and that would make it a 'child-related payment'. It is plausible that it would seem that way to low-income families without children who become eligible for and claim WFTC when their first child is born: they were getting no extra support when they had no children and the adults were working, but with one child they became 
entitled to the basic credit and a child credit of WFTC. But in HM Treasury (2000b), the government treats the basic credit as an 'adult-related payment' because it has also announced that, from 2003, low-income adults without children will be able to claim an in-work tax credit through an employment tax credit (discussed more in Chapter 7). ${ }^{9}$ So Figure 2.2 shows the current system broken up into adult and child payments, having split WFTC in the way suggested in HM Treasury (2000b) and assuming that the new employment tax credit is equal in value to the current basic credit in WFTC!

\section{Figure 2.2. Financial support for a family with one child from April 2001, split into 'adult' and 'child' components (f p.w.)}

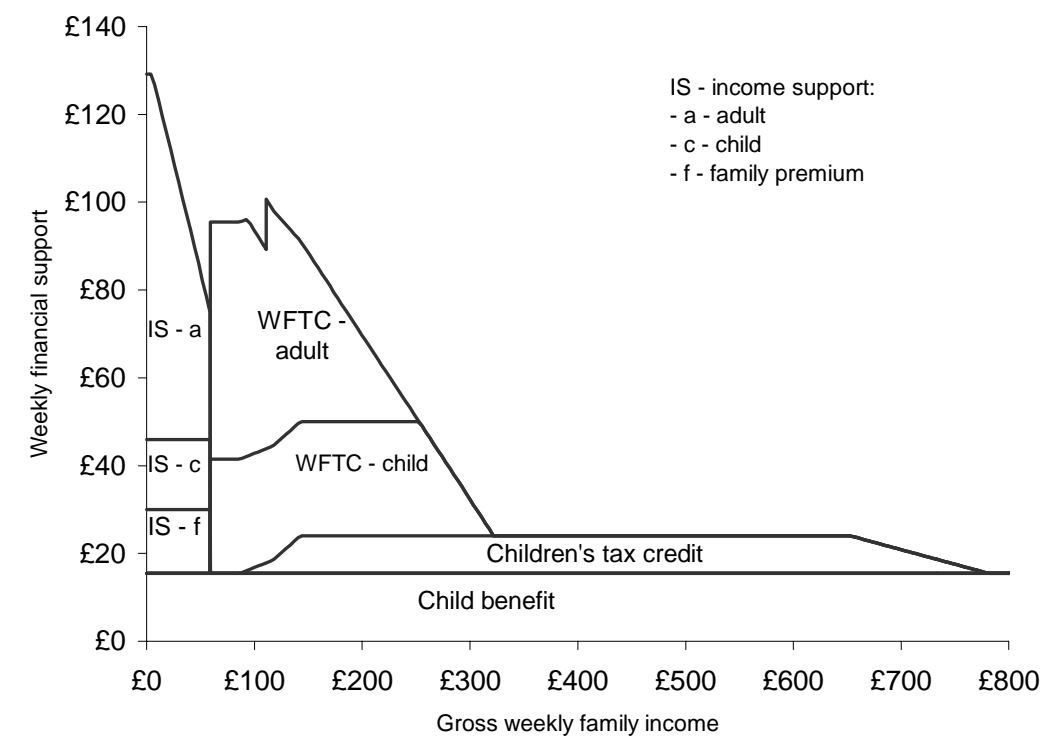

Source: Authors' calculations from the IFS tax and benefit model, TAXBEN. The figure assumes that the family qualifies for WFTC at a weekly wage of $£ 59.20$, corresponding to 16 hours of work at the national minimum wage.

Under these assumptions, and from April 2001, 'child-related support' for the first child will vary from $€ 15.50$ for the richest families to $£ 45.95$ for the poorest, but will reach $£ 50$ for some families on WFTC. payments reduced before the child-related payments as income rises: this is, of course, arbitrary, and we could just as well have presented a figure showing the opposite.

\footnotetext{
7 Just to demonstrate that no study of the tax and benefit system is simple, disabled person's tax credit - which is similar to working families' tax credit except that it is available to people with disabilities who are in work, whether or not they have children - has a higher 'basic credit' for families with children than it does for single people without children.

8 We maintain this assumption throughout the Commentary.

9 The poorest do not receive the greatest amount of financial support because the government allows for the fact that, since 1988, families with children on in-work benefits have not been eligible for free school meals and welfare foods. Valuing free school meals would broadly equalise the per-child payments.
} 


\subsection{An illustrative integrated child credit based on the current structure}

The government has released very few details of how an integrated child credit could be structured and operated, so Figure 2.3 shows how an integrated child credit could be constructed from the current levels of transfer payments for families with children. $1 \mathrm{We}$ have assumed that the total value of the integrated child credit together with child benefit is equal to $€ 50$ a week - the maximum amount payable for children at present (under the breakdown above). Above 16 hours a week, a family would no longer be entitled to jobseeker's allowance or income support and would claim employment tax credit instead. But the integrated child credit would still be paid at the same level (or: 'a seamless payment across the welfare to work divide' (HM Treasury, 2000b)).

\section{Figure 2.3. How an integrated child credit might be formed from the current system of financial support for a family with one child (f p.w.)}

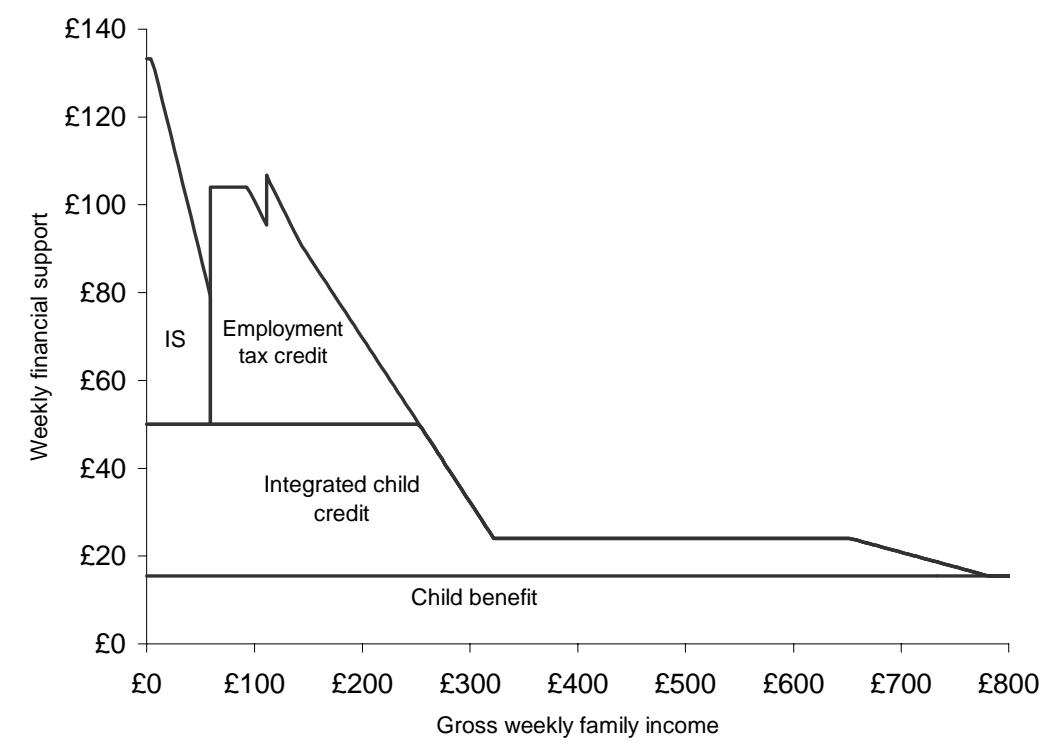

Source: Authors' calculations from the IFS tax and benefit model, TAXBEN. The figure assumes that the family qualifies for the new employment tax credit at a weekly wage of $£ 59.20$, corresponding to 16 hours of work at the national minimum wage.

The government has said that child benefit will remain separate from the integrated child credit. There is no reason why an integrated child credit could not also include child benefit, so that all child-related payments were made through one mechanism that would apply to all families with children in the UK. This could further increase transparency and reduce administration costs for government. On the other hand, child benefit is a popular and well-recognised benefit, with almost full take-up. As well as wishing to avoid the political disadvantages of appearing to abolish a popular benefit, the government may want to use and retain the child benefit records as an almost-complete register of families that could claim the integrated child credit.

10 This graph is broadly the same as Figure 2.6 in HM Treasury (2000b). 
Some key features of the new integrated child credit system, if it mirrored the current structure of financial support, would be as follows:

- There would be a core part of the integrated child credit payable to all families with children with (gross) incomes below around £33,935, regardless of how many children they have, corresponding to what is now the children's tax credit. Better-off families would receive less or none.

- Lower-income families receiving the full integrated child credit award would receive an extra $£ 36.35$ a week for each child beyond the first (£10.35 in child benefit and $£ 26$ in the integrated child credit); better-off families would receive less than that for children beyond the first.

- Lower-income families (below around $£ 13,000$ a year) would receive the same value of integrated child credit whether they were out of work or in low-paid work.

As the integrated child credit represents a radical reform of the tax and benefit system for families with children, and the government has given itself a long time to get it right, it is important to realise that almost any of the major parameters of the integrated child credit could be changed. These are the issues we turn to in the rest of this Commentary. 


\section{Why do governments support families with children? The economics of financial support for children}

'Children are not simply a private luxury. They are an asset to the community, and the community can no longer afford to leave the provision for their welfare solely to the accident of individual income.'

Eleanor Rathbone, The C ase for F amily A llowanos, 1940.

In this chapter, we look at why almost all governments direct cash resources to families with children. As the quotation above illustrates, this is not a new debate. It is possible to distinguish between equity (as in faimess) and efficiency arguments for supporting families with children.

The efficiency argument is that society cares about the well-being of all children as they represent future productive members of society. There are two equity arguments. Pursuing horizontal equity means trying to reduce the inequality in living standards between households of different compositions. But governments may also have vertical equity goals which mean that they treat households with different compositions differently. We discuss the role of equivalence scales in helping governments make comparisons of living standards between different sorts of households, and the implications of equivalence scales for structuring financial support for children (Section 3.2). We then illustrate the position of children in the income distribution and recent trends in child poverty in the UK (Section 3.3). Having examined these issues, we sketch out the history of financial support for children in the UK (Section 3.4) and highlight an important recent study that has compared the systems for supporting children in four countries (Section 3.5). This will provide some context before we analyse options for the new integrated child credit in subsequent chapters.

\subsection{Why do govemments support families with children?}

Economists usually distinguish arguments for any form of government intervention into those concerning efficiency and those to do with equity. We can do the same for financial support for children:

- The horizontal equity argument is about redistribution: most governments redistribute money from the richest households to the poorest households because they want to achieve a fairer distribution of living standards or income (however that may be measured). 1 But it would not be sensible, when governments measure living standards and compare incomes, simply to take money from the households with the highest incomes and give it to those with the lowest without taking account of the composition of those households. Smaller households will generally need fewer

\footnotetext{
11 We are simplifying the equity arguments for government intervention here. Governments are presumably interested in ensuring greater equality of well-being, but that is impossible for governments to affect directly, so inoome is usually used as a proxy. And governments usually look at household income because they cannot directly affect all individuals' incomes (such as the incomes of children) and because individuals in households probably share some amount of their incomes with each other.
} 
resources to achieve a certain standard of living than larger households, such as those with children. This horizontal equity argument is not exclusively a rationale for directing resources to families with children; it is a rationale for directing resources to poorer households, having taken account of the composition of the households.

- The vertical equity argument is that governments may have a desire to redistribute money to families with children through some other value judgement about the value of children and parenting 1 This will represent a redistribution between people at different stages of their lives, as families with children have not always had children and do not remain families with children for ever.

- The efficiency argument is that society has an interest in the outcomes for all children over and above the parents' own interest (or that there are externalities attached to the outcomes for children). There is strong evidence ${ }^{13}$ that children who grow up in low-income families are more likely than better-off children to be unemployed, to be low-skilled, to be unhealthy, to commit crime and to be a teenage parent in adulthood. Most of these outcomes will impose costs on society in future years in forgone taxes and extra spending on health, law and order, and social security.

So the horizontal equity argument leads governments to direct resources towards poor households, whether or not they have children, but taking account of their composition. If governments do pursue horizontal equity goals, then families with children benefit both because families' consumption needs increase and because their ability to do paid work falls as they have children. 14 The vertical equity and efficiency arguments both give rationales for doing more than reducing inequality in living standards having controlled for the composition of the household. The vertical equity case appeals to some unquantifiable pro-parenting sentiment; the efficiency argument is that governments are more worried about the lasting effects of low incomes on children than on adults.

\subsection{What is the best way to achieve these aims?}

Any government that sets out to achieve these equity and efficiency goals will encounter several issues of practical policy. First, is directing income towards low-income families with children the best way to improve the outcomes or the well-being of children? Second, how should the government best measure the costs of children in order to redistribute income fairly and thereby meet any possible equity aims?

\footnotetext{
12 Theoretically, increasing the cash given to adults for their children should also increase the birth rate. Certainly, there are international examples of countries using the tax and benefit system to give incentives to have large families (for example, the French A llocations Familiales are non-means-tested transfers where the amount per child is an increasing function of the number of children). But we do not think that this is an important issue in the UK at this time, and do not discuss it further here.

13 See, for example, Hobcraft (1999), Gregg and Machin (2000a and 2000b), Hills (1999) and Bradshaw and Barnes (forthcoming).

14 Estimates of the latter are given in Rake (2000).
} 


\subsubsection{H ow closely does children's well-being relate to family inoome?}

One problem that confronts all governments that want to help children is that governments cannot directly affect children's own incomes, nor can they even be sure that increasing incomes in families with children will help children's well-being. In fact, although there is a great deal of evidence that links deprivation as an adult to growing up in a low-income family when a child (see references in footnote 13), there is little UK evidence yet on what impact increasing incomes through extra government transfers has upon children's well-being. Even if low incomes are linked with adverse outcomes, it need not be the case that increasing family income will improve these outcomes - there may be some hidden factor that is producing the apparent causation (for example, parental characteristics may lead to both higher parental incomes and better child outcomes).

Two recent studies show how the link between family incomes and child poverty may be more complex than first thought. One looked at patterns of spending on over 1,000 children.5.5 It showed that children in low-income households have broadly similar amounts of money spent on them as children in higher-income households, but parents in low-income families were much more likely to go without essentials - even regularly skipping meals in some cases - than parents in higher-income families. Another study, which looked at poverty defined in terms of a lack of necessities, showed that the link between living in a low-income household and being in poverty was weak er for children than for adults (in other words, children in low-income households were less likely to go without essentials than adults in low-income households).

Both these results suggest that parents tend to protect their children from the effect of low incomes by making sacrifices themselves. If this is happening, then increasing the amount of money going to low-income families with children may help the parents more than the children. As we discuss in Chapter 7, we can expect some improvements in children's outcomes by redirecting financial support for children to the main carer, rather than the main earner, in couple families. But a proper evaluation of increased financial support for children as an anti-poverty measure would ideally need to compare it with schemes that gave non-financial help to families with children.

This discussion also helps explain why governments provide a great deal of support and assistance for parents and children through public services as well as through income transfers. For example, families with children tend to use the NHS more than families without children, and childcare, nursery schools and education all benefit parents and children more than families without children. It is beyond the scope of this paper, though, to attempt to identify the total value of government help for children: in subsequent chapters, we will focus on the appropriate level of financial transfers through the tax and benefit system, taking the current provision of public services to families with children as given. But it is important to realise that giving parents money is not the only way to help children.

\footnotetext{
15 See Middleton, Ashworth and Braithwaite (1997).

16 See Gordon et al. (2000).
} 


\subsubsection{M easuring the cost of children}

We said above that it would be naïve for a government that wanted to achieve greater equality simply to redistribute from large households to small households. This is because a large household needs more income to reach a given standard of living than a smaller household. Without adjusting household incomes, one-person households might seem poorer than, say, four-person households. Social scientists have developed techniques that allow incomes of different-sized households to be compared. This process of adjusting incomes is called equivalisation, as the 'equivalence scales' that are estimated allow the living standards of families of different types to be brought into equivalence. Equivalence scales can therefore help governments better identify which households are poor, given their composition, and structure the form of redistribution through the tax and benefit system.

\section{Equivalence scales}

Equivalence scales seek to tell us how the 'economic well-being ' 1 of a household varies with the composition of the household. For example, an equivalence scale provides an answer to the question 'how much extra resources does a household with a child need to enable it to reach the level of economic well-being it would have without the child?' (or 'how much extra resources does a household with a child need before we can say that it is better off - in welfare terms - than an otherwise-equivalent household without a child?').

A variety of approaches have been used by social scientists to estimate equivalence scales, but one crucial and common weakness of studies that focus on the extra resources needed by families with children is that they tend to treat children merely as a drain on family resources. They therefore do not acknowledge that the majority of those who have children have taken a decision to become parents, and no doubt derive enormous satisfaction from that. There are two broad methods of estimating equivalence scales:

- Some studies attempt to construct a basket of goods and services that would be needed by households of different compositions, and then calculate the differences in costs between these baskets. This is known as the 'budget standards' method.

- Another approach is to say that the cost of an extra household member (such as a child) is the amount of money that the newly expanded household would need to achieve the same level of welfare or economic well-being as an otherwise-equivalent household. This method dates back to 1895 and was first used by Engel, and it has been used a great deal by economists since then.

A recent example of the budget standards method that looked at families with children is given in Parker (1999). A survey of studies that used the second, utility-based, method to look at the costs of children is given in Banks and Johnson (1993). Each approach has its strengths, but each has an important limitation.

The drawback of the budget standards methodology is that researchers have to set in advance what criteria they are going to use to define a 'minimum' basket of goods and

17 Or 'standard of living' or 'welfare' (in the economist's sense). 
services. For example, does the minimum relate to physical needs such as clothing, heat and food, or does it include items needed for normal child development and social inclusion? Is the basket an absolute measure that does not change in composition over time, or is it defined relative to the average standard of living? The method therefore calculates the costs of a hypothetical basket of goods which may not be what parents actually buy; this could be seen as an advantage or a disadvantage.

The second, 'utility-based', methodology assumes that researchers can measure something that closely approximates 'economic well-being'. The most common method is to assume that the proportion of total household expenditure spent on food (or food plus other necessities) is a good indicator of well-being, with a higher proportion of total income spent on necessities indicating a lower level of well-being, since rich households generally spend a smaller proportion of their budget on food and necessities than poorer households. But this is an untestable assumption. Also, as we noted above, this method cannot allow for the fact that most families with children chose to have children, presumably because they derive pleasure from being parents, so it cannot make a perfect comparison between two households' welfare or happiness.

There is an enormous literature, with little consensus, on how to estimate equivalence scales and the results of such studies. There have been fewer examples of the budget standards methodology. But it is possible to make some broad generalisations of the results:

- 'utility-based' methods find that a family's first child seems to cost more than subsequent children (in other words, there seems to be a fixed cost to having children) (see Banks and Johnson (1993, Table 5.3));

- there is good evidence that older children cost more than younger children (see Banks and Johnson (1993, Tables 2.2, 2.3, 2.4 and 5.3), Middleton, Ashworth and Braithwaite (1997) and Parker (1999)).

A related exercise is to look at what parents actually spend on their children: a recent example is given in Middleton et al. (1997). This study found that children had an average of $£ 57$ a week spent on them in 1995, £52 of which came from parents. This amount increased with the age of the child, although not by much. Parents on income support spent around 10 per cent less a week on their children than the average for all parents, but this was still far more than the child allowances in income support at the time of the survey and represented a greater proportion of total family income than the average for all families. However, it would be wrong to use these figures as a firm guide as to what the level of government financial support for children should be. Parents choose what they spend on their children, limited, of course, by their income. The fact that the poorest parents spent between $£ 45$ and $£ 50$ a week on children does not tell us what children cost, as we do not know whether those parents were spending enough however that is to be defined - on their children. ${ }^{18}$

${ }_{18}$ Although, as we noted above, parents in the poorest families seemed to be making sacrifices in order to be able to spend this amount on their children. 


\section{The implications of equivalence scales for the structure of financial support for children}

Successive UK governments have used a semi-official equivalence scale - the McClements scale - in publications such as the Department of Social Security's $\mathrm{H}$ ouseholds Below A verage Inome (HBAI) for a number of years. Because it is used by UK governments, it tends to be used by academics working on similar issues. But this does not mean that there is any agreement over whether McClements is the right scale.19 The government's position is that it will continue to use McClements, but the reasons seem more about the benefits of using a consistent equivalence scale over time and the fact that many of the headline income distribution statistics do not change markedly under different equivalence scales, than they are to do with whether McClements is a good equivalence scale.

Table 3.1. The McClements equivalence scale

\begin{tabular}{l|cc}
\hline \hline & Before housing costs & After housing costs \\
\hline First adult & 0.61 & 0.55 \\
Second adult (spouse) & 0.39 & 0.45 \\
Second adult (other) & 0.46 & 0.45 \\
Third adult & 0.42 & 0.45 \\
Other adults & 0.36 & 0.40 \\
Child aged 0-1 & 0.09 & 0.07 \\
Child aged 2-4 & 0.18 & 0.18 \\
Child aged 5-7 & 0.21 & 0.21 \\
Child aged 8-10 & 0.23 & 0.23 \\
Child aged 11-12 & 0.25 & 0.26 \\
Child aged 13-15 & 0.27 & 0.28 \\
Child aged 16 or over & 0.36 & 0.38 \\
\hline \hline
\end{tabular}

Sourœ: Department of Social Security, 2000a, Appendix 4.

The McClements scale expresses equivalence scales as ratios compared with a reference household. 21 The reference household is a (cohabiting or married) couple with no children, and this has a weight of 1 . The weight of any other household gives the ratio of income that is needed, on average, to achieve a similar level of welfare. To calculate the total weight for any other household, the weights of all the individuals in that household are added up. The weights are shown in Table 3.1. For example, on the 'beforehousing-costs' scale, a household consisting of a lone parent with one child aged 3 has a weight of 0.79 , and a household of four unrelated adults has a weight of 1.85 . This implies that a lone parent with a child aged 3 needs, on average, 79 per cent of the income of a couple with no children to achieve the same standard of living, and a four-

19 See, for example, Coulter, Cowell and Jenkins (1992), Banks and Johnson (1994), McClements (1977 and 1979) and Muellbauer (1979a and 1979b).

20 We are drawing our own inferences from the arguments in Appendix 4 in Department of Social Security (1998 and 2000a).

${ }^{21}$ Equivalence scales need not be ratios - they could be expressed as absolute amounts of income or as ratios that vary with income in a non-parametric way (see Banks and Johnson (1993) for some examples of all of these).

22 There are different weights for 'before-housing-costs' income and 'after-housing-costs' incomes. This is because a significant part of the extra cost of extra household members is the increased housing costs. 
adult household needs 85 per cent more than the couple with no children. ${ }^{23}$ Two features of the McClements scale - which we shall return to in Chapter 5 - are that it gives more weight to older children than to younger children and that it assumes that the first child costs no more and no less than the second or third child.

As we said above, the McClements scale is used by the government to calculate income inequality statistics. It was also used to structure the payments in supplementary benefit (the precursor to income support - see Section 3.4), but there is no link now between it and the structure of financial support for the poorest children. This is shown in Table 3.2, which compares the current rates of income support with the McClements scale for different families. It expresses the maximum award of income support for a particular family as a fraction of that received by a cohabiting or married couple with no children. This sort of analysis does not help us assess whether income support payments are sufficient to cover families' needs; it only helps us assess the structure of income support payments. As people on income support can claim separate help with housing costs, we use the 'after-housing-costs' McClements scale. For example, a lone parent with one child aged 3 receives 19 per cent more in income support payments than a couple with no children. But the McClements scale suggests that that family type would need only 73 per cent of the income of a couple to achieve the same standard of living.

\section{Table 3.2. Comparing McClements weights with income support payments}

\begin{tabular}{l|cc}
\hline \hline Family type & $\begin{array}{c}\text { Maximum income support } \\
\text { award relative to couple } \\
\text { with no children }\end{array}$ & $\begin{array}{c}\text { McClements weights } \\
\text { (after housing costs) }\end{array}$ \\
\hline Single adult & 0.64 & 0.55 \\
Couple with no children & 1.00 & 1.00 \\
Couple with one child aged 3 & 1.55 & 1.18 \\
$\begin{array}{l}\text { Couple with one child aged 3 } \\
\text { and one child aged 9 }\end{array}$ & 1.93 & 1.41 \\
$\begin{array}{l}\text { Couple with one child aged 9 } \\
\text { and one child aged 17 }\end{array}$ & 1.94 & 1.61 \\
Lone parent with one child aged 3 & 1.19 & 0.73 \\
Lone parent with one child aged 3 & 1.57 & 0.96 \\
and one child aged 9 & 1.58 & 1.16 \\
$\begin{array}{l}\text { Lone parent with one child aged 9 } \\
\text { and one child aged 17 }\end{array}$ & & \\
\hline \hline
\end{tabular}

N otes: IS and JSA rates from April 2001. Adults aged 25 or over.

But we have not made an entirely fair comparison in Table 3.2. The McClements scale is implicitly an average of the weights across the population, and we have shown the comparison with financial support for children for the poorest families. Figure 3.1 expands the calculations by showing the ratios of income after tax and benefits of a couple with one child to that of a couple without children under the tax and benefit systems in 2001, and assuming an illustrative employment tax credit for families without

\footnotetext{
23 When the government calculates inequality statistics in HBAI, it performs this calculation in reverse, by dividing a household's total income by its McClements weight to obtain 'household equivalised income' which is directly comparable with that of other households. So if a lone parent with one child aged 3 had weekly income of $£ 79$, and a household of four adults had income of $€ 185$, they would both have an equivalised weekly income of $£ 100$, implying the same level of economic well-being as a couple with no children with an income of $£ 100$ a week.
} 
children equal to the basic credit in WFTC. It shows that, from April 2001, a couple with children with no gross income (and therefore on income support or jobseeker's allowance) would have a net income about 55 per cent higher than a couple without children. The same family on a gross annual income of $£ 6,000$ would have 89 per cent more net income than a couple without children, and on $£ 20,000$, only 8 per cent more. The massive jump in the ratio at around $£ 3,000$ represents the generosity of WFTC. This relative generosity to families with children (or relative meanness to families without children) would be reduced if there were an employment tax credit for those without children, as shown by the grey line in Figure 3.1.

\section{Figure 3.1. The equivalence scales implicit in the UK tax and benefit system in 2001 and after an illustrative employment tax credit for those without children}

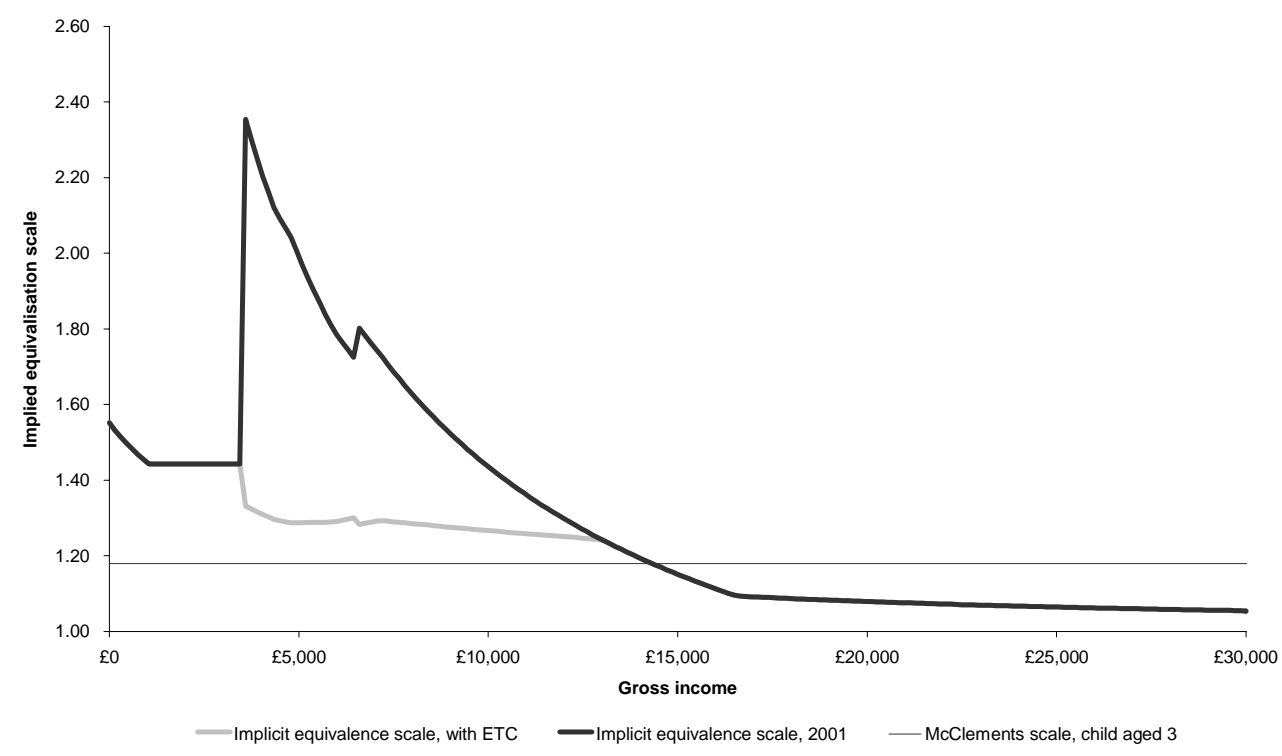

$\mathrm{N}$ otes: Figure shows ratio of income of a couple with one child to that of a couple without children after tax and benefits under the tax and benefit system in 2001, and with an employment tax credit available to people without children at the same rate as the basic credit in WFTC. The family qualifies for WFTC at an annual income that represents 16 hours of work a week at the minimum wage.

Taken together, Table 3.2 and Figure 3.1 show that, although the government is using the McClements scale to adjust household incomes in the inequality statistics in HBAI, it is not explicitly using it to structure financial support for children (although the McClements scale is an average across all families). Compared with the relative weights in McClements, it is directing more resources at younger children, the first child and poorer families.

There are two possible implications. It may be that the government does not believe that the McClements scale captures the variation in needs, in which case the government should use a better equivalence scale when calculating income inequality statistics. Alternatively, the government may be deliberately doing more than merely compensating families for the extra consumption needs of children when it sets levels of financial support for children. As we discussed earlier, it could be doing this either to achieve some vertical equity goals or because of the efficiency arguments. 


\subsection{Where are children in the income distribution?}

Arguments about why governments may choose to help children are backed up by evidence from the UK (as well as other countries) which suggests that families with children predominate at the bottom of the income distribution - even after government transfers. The distributions of income for families with children, for working-age families without children and for pensioners are shown in Figure 3.2. There are around 29 million families in Great Britain.24 around 7.8 million are pensioner families, 7.0 million are families with children and the other 13.5 million are working-age families without children.

\section{Figure 3.2. Income distribution for families with children, for pensioners and for families without children}

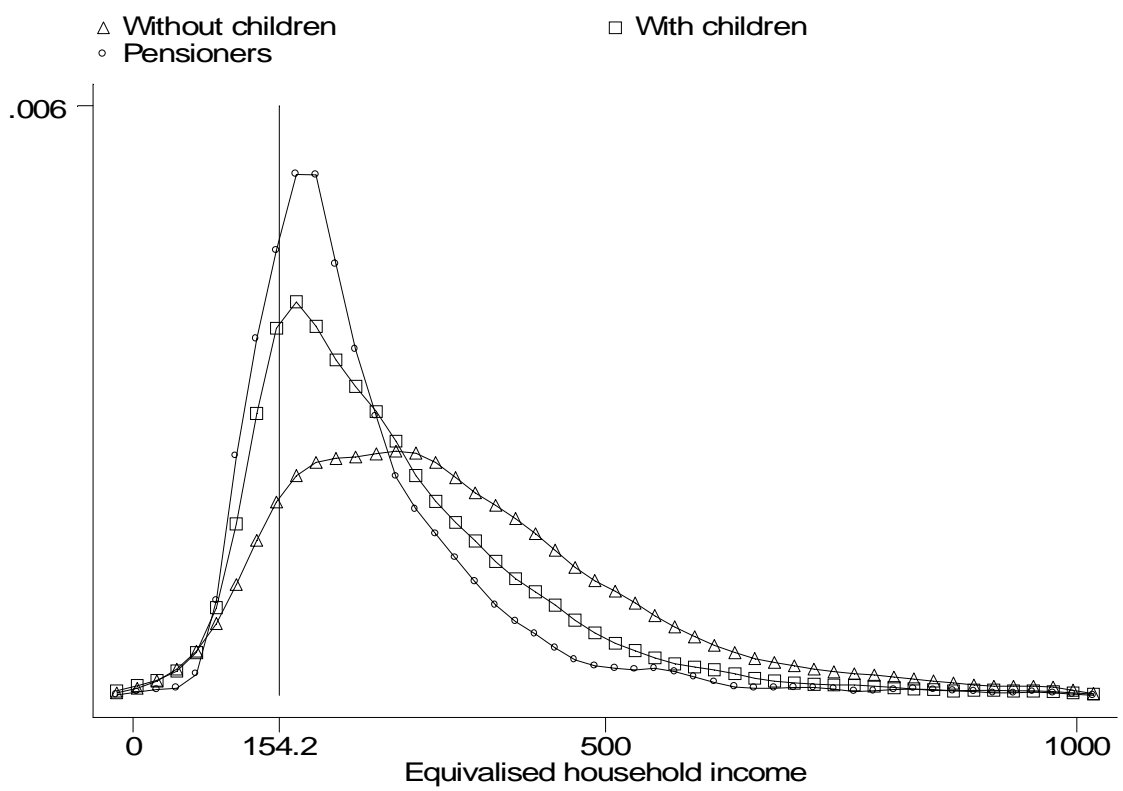

$\mathrm{N}$ otes: Figure shows the estimated income distribution for families based on equivalised household income before housing costs. Our estimate of 60 per cent of median household income is shown at $€ 154.20$ a week. The figure is drawn as a kernel density, which is like a smoothed histogram showing the proportion of families at each level of income. The area under each curve is equal to 1.

Sourœ: Authors' calculations from HBAI 1998-99 dataset.

All three distributions are skewed, in that there is a long 'tail' of high-income households. But families with children (and pensioners) are more concentrated in the bottom end of the income distribution than families without children. The figure also shows that the peak of the income distributions for both pensioners and families with children is close to 60 per cent of median income - one of the government's low-income indicators showing that there are a lot of families with children around the poverty line.

24 The dataset used to describe the income distribution does not cover Northern Ireland. 
There is a striking difference between the income distribution for couples with children and that for lone parents, as Figure 3.3 shows: lone parents are more concentrated around the poverty line than couples with children. . $^{-5}$

\section{Figure 3.3. Income distribution for couples with children and for lone parents}

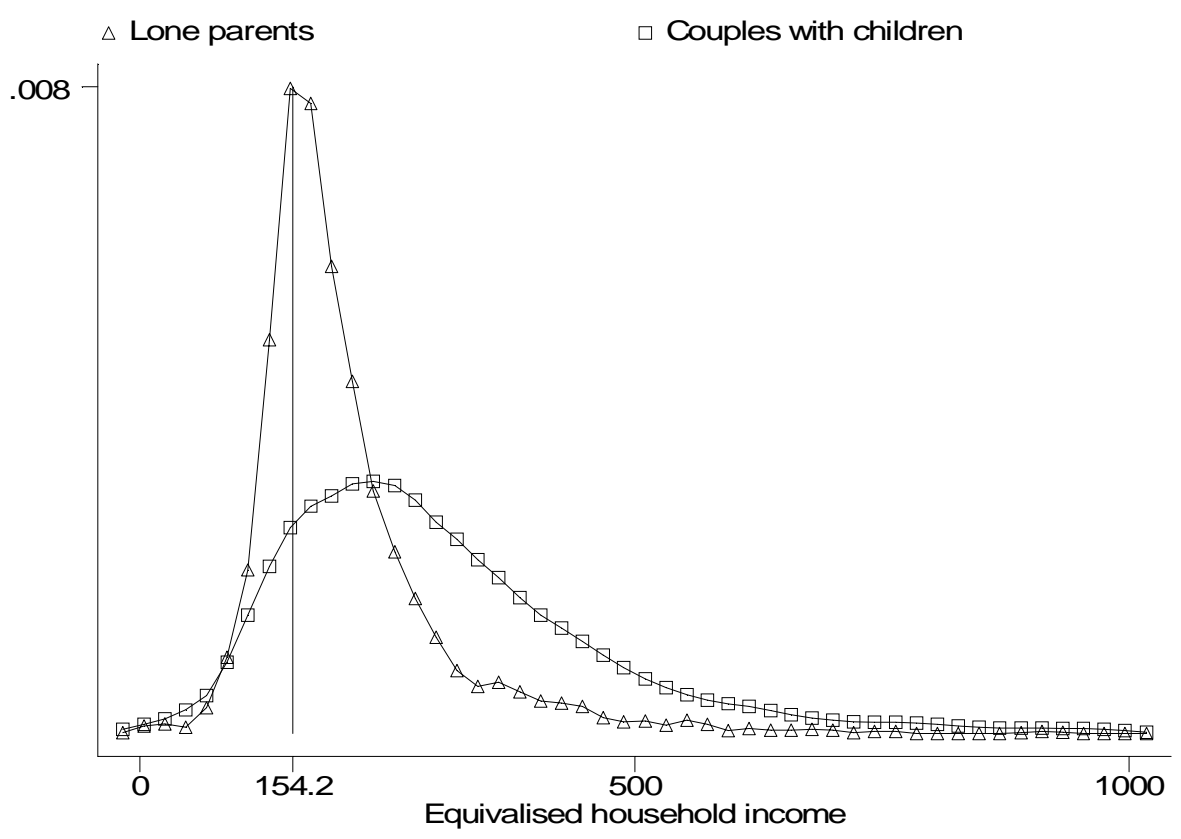

N otes and Source: See Figure 3.2.

Looking within all families with children, Figure 3.4 shows how families with one or two, three, or more than three children are distributed across the 10 income deciles.6. For example, around 45 per cent of families with four or more children have incomes that place them in the poorest 10 per cent of all families in the UK, compared with 8 per cent of families with one or two children. Alternatively, the median family for each of these three family types is in a very different part of the income distribution: the median family with one or two children is in decile 6 of the income distribution, the median family with three children is in decile 4 , but the median family with four or more children is in decile 2. 2.7

However, the income comparisons in Figures 3.2-3.4 were calculated using equivalised household income, which - as we discussed earlier - reduces the incomes of large households compared with the reference household of a couple with no children. Figure 3.5 presents the proportion of families of different sizes in the unequivalised income

\footnotetext{
25 These figures use equivalised incomes, and lone parents tend to have smaller households than couples with children, so if we drew the unequivalised income distribution, it would show an even greater inequality between lone parents and couples with children.

26 We have ranked all families (with or without children) by household income, and then split the income distribution into 10 equal-sized groups of around 3 million families.

${ }_{27}$ For example, there are as many families with four or more children with incomes lower than that of the median family with four or more children as there are similar-sized families with higher incomes.
} 
Figure 3.4. Proportion of families with different numbers of children in each equivalised income decile

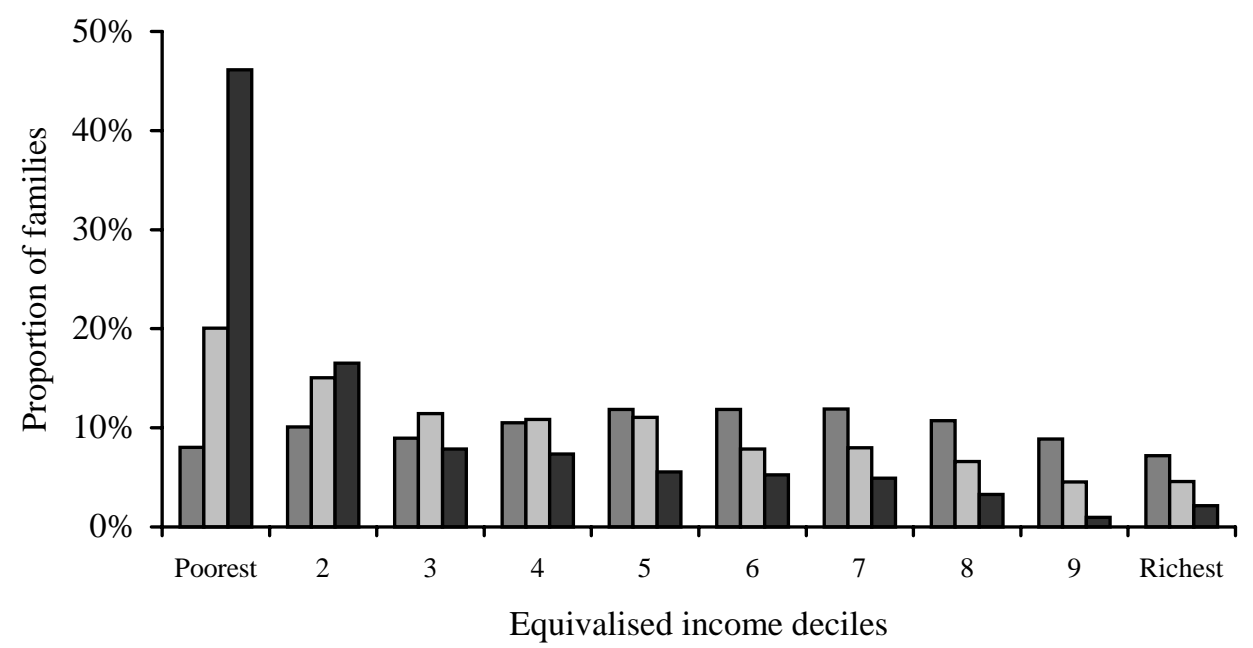

$\square$ One or two children $\square$ Three children $\square$ More than three children

N ote: D eciles were calculated from net weekly household equivalised income. Sourœ: Authors' calculations based on Family Resources Survey 1998-99.

\section{Figure 3.5. Proportion of families with different numbers of children in each unequivalised income decile}

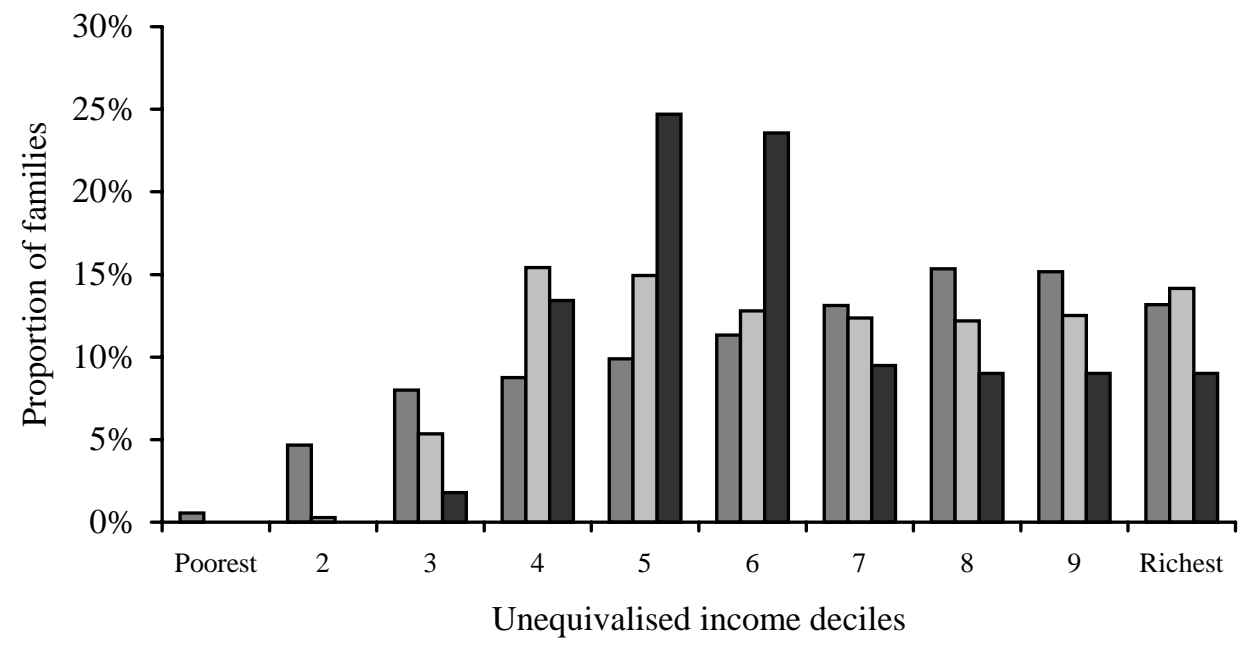

$\square$ One or two children $\square$ Three children $\square$ More than three children

$\mathrm{N}$ ote: D eciles were calculated from net weekly household unequivalised income.

Sourœ: Authors' calculations based on Family Resources Survey 1998-99.

distribution. It shows that there are very few families with children at all in the bottom three deciles - these deciles are composed of low-income, probably single-person, 
households - showing that the equivalisation process tends to move families with children down the income distribution. But the relative position of families of different sizes is similar in both the equivalised and unequivalised distributions: in the unequivalised income distribution, families with four or more children are heavily concentrated in deciles 4-6, families with three children are fairly evenly distributed across deciles 4-10, but families with one or two children are more likely to be found in the top four deciles than any other.

So Figures 3.4 and 3.5 together show that large families are worse off in a welfare sense than families with one or two children both because they have lower average disposable incomes - perhaps because of constraints on the amount of paid work the parents can do - and because the equivalence scale gives them a higher weight (crudely, they have more mouths to feed).

\subsubsection{Child poverty in the U K}

The proportion of children in relatively low-income households rose dramatically through the 1980s and early 1990s, from 15 per cent in 1980 to 30 per cent in 1990, and has remained consistently high since then (see Figure 3.6, which shows the proportion of children in households with less than 60 per cent of median income since 1968). On a relative measure of child poverty, the UK has one of the highest child poverty rates in the developed world (see UNICEF (2000)). There is also evidence that children are more likely to be in households with persistently low incomes - which probably have a more substantial affect upon children's well-being then temporary periods of low income than working-age adults or even pensioners (see D epartment of Social Security (2000a)

Figure 3.6. Child poverty in the UK

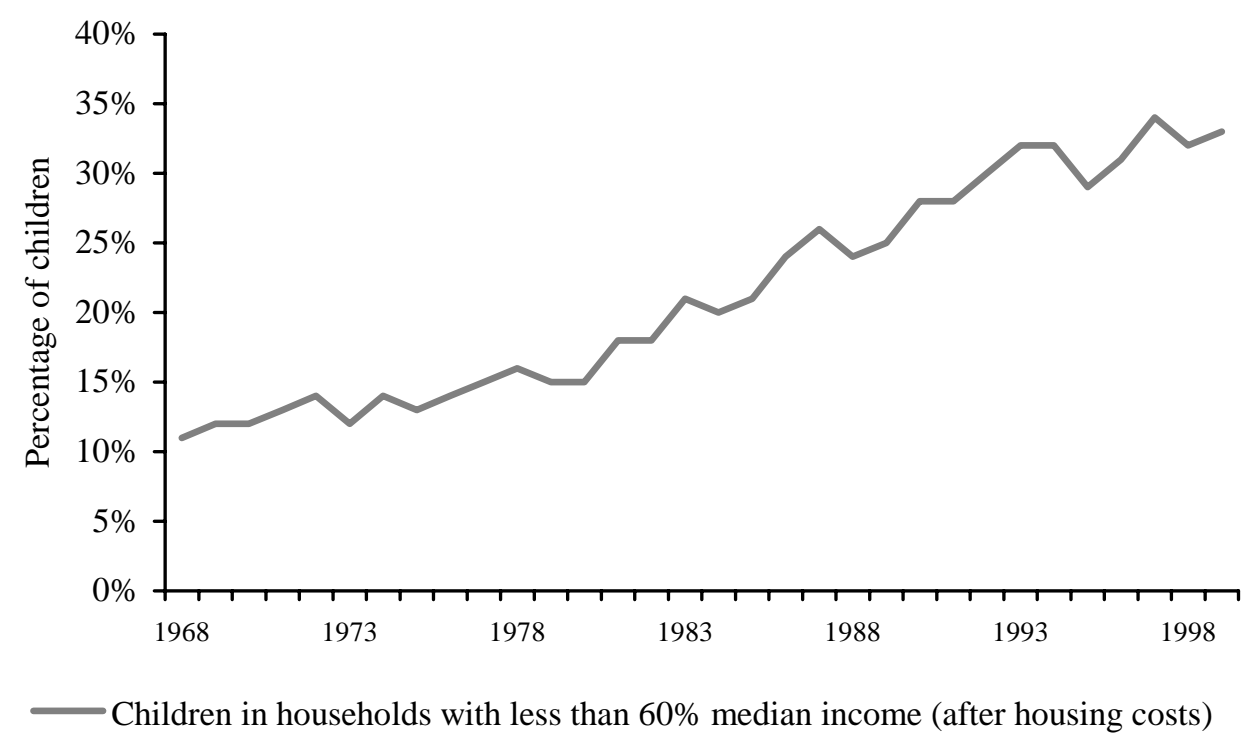

$\mathrm{N}$ ote: $\mathrm{G}$ raph shows the proportion of children in households with less than 60 per cent of median income after housing costs, one of the government's poverty indicators (see Department of Social Security (2000b)).

Sourc: D erived from Family Expenditure Survey data used in Dickens and Ellwood (2000). Similar data are presented in Gregg, Harkness and Machin (1999). 
or Hill and Jenkins (1999)). The analysis is different if we look at the number of children in households with absolute low incomes (for example, the proportion living in households with less than half the 1979 mean household income), but even on that definition, families with children have seen less improvement in real incomes than families without children over the past few decades (see Gregg, Harkness and Machin (1999)).

\subsubsection{The effect of recent Budgets on families with children}

O ne of the objectives set by the government for the integrated child credit is 'to facilitate public debate about the appropriate level of support in the context of the Government's commitment to abolish child poverty' (HM Treasury, 2000b). The reforms since 1997 that have directed extra resources to families with children have been progressive, with substantially larger increases - in cash and percentage terms - going to poorer families than to rich families. For example, families in the poorest decile gained over 8 per cent of net income, compared with 2 per cent for families in the middle of the income distribution and less than 1 per cent for the richest families (see Figure 3.7). The only change that has benefited all families has been the increase in child benefit for the eldest child: the other reforms - WFTC, children's tax credit and increases in means-tested benefits - have all been targeted at a particular part of the income distribution. The government estimates - and independent analysis broadly confirms (see Piachaud and Sutherland (2000)) - that the first-round effect of the tax and benefit reforms will be to reduce the number of children in poverty by around 1 million.

\section{Figure 3.7. The distributional impact of child-related reforms since 1997}

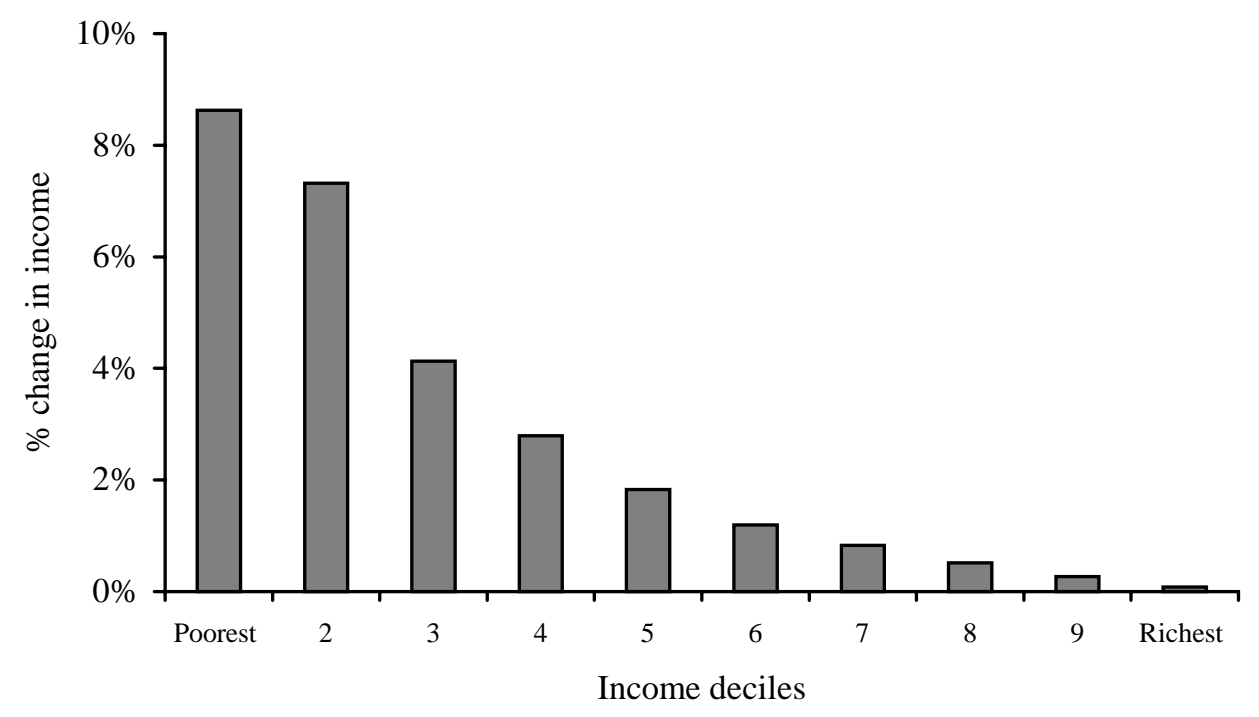

$\mathrm{N}$ ote: The simulation includes the changes in IS and CB, the WFTC reforms and the introduction of the CTC, but does not include other reforms that have been introduced since 1997. Some of these have had additional impact on income of families with children (such as reforms to income tax and National Insurance: see Myck (2000)). The simulation does not show the effect of abolishing the married couple's allowance as that affected married couples with and without children equally.

Sourœ: Authors' calculations from the IFS tax and benefit model, TAXBEN. 
There are a number of ways that the introduction of an integrated child credit could affect child poverty:

- The introduction of a seamless system of financial support may ease the transition from being out of work to being in work, and that may increase the proportion of mothers who work.

- The payment of financial support for children to the mother tends to be associated with better outcomes for children (we discuss this more in Chapter 7).

- The government may increase the real value of financial support for children as it introduces the integrated child credit. It has said already that it hopes that the introduction of an integrated child credit will encourage a debate about the level of financial support for children in the context of its commitment to abolish child poverty.

\subsection{The history of financial support for children in the UK}

Having set out the broad principles of why governments direct financial support to families with children, it is worth looking at the history of financial support for children in the UK tax and benefit system. Table 3.3 gives a concise timeline.

Extra tax allowances for families with children were introduced in 1909, although these only benefited the very small proportion of the population that then paid income tax. The first national scheme to direct support to families with children began in the late 1940s, with the introduction of family allowance - a means-tested, taxable benefit paid to families with two or more children. In 1977, family allowance was replaced by the flatrate, non-taxable, child benefit, and the child tax allowances were phased out over the next two years. This change was to ensure that non-taxpayers were not missing out on financial support for children and also reflected a desire to pay support to the main carer. Extra targeted supplements for children living in out-of-work families began in the national assistance (1948) and supplementary benefit (1966) systems - the previous unemployment assistance payments did not vary with family size - and continued in income support (1988). In-work benefits for low-income families with children began in 1971 with family income supplement, replaced in 1988 by family credit and in 1999 by working families' tax credit. The table shows that, for many decades, past governments have used a mixture of means-tested benefits, support through the tax system and universal payments.

The changing real value of support for children aged under 11 is shown in Figure 3.8. The real value of the child allowance in supplementary benefit and income support hardly changed between 1977 and 1997, but it has risen by over two-thirds since then (this is the amount that out-of-work families get for the second and subsequent children, shown by the solid black line). The real value of the equivalent for low-income working families is slightly higher than the value for out-of-work families, reflecting the loss of 
Table 3.3. Timeline of financial suppont for children in the UK, 1900-2001

\begin{tabular}{|c|c|c|c|c|}
\hline & 1900s-1950s & 1960s-1970s & $1980 s$ & 1990s onwards \\
\hline $\begin{array}{l}\text { Universal, non-means- } \\
\text { tested payments }\end{array}$ & & Child benefit introduoed (1977) & & $\begin{array}{l}\text { Higher rate for eldest child } \\
\text { introduced (1991) }\end{array}$ \\
\hline \multirow[t]{2}{*}{$\begin{array}{l}\text { Support through the tax } \\
\text { system }\end{array}$} & $\begin{array}{l}\text { Larger tax allowanoes for } \\
\text { families with children (1909) }\end{array}$ & $\begin{array}{c}\text { Child tax allowanoes abolished } \\
\text { (1977-79) }\end{array}$ & & $\begin{array}{l}\text { Individual system of income tax } \\
\text { introduced (1990) }\end{array}$ \\
\hline & $\begin{array}{l}\text { Child tax allowanoes introduced } \\
\text { (1948) }\end{array}$ & & & $\begin{array}{l}\text { Children's tax credit replaced } \\
\text { manied couple's and related } \\
\text { allowanoes (2000-01) }\end{array}$ \\
\hline \multirow[t]{2}{*}{ Means-tested benefits } & $\begin{array}{l}\text { Unemployment Assistance } \\
\text { Board Act (1934) }\end{array}$ & $\begin{array}{l}\text { Supplementary benefit (SB) } \\
\text { replaced NA (1966) }\end{array}$ & $\begin{array}{l}\text { Inoome support (IS) replaced } \\
\text { SB (1988) }\end{array}$ & $\begin{array}{l}\text { Jobseeker's allowance replaced } \\
\text { IS for couples with children and } \\
\text { adults without children (1996) }\end{array}$ \\
\hline & $\begin{array}{c}\text { National assistanoe (NA) and } \\
\text { family allowance introduced } \\
\text { (1948) }\end{array}$ & $\begin{array}{l}\text { Family allowance abolished } \\
\text { (1977) }\end{array}$ & & $\begin{array}{l}\text { Rates of child premiums } \\
\text { equalised for all children under } \\
16 \text { (1998-2000) }\end{array}$ \\
\hline
\end{tabular}




\section{Figure 3.8. The changing real value of financial support for children}

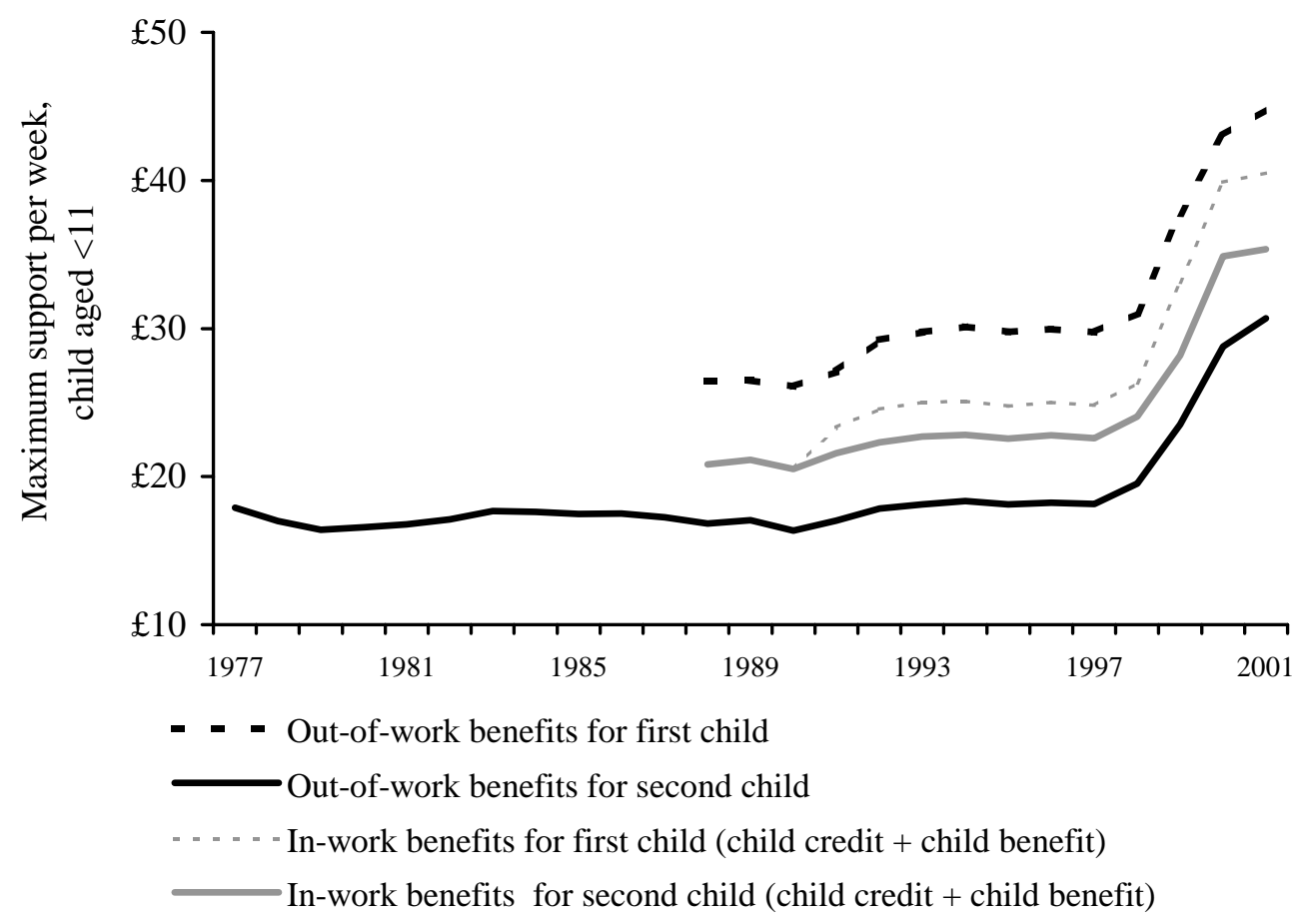

N otes: Y-axis shows support for children (assumed aged under 11), averaged over the financial year, deflated using the all-items RPI. For out-of-work benefits, data do not include the value of free school meals. For in-work benefits, the value is child credit plus child benefit. Support through the tax system is not shown.

Sourœ: Authors' calculations.

free school meals (shown by the solid grey line). The dashed grey line represents the value of child-related support for the first child for low-income working families, and shows the effect of the higher rate of child benefit for the first child. The dashed black line shows the value of support for the first child in out-of-work families: these families see no gain from child benefit but do benefit from changes in the family premium in income support.

The two black lines can be interpreted as the extra amount of financial support received by out-of-work families for the first (dashed line) and subsequent (solid line) children. The two grey lines, though, do not include the basic credit in family credit, and so underestimate the total additional financial support received by low-income working families when they have children.

\subsection{Systems for directing financial support to families with children in other developed countries}

Having seen the complexity of the UK's system of financial support for children - with the mixture of means-tested benefits, non-means-tested benefits, tax credit and tax

${ }^{28}$ The pre-1988 family income supplement is not directly comparable to the post-1988 systems and is therefore not shown. 


\section{Box 3.1. Three other countries' systems for financial support for children}

In Australia, a single family tax payment is paid to all but the richest 10-15 per cent of families. About half of the recipients receive the payment at a top rate, most of the rest at a single lower rate. Families with only one earner get more; this supplement is higher for those with children under five. The system, introduced in 2000, is the product of years of reform and simplification. People on low and middle incomes receive stable payments for their children, but other benefits and taxes for people on lower incomes are redistributive, with high withdrawal rates as income rises. Australia has, through the tax and benefit system, managed to limit the growth in inequality after taxes and benefits, while avoiding high marginal deduction rates on payments for children.

In Canada, a federal child tax benefit is paid directly to the great majority (soon it will be about 90 per cent) of families. O nly the poorest - on below 46 per cent of average family income - get the maximum rate, but the withdrawal rates are very low: 2.5 per cent of income for families with one child and 5 per cent for other families. This federal benefit is progressively replacing provincial social assistance payments for low-income households. By making benefits to children available to a large majority of families, Canada is aiming to promote social cohesion. The administration of the benefit through the income tax system is intended to reduce stigma.

The US has no single benefit to support families with children. Taxpayers get a tax allowance of $\$ 2,750$ per child and a non-refundable credit against income tax liability of $\$ 500$ per child, and may get a larger personal allowance. Families with children on low earnings are eligible for the earned income tax credit. There is no universal equivalent of the income support safety net, but states give various forms of assistance to non-working parents and to those participating in welfare-to-work programmes. This system puts great emphasis on encouraging and rewarding work, but less on relieving poverty. It has worked reasonably well in times of plentiful jobs, but has not yet been tested (since the big 1996 welfare reform) in a downturn or recession.

Souros: Battle and Mendelson, 2001; Hirsch, 2000.

allowances - it can be appreciated that making comparisons across countries is not simple. But there are lessons to be learnt from other countries that have attempted to reform their systems of financial support for children using similar strategies in recent years. A recent study part-funded by the Joseph Rowntree Foundation looked at three other countries with systems and recent developments most similar to the UK's. The results are summarised in Box 3.1.29

\footnotetext{
29 The most recent definitive EU comparison dates from 1996 (Ditch et al., 1998). MISSO C (1999) details social protection policies across the EU, but not in a way that enables comparisons of the full package of financial support for children.
} 


\section{How should we judge the success of an integrated child credit?}

As we saw in Chapter 3, the structure and administration of the current system of financial support for children are a result of the evolution of different channels of assistance over several decades. The government now aims to correct what it sees as the weaknesses of the current design through the introduction of the integrated child credit. However, the current system has evolved to ensure that particular objectives are met, and there is a strong case for making sure that these are also achieved by the integrated child credit.

We discuss below some general principles that we would expect the tax and benefit system to seek to adhere to, and we assess how well these are met in the current system of financial support for children. The discussion highlights some desirable features of the current system that we think the government will want to preserve in a new system of assistance. Later, we will analyse concrete options for an integrated child credit in the next two chapters: in Chapter 5, we discuss the structure of the current system and possible structure of an integrated child credit, and Chapter 6 looks at the details of payment administration. By the structure, we mean how the integrated child credit relates to family structure and family income. By administration, we mean parameters such as how entitlement is assessed, the frequency of payments, the period of award and the means of payment.

\subsection{Objectives for the integrated child credit}

The government saw the overlap between taxes and benefits - the fact that some families both pay taxes and receive means-tested benefits - as a sign of failure in the tax and benefit system and as a rationale for reform when it introduced WFTC (see HM Treasury (1998)). D esigning the integrated child credit afresh certainly gives the government a great opportunity to rationalise the rules in the existing mechanisms for directing financial support to children, which have each evolved individually over time to achieve their different objectives. On the other hand, there may well have been good reasons why the tax system and safety-net benefit systems have evolved separately. This point has been long recognised: Dilnot, Kay and Morris (1984) argue that it is an advantage to have people who both pay tax and receive benefits because it 'may be desirable to award benefits on a basis which discriminates more carefully between different types of households than is appropriate for tax credits'.

To illustrate this point, we list below the government's objectives for the integrated child credit as well as some other, more general, objectives that we think should apply to all parts of the tax and benefit system. We then evaluate the current system of financial support for children against both sets of objectives. Not surprisingly, the objectives highlighted by the government for the new integrated child credit are ones that the current system of financial support for children is failing to meet well. On the other hand, some of the more general objectives of the tax and benefit system are met well by the current system. Viewed in this light, the government may have to design the integrated child credit carefully to avoid making compromises in moving from three well- 
targeted mechanisms for providing financial support for children to just one covering all families in the UK.

The government has said that an integrated child credit will provide (see HM Treasury (2000b)):

i. 'a more transparent system of support for children, helping parents understand what they can expect to receive, and facilitating public debate about the appropriate level of support ... ;

ii. 'a portable and secure income bridge spanning welfare and work to improve work incentives ... ;

iii. 'a common framework for assessment and payment, where all families will be part of the same system, rather than dealing with low-income families through the benefits system while giving tax allowances to the better-off. Awards would be assessed on the joint income of couples;

iv. 'a system where support for children is paid to the main carer ... ;

v. 'efficiency gains for Government, and reduced hassle for parents, from moving away from a system where support for children is delivered through four different mechanisms'.

The other, more general, objectives that we think should apply to all parts of the tax and benefit system are:

a) ensuring the existence of a safety-net system, by getting payments to those in greatest need with minimal delay;

b) preserving work incentives, by ensuring both that work pays financially and that marginal withdrawal rates for families in work are not too high;

c) guaranteeing fairness (or equity) between families of similar resources and needs;

d) reducing unnecessary government expenditure, by targeting money on those that need it most, and avoiding fraud;

e) minimising administrative costs, particularly with the aim of ensuring take-up rates as high as possible;

f) avoiding over-payment to parents who may have difficulties in repaying it.

\subsection{How does the current system rate when assessed on these criteria?}

Below, we discuss to what extent the broad objectives above are met by the current system of financial support for children.

How well a new integrated child credit meets the objectives above will depend partly on the structure of the new system and partly on its administration. We described the 


\section{Box 4.1. Administration of the current system of financial support for families with children}

Child benefit (CB): A universal benefit for all families with children - the only element independent of family income. Payments are made automatically until the child reaches 16 or 18 (if stays in full-time education).

Income support (IS): Awards based on weekly income. Claimants have to inform the Benefits Agency of income changes each week and are liable for over-payments. Income support responds immediately to changes in circumstances, but at the cost of frequent contact between parents and the Benefits Agency and of high administration costs. Payments cease when work reaches 16 hours per week.

Working families' tax credit (WFTC): Awards based on a one-off assessment of income, and then fixed for six months regardless of changes in household circumstances or income. This means that WFTC can take up to six months to respond to a change in circumstances and that income during some months is completely ignored when calculating awards. The period taken into account when calculating the amount a family is eligible for is between four months and seven weeks (depending on how frequently claimants are paid). Work requirement of 16 hours per week.

Children's tax credit (CTC) (from April 2001): a non-refundable credit, paid monthly through the PAYE system. Only those who are liable to pay income tax receive the credit. Its value will adjust over the financial year to minimise under- or over-payment by the year-end. Administration of the children's tax credit will be carried out by the Inland Revenue through the PAYE system. The children's tax credit will respond monthly to changes in circumstances, but it will respond to annual income, so it will be unlikely to change significantly month by month.

structure of the current system in Chapter 2; the main features of administration of income support, WFTC, the children's tax credit and child benefit are described in Box 4.1 .

Table 4.1 outlines ways in which the current system fails to meet the government's objectives for the integrated child credit. However, these failings should be balanced against what we think are the relative successes of the current system of financial support for children in meeting the other, general, objectives for a tax and benefit system, and those are highlighted afterwards.

We now consider how well the current system meets the general objectives for the tax and benefit system.

\section{a) E nsuring the ex istence of a safety-net system}

Currently, all families on very low incomes are eligible for government support through income support. Because of close weekly monitoring, the system is able to assist the 


\section{Table 4.1. Cument system of support for families with children and government objectives for the integrated child credit}

\begin{tabular}{l}
\hline i) T ransparency \\
ii) M oving from welfare to \\
work
\end{tabular}

iii) Framework of assessment

iv) Person to whom transfer payments are made

\section{v) E fficient administration of support ...}

... and hassle for families
The system is made up of three separate components requiring separate application and administration procedures. It is difficult to identify the level of support for children from the overall level of payments (see Figure 2.2).

People in and out of work are treated separately; moving from welfare to work may lead to temporary loss of income as a result of separate applications and administration of IS and WFTC. ${ }^{\text {a The }}$ transition also involves uncertainty as to the level of support after moving into work (before moving into work, people may not know their eligible level of WFTC support).

Assessment and payment differ between the components of the system. There is some overlap between the elements, but workless families are treated separately from those with working adults. The incomes of families at the lower end of the income distribution are monitored much more frequently and closely. The definition of income differs between the three components.

The payment system differs for each component. For couples: IS/ JSA is paid to the claimant (in most cases of jobseeker's allowance, this will be the father), WFTC is paid to the parent chosen by the partners (in most cases, this is the mother), CTC recipients will select who the credit is paid for and will be able to split the value of the credit between them (unless one or both of them are higher-rate taxpayers, in which case the value of the CTC will be determined on the basis of the income of the higher earner).

The system is administered through the D SS (IS) and the Inland Revenue (WFTC, CTC) and requires separate processing of claims for all elements.

In cases of income variation, families may have to apply for all three elements of the system separately in a short span of time. The hassle is greatest for families at the bottom of the income distribution. Less than 100 per cent take-up rates may partly reflect the hassle with application for transfers.

a Although there are a variety of benefit 'run-ons' and plans for a $£ 100$ employment grant for those moving from means-tested benefits into work. The Inland Revenue also aims to process new claims for WFTC quickly and always makes the first payment directly by a $\mathrm{G}$ iro or into a bank account.

most needy relatively rapidly in a situation of a sudden fall in income. It therefore constitutes a reasonably effective safety net (although we are not asserting that the level of income support is sufficient or otherwise, just that it can respond quickly to financial hardship). 


\section{b) Preserving work incentives}

Marginal deduction rates are one of the major concerns regarding work incentives. ${ }^{00}$ Income support is withdrawn at 100 per cent once people reach their limit of income disregard, and the withdrawal rate of WFTC is 55 per cent once net family income exceeds the specified 'applicable amount' (equivalent to a tax rate on gross income of 69 per cent for a basic-rate taxpayer). In combination with withdrawal of other means-tested benefits - such as housing benefit - families claiming WFTC can still face marginal deduction rates of above 90 per cent. Although the number of people facing marginal deduction rates above 70 per cent fell with the introduction of WFTC, the number of those facing rates above 50 per cent increased significantly.

The other aspect of work incentives - that of providing certainty of income at the time of transition from welfare to work - was discussed in Table 4.1.

\section{c) $G$ uaranteeing fairness}

In the context of the tax and benefit system, fairness means providing the same level of financial support to families with similar levels of income and similar needs (this is the notion of horizontal equity). We think the current system of financial support for children achieves fairness in some respects, but with some concern about WFTC.

Every family with children is eligible to claim child benefit. Its value depends on the number of children in the family (and thus responds to 'needs') but is independent of the family income, so a poor family receives the same amount of child benefit as a rich family with the same number of children.

O ut-of-work families are eligible for income support, which varies by income and family size, thus ensuring fairness between similar families. If two families of the same composition and with the same income claim WFTC, then they will receive the same amount for the next six months. But WFTC is paid at a constant rate for six months and there are no adjustments at the end of the payment period for under- or over-payment. Moreover, the next assessment period does not cover the whole period of the most recent payment period. This arrangement favours families that can lower their incomes during the assessment period, and may seem unfair to families that suffer negative income shocks in periods not covered by the assessment period.

The children's tax credit is the least responsive element of the current system of financial support for children to temporary changes in income. But, because it will be an element of the cumulative UK tax system, fairness in its application will be preserved, as highest earners in all families with children who receive a certain level of income in the financial year will receive the same amount of the credit. However, because the children's tax credit is based on individual and not family income, families with the same family income but differing work patterns between partners in couples may receive different amounts of the credit.

\footnotetext{
${ }^{30}$ A marginal deduction rate measures the extra tax paid and benefits withdrawn when income rises by $£ 1$.
} 
While the values of income support, WFTC and child benefit depend on the number of children in the family, the amount of the children's tax credit is independent of whether there is one child or more. Thus the children's tax credit does not respond to family needs in the way that the other three elements of the current system do.

\section{d) Reduaing unneecssary government ex penditure}

If the government's aim is to target resources at the poorest families, then support for children must be means-tested and withdrawn as family income rises. O ne could claim that the current system is well targeted, in that transfers are withdrawn when family income rises and, in the cases of income support and the children's tax credit, overpayments are adjusted for. But families claiming WFTC are not required to pay back any 'excess' amount they receive ${ }^{\text {I1 }}$ if income rises during a WFTC award. While this form of over-payment may be considered as unnecessary expenditure, one could argue that fixing the amount of WFTC over six months may act as an additional incentive to work, as the actual marginal tax rates are not increased by the WFTC withdrawal taper.

So, just as the current system manages to avoid over-payment reasonably successfully, it also manages on the whole to avoid paying financial support for children to families who do not need it. Child benefit might be seen as an exception to this, since it is paid to all families irrespective of their income. The advantage of the universality of child benefit, though, is that take-up rates are very high, suggesting that there is little stigma or hassle associated with claiming it, perhaps because it is not means-tested.

\section{e) Minimising administrative costs and the hassle for parents}

Of the three elements of the tax and benefit system that will be combined into the integrated child credit, the administration of income support currently involves the highest cost to the government and requires most involvement on the part of families themselves. Currently, all families receiving income support theoretically have to report any change in their income to the Benefit O ffice on a weekly basis. WFTC is assessed for six months, so is less well-targeted than income support but has lower administrative costs and much less hassle for families. The children's tax credit - once parents have told the Inland Revenue that they have a child - will be administered automatically through the PAYE system on the basis of information supplied to the Inland Revenue (although families with higher-rate taxpayers need to provide more information). So, in the current system, the hassle for parents is highest for the poorest families who apply for income support and lowest for those further up the income scale who qualify only for the children's tax credit.

The hassle factor is one reason why families do not claim benefits to which they are entitled, and the government estimates that nearly a third of those entitled to family credit did not claim it in 1998-99 (although take-up of income support was higher - see Department of Social Security (2000c)).

31 'Excess' relative to that which they would be eligible for if entitlement were assessed continuously. 
Currently, families on income support whose income rises unexpectedly may have to return any excess payments. However, any liability should be small as eligibility is monitored on a weekly basis. O ver-payment of the children's tax credit is also possible, as the credit is awarded monthly on the basis of an expected annual income and family structure. Any accumulated debts are, though, unlikely to be high, as the maximum annual award is $£ 442$, which will not be a significant proportion of most recipients' incomes. Because WFTC is paid at a fixed rate for six months regardless of changes in income or circumstances, no over-payments are made and none of the payments have to be returned. So the current system of financial support for children is reasonably effective at not over-paying financial support for children and then trying to reclaim it from low-income families (we ignore housing benefit here, as it is not a payment exclusively for families with children).

\subsection{How would an integrated child credit meet these objectives?}

The extent to which the integrated child credit meets the objectives above will depend on the specific parameters the government chooses, and we discuss some of the options in the next two chapters. We will focus particularly on the conflicts between providing a safety net of support, protecting work incentives and reducing unnecessary government spending. These trade-offs are inherent in any tax and benefit system, so it is unlikely that all the potential problems will be solved through the introduction of the integrated child credit. A careful design of the system, however, may maintain the advantages of the current structure and help alleviate some of the problems encountered in the three elements of financial support for children that the government has proposed to integrate.

But we first highlight some of the objectives that should be met by the integrated child credit regardless of the detailed choice of parameters.

\subsubsection{T ransparency and reduced stigma}

The transparency of financial support for children would be improved under an integrated child credit as there would only be one means-tested transfer, rather than the three systems there are at present. Moreover, the stigma associated with claiming meanstested benefits could be lower, as almost all families with children would be eligible for the integrated child credit. This might increase take-up rates from their current levels.

\subsubsection{W ork incentives}

O ne of the major objectives of the integrated child credit reform is to address the work disincentive impact of the temporary fall in income and the uncertainty of future levels of financial support for children when income support is withdrawn when people move into work. The integrated child credit would provide a 'bridge' spanning across the welfare and work divide in that it would be a secure payment independent of the number of hours of work. Although the 'adult' part of income support will be withdrawn at 100 per cent, the value of the integrated child credit proposed by the government will be 
constant across the welfare-to-work divide - i.e. its value will be the same for all families who are either out of work or in low-paid work.

However, because an integrated child credit will be a means-tested transfer whose highest values will be targeted on the poorest families, the government will have to decide on the withdrawal rate(s) and the appropriate levels of income over which they would apply. We discuss these issues in more detail in Chapter 5.

\subsubsection{Reduced hassle for families and lower administrative osts for parents}

Another potential advantage of introducing the integrated child credit is the possibility of reducing the monitoring of families on the lowest incomes. Since the integrated child credit will be paid at the same level for families on a large range of incomes, weekly eligibility assessments need not be necessary (although the remaining adult component of income support may retain weekly means tests).

The administration of the integrated child credit will clearly have an important impact on the realisation of government objectives. The role of administrative parameters and some possible administrative designs for the integrated child credit are discussed in Chapter 6. 


\section{The structure of an integrated child credit}

In this chapter, we discuss the parameters of the integrated child credit that will determine the budget constraint of families with children. We support the analysis with examination of the aggregate cost and distributional effects of various options using the IFS micro-simulation model, TAXBEN. The government has already said that the integrated child credit will depend upon a family's joint income, so we take that as given. But the key parameters that the government still has to decide upon and which we discuss in this chapter are:

- the value of the credit, including the variation with family size;

- how the integrated child credit is reduced as family income increases;

- what income to include in the assessment and whether there will be any restrictions on entitlement due to capital.

We discuss the options and then model some reforms. Chapter 6 complements this chapter by discussing the administrative aspects of the integrated child credit, such as how responsive it should be to changes in family income and structure.

\subsection{What should the maximum level of integrated child credit be for each child?}

We showed in Chapter 2 that, from April 2001, weekly financial support for the first child under the government's assumptions will vary from $£ 15.50$ to $£ 50$, and from $£ 10.35$ to $€ 36.35$ for subsequent children, with no variation by age for children under 16 . As we introduce an integrated child credit, it is sensible to examine whether these levels and the balance between the first and subsequent children - are the right ones.

We also argued, in Chapter 3, that the rationale for financial support for children depended on horizontal equity arguments - linked to equivalence scales - and efficiency and vertical equity arguments - linked to society's concerns about the damaging effects of low income on children or its wider regard for children and parents. If the government were only concerned about horizontal equity issues, then financial support for children would be structured in line with the evidence from equivalence scale studies. As we discussed in Section 3.2.2, most equivalence scales imply that there should be a premium for the first child and that financial support for children should increase as they get older.

But one of the other reasons for supporting families with children is that society has wider concerns about the damaging effects of low income on children. The government's view is that young children are particularly vulnerable to the damaging effects of low incomes (some of the evidence was discussed in HM Treasury (1999)), and this has been its rationale for the greater increases in benefits for children under 11 than for those over 11.

In addition, children in large families seem to be disadvantaged compared with those in smaller families. For example, Table 5.1 shows the proportion of children in households 
of different sizes who lack socially perceived necessities. 32 This approach tries to measure directly something closely related to people's standards of living and material deprivation. Children in households with three or more children are much more likely to lack these necessities than those in households with one or two children. There is less variation by age of child, but results cited in the study suggest that young children may be more vulnerable than older children.

Table 5.1. Poverty rates by family size and age of children

\begin{tabular}{l|cc}
\hline \hline Number of children in household & $\begin{array}{c}\text { \% of children lacking one } \\
\text { or more item }\end{array}$ & $\begin{array}{c}\text { \% of children lacking two } \\
\text { or more items }\end{array}$ \\
\hline 1 & 29 & 13 \\
2 & 25 & 11 \\
3 & 42 & 25 \\
4 or more & 68 & 39 \\
\hline \hline
\end{tabular}

Source: Gordon et al., 2000.

Crucially, this variation by the number of children in the household was significant in a regression framework when other factors, including equivalised income, were controlled for. In other words, children in large families have worse outcomes than children in small families even after controlling for income and 'consumption needs' using an equivalence scale. ${ }^{3}$

There are a number of possible explanations for this - it may be due to some extra cost (whether financial or not) that is incurred by families with three or more children, or some hidden characteristic that links families with large numbers of children with bad outcomes for children. But if the government is concerned about these effects and it thinks that extra money will help reduce these differences, then we would expect to see support for young children and for larger families to be more generous than that suggested by the McClements equivalence scale. We now look at the current system and suggest some ways that the government could introduce an explicit bias for larger families.

\subsubsection{The system of financial support for children from A pril 2001}

We look at two aspects of the system of financial support for children from April 2001: how it treats children of different ages and how it treats the first and subsequent children.

\section{Variation by age of child}

The current system treats children of all ages under 16 equally, with higher payments only for children aged over 16 but under 18 in full-time education (for families on income support or WFTC). This is a change from the historical pattern of support: since

\footnotetext{
32 See Gordon et al. (2000). The study first identified items that were thought by the population as a whole to be essential for families with children and then estimated which families lacked these.

${ }^{33}$ Lacking a necessity is not a true outcome in the sense that we used the phrase in Chapter 3, but the authors of this study argue that lacking necessities is a good proxy for experiencing social and material deprivation, which is very likely to be linked to real outcomes (such as health, educational and behavioural outcomes).
} 
the introduction of family allowance in 1948 right up to 1999, families received more support for children aged 11-16 than for those aged under 11 (see Figure 3.1 in Banks and Johnson (1993)).

\section{Variation by number of children}

Table 5.2 shows that the current system of support for children is weighted towards payments for the first child. This is a result of higher child benefit for the first child than subsequent children, of the value of the children's tax credit not varying with the number of children and of the family premium in income support. As we discussed in Chapter 2, the table assumes that the basic credit of WFTC is not counted as support for children. If we treated the 'basic credit' in WFTC as a family premium, the results in Table 5.2 would be even more skewed towards the first child.

Table 5.2. Weekly financial support for children from April 2001

\begin{tabular}{l|ccc}
\hline \hline & For first child & $\begin{array}{c}\text { For each } \\
\text { subsequent child }\end{array}$ & $\begin{array}{c}\text { Support for } \\
\text { second child as } \\
\text { a \% of support } \\
\text { for first child }\end{array}$ \\
\hline $\begin{array}{l}\text { Families receiving income support } \\
\text { and child benefit }\end{array}$ & $£ 45.95$ & $£ 31.45$ & $68 \%$ \\
$\begin{array}{l}\text { Families receiving WFTC, the } \\
\text { children's tax credit and child } \\
\text { benefit }\end{array}$ & $£ 50.00$ & $£ 36.35$ & $73 \%$ \\
$\begin{array}{l}\text { Families receiving the children's } \\
\text { tax credit and child benefit }\end{array}$ & $£ 24.00$ & $£ 10.35$ & $43 \%$ \\
$\begin{array}{l}\text { Families only receiving child } \\
\text { benefit }\end{array}$ & $£ 15.50$ & $£ 10.35$ & $67 \%$ \\
\hline \hline
\end{tabular}

N ote: Children under 16 only; the amounts may be different for dependent children aged 16-18.

\subsubsection{0 ptions for the integrated child credit}

Having reduced the variation in support by children's age over the past three years, we assume that the government will maintain a single rate of integrated child credit for all children under 16.

If the government wanted to preserve the existing bias towards the first child, it could replicate the current structure under an integrated child credit, by giving to all entitled families a credit that did not vary with family size, with extra credits for each child. But there are a number of ways the government could skew support towards larger families:

- It could increase the per-child element of the integrated child credit. Although this might leave the integrated child credit as a whole with a bias towards the first child, most of the money from the increase would go to larger families.

- It could remove the 'basic amount' or 'family premium' from the integrated child credit, so that families get as much extra support for their second child as for their first. 
- It could even introduce an explicit bias towards large families, either by having an extra premium for families with three or more children or by increasing the per-child payments with family size (so families would get more for their second child than for their first, for example).

The government will also need to decide what to do with free school meals. At present, only children in families on income support are entitled to free school meals (or welfare foods for children below school age). As shown in Figure 3.8 (and Figure 5.3), lowincome working families receive higher per-child payments, as they are not entitled to free school meals. The government could keep this distinction, but that would go against its objective of smoothing the transition between being out of work and being in work. Alternatively, it could extend entitlement to free school meals up the income distribution and 'level up' the per-child payments in income support so that all out-of-work and lowincome working families received the same amount per child. The decision will depend partly on whether the government thinks that providing free school meals is a better way of raising children's well-being than giving parents the financial equivalent.

\subsection{How should the integrated child credit be tapered with extra income?}

Figure 2.2 (repeated here as Figure 5.1) shows how financial support for children from April 2001 will vary with income. There will then be two income thresholds that are relevant for the integrated child credit:

- the threshold where the child credits in WFTC start to be tapered away;

- the threshold where the children's tax credit starts to be withdrawn for higher-rate taxpayers.

Figure 5.1. Financial support for a family with one child from April 2001 (f p.w.)

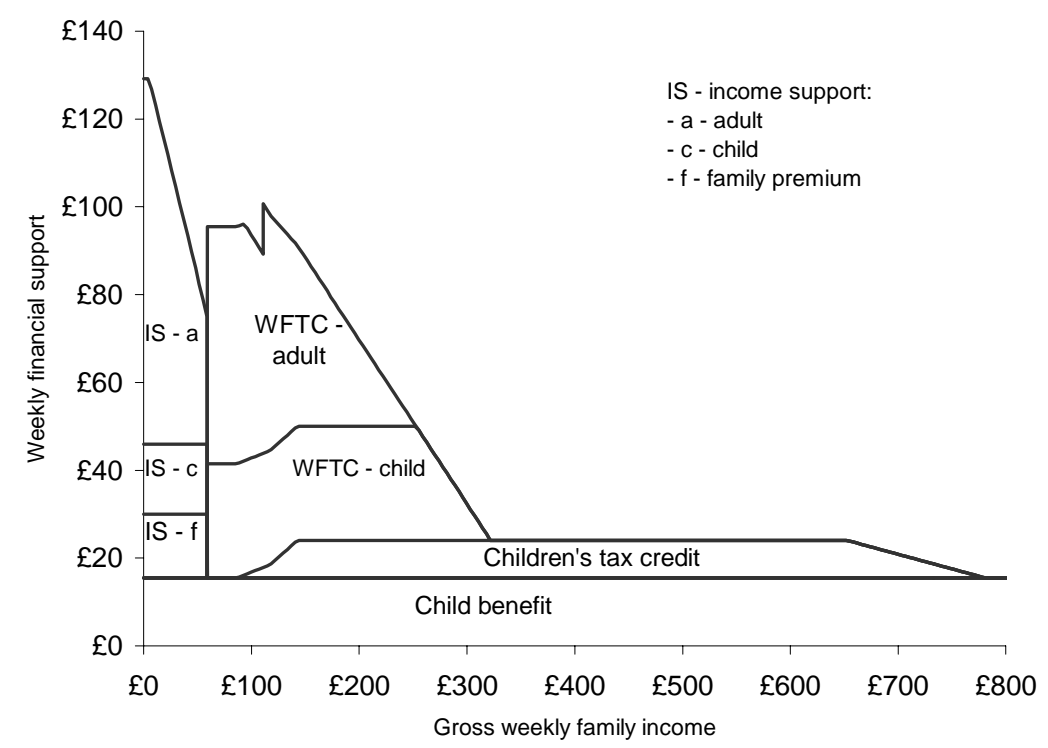

Souro: Authors' calculations from the IFS tax and benefit model, TAXBEN. The figure assumes that the family qualifies for WFTC at a weekly wage of $£ 59.20$, corresponding to 16 hours of work at the national minimum wage. 
Corresponding to these two thresholds (which we call the lower and higher thresholds respectively) are lower and higher withdrawal rates. Currently, the two thresholds are $£ 212$ a week and £33,935 a year, and the two taper rates are 55 per cent and 6.7 per cent respectively. 34

The principles for determining how transfer payments for children should be tapered away with income were discussed in Chapter 4 . The problem reduces to a pragmatic policy-design question that is faced when designing any means-tested benefit or tax credit. The trade-offs are between targeting need and reducing expenditure against reducing either the unemployment or poverty trap ${ }^{65}$ For example:

- a short, steep taper means that a few families will be subject to high marginal deduction rates, but it allows the government to target benefits precisely, either reducing unnecessary expenditure (from a distributional point of view) or permitting increased generosity to reduce any unemployment trap;

- a longer, shallower taper means that more families are affected by it, but marginal deduction rates will not be as high, reducing the poverty trap. But, for a given maximum level of integrated child credit, total expenditure will be higher, the shallower is the taper.

Avoiding tapers altogether also has advantages: if the integrated child credit does not depend on income over a portion of the income scale, then the government can ignore small income changes for a lot of people, and this has considerable savings in administrative costs for government and in hassle for parents. By contrast, the more people who are on or near a taper, the more the Inland Revenue would need to worry about fluctuations in their income to ensure they received the right level of support.

There is certainly no reason why the government needs to keep the two-taper structure in the current system - it could just introduce a long taper down from the maximum amount to zero across the income distribution. We now look at the options if the government were to keep the current structure of two tapers.

\subsubsection{Setting the lower threshold and taper}

WFTC is currently withdrawn at 55 per cent of net income and the child credits begin to be withdrawn at incomes of $£ 212$, but there is no reason to maintain these parameters.

In choosing the position of the lower threshold, the government will need to decide whether the employment tax credit and integrated child credit tapers will be completely consecutive, as suggested in HM Treasury (2000b). This suggests that, as family income increases, a family with children would first lose entitlement to employment tax credit and, when that had been exhausted, would then start losing entitlement to the integrated child credit. There is no reason why the government could not set a different threshold

\footnotetext{
34 The WFTC taper applies to net income, the children's tax credit taper to gross income. The combined WFTC, income tax and National Insurance contributions taper on gross income is 69 per cent, and $£ 212$ a week corresponds to a gross income of $£ 252$ a week, or $£ 13,104$ a year.

35 We cannot say unambiguously that lower marginal deduction rates are better for work incentives, as this ignores the effect of increased income on the decision to work.
} 
for the integrated child credit. A lower threshold would be unlikely - that would lead to cumulative tapers with very high marginal deduction rates - but a higher threshold is possible, effectively separating employment tax credit from the integrated child credit. For example, the government might want to stipulate that all families with weekly incomes less than $£ 250$ a week, say, will receive the full amount of the integrated child credit. 36

The government took a view on the trade-off in setting marginal deduction rates when it first introduced WFTC, as it lowered the taper rate from 70 per cent on net income under family credit to 55 per cent. This reform, by increasing the number of families eligible for WFTC, increased the number facing marginal deduction rates of over 60 per cent from 760,000 to 950,000. But it lowered the number of families facing very high rates (over 70 per cent of gross income) from 740,000 to 250,000.37

\subsubsection{Setting the higher threshold and taper}

The government has said that the integrated child credit will be assessed on joint family income. Currently, this is how both income support and WFTC are assessed, but it is not so for the children's tax credit, which is based on the income of the higher earner in the family. This means that the integrated child credit is very likely to have a financial effect (albeit small) on the higher-income families with children who only receive support through the children's tax credit. This is inevitable: it is impossible to design a system that gives the same value under joint assessment as it would under an assessment of the

Figure 5.2. Families with children and the children's tax credit

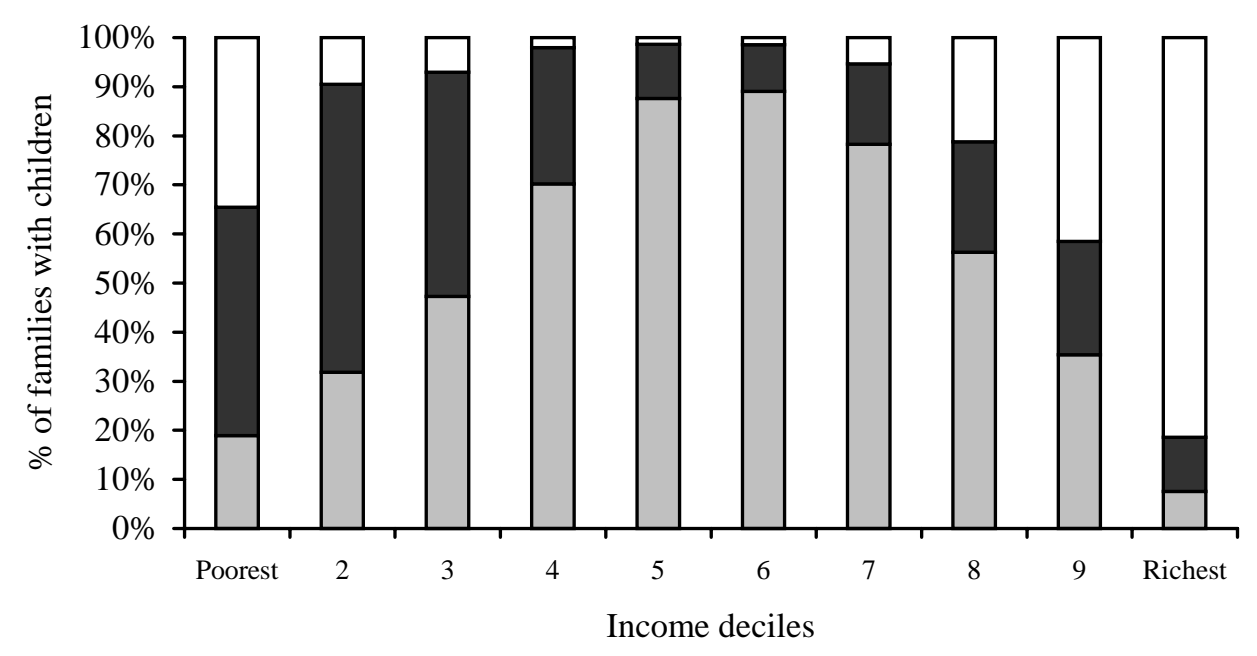

$\square$ Receiving full value of CTC $\square$ Receiving some CTC $\square$ Receiving no CTC

$\mathrm{N}$ otes: D eciles were constructed using all households.

Souro: Authors' calculations.

36 Shown graphically in Chennells, Dilnot and Emmerson (2000).

${ }^{37}$ From HM Treasury (2000a). 
income of the higher earner. To illustrate which families might be affected, Figure 5.2 shows the proportion of families with children who are currently eligible for all, some or none of the children's tax credit from April 2001: the poorest families are less likely to be entitled to the children's tax credit as they pay little or no tax, and the richest families do not benefit from the full amount as it is withdrawn for higher-rate taxpayers.

From April 2001, the highest joint family income that would still allow eligibility for the full children's tax credit will be $£ 67,870$ - where both partners' incomes are just below the point at which higher-rate tax is payable. But a family where only one parent works will only be entitled to the full value of the children's tax credit on income up to £33,935. To ensure that there are no losers from a move to joint assessment, the government would therefore need to set the higher threshold of an integrated child credit at $£ 67,870$. At this level, families with joint incomes of between $£ 33,935$ and $£ 67,870$ would gain.

\subsection{The treatment of income and capital}

The integrated child credit will be merging three systems of financial support, each with its own definition of income and its own treatment of capital. Table 5.3 summarises the current system.

\section{Table 5.3. Key components of income and capital in current mechanisms of financial support for children}

\begin{tabular}{|c|c|c|}
\hline & Main components of 'income' & Treatment of 'capital' \\
\hline $\begin{array}{l}\text { Income support } \\
\text { and income-related } \\
\text { jobseeker's } \\
\text { allowance }\end{array}$ & $\begin{array}{l}\text { Earned income and self- } \\
\text { employment income (subject to a } \\
\text { small disregard), maternity pay,a } \\
\text { most non-means-tested benefits, } \\
\text { child support ( } 110 \text { disregard from } \\
\text { 2001), other unearned income } \\
\text { ex cept income from capital. }\end{array}$ & $\begin{array}{l}\text { Income from capital is ignored. An } \\
\text { income of } £ 1 \text { a week is assumed } \\
\text { for every } £ 250 \text { of capital over } \\
£ 3,000 \text {. Entitlement ends with } \\
\text { capital of } £ 8,000 \text {. }\end{array}$ \\
\hline WFTC & $\begin{array}{l}\text { As for income support except that } \\
\text { maternity pay and child support are } \\
\text { ignored. }\end{array}$ & As for income support. \\
\hline Children's tax credit & $\begin{array}{l}\text { As for income support except that } \\
\text { income from capital and statutory } \\
\text { maternity pay are included and } \\
\text { child support is ignored. }\end{array}$ & No special rules. \\
\hline
\end{tabular}

a Maternity allowance and statutory maternity pay.

N otes: Authors' interpretations of G eorge et al. (2000) and Tolley's (2000). There are many other smaller differences in the treatment of income sources, which may be very important in particular circumstances.

Three of the most significant inconsistencies between the systems are:

- the treatment of capital and income from capital, where families on income support and WFTC face a less generous regime than those just benefiting from the children's tax credit; 
- the treatment of child support, where parents in receipt of income support face a less generous regime than other parents;

- the treatment of maternity pay, where mothers on WFTC face the most generous regime and mothers on income support the least generous regime.

The government has said that it wants the integrated child credit to provide a common framework for assessment and payment, a more transparent system of support for children, and a system that is simple for people to understand so that recipients are aware both of their entitlement and of their responsibilities. HM Treasury (2000b) says that

'the next phase of modernisation offers an opportunity for a thorough review of the treatment of income and capital in assessing a person's or family's entitlement to support. The current rules applied in Income Support and those inherited from FC by WFTC have developed over a considerable period of time and reflect a process of incremental change. The modernisation of IT systems offers an opportunity to rethink the way the system works'.

This all strongly suggests - although falls short of a commitment - that the government would like a common definition of income and capital throughout the integrated child credit. This would represent a simplification and lead to administrative benefits both for parents and for the Inland Revenue.

The most important criterion for deciding in which direction to move - whether to extend the most or least generous regime to all parents - may be cost. Excluding various components of income and scrapping the capital tests will increase the cost of the integrated child credit. But recent changes in tax and benefit rules may help suggest which way the government might move on the integrated child credit:

- The treatment of child support under WFTC is different from (and more generous than) that under its predecessor family credit (see Paull, Walker and Zhu (2000)). It seems unlikely that the government would want to reverse the changes so quickly.

- In the 2000 Budget, the government increased the capital thresholds for pensioners claiming income support, and the new pension credit will not have any capital limits at all. Both reforms were intended to reduce any disincentive to save for pensioners and people near retirement. A recent government document on savings has acknowledged that these arguments apply equally well to non-pensioners (see HM Treasury (2000c)).

- The government is currently reviewing maternity-leave provisions. But government documents have said often that the early years of childhood are all-important (see HM Treasury (1999)). Certainly, poverty rates are higher for families that contain a pre-school child, and the effects of low incomes on children's development can be observed at very young ages. Given this concern, it seems odd that the poorest mothers - those on income support - benefit less from maternity pay than better-off mothers. 


\subsection{Modelling options for an integrated child credit}

This chapter has outlined some of the main options the government has when it decides on the structure of the integrated child credit. We now examine the distributional consequences of different structures of the integrated child credit. The simulations are based on information from the Family Resources Survey - a representative survey of over 20,000 UK households - and a model of the UK's tax and benefit system, TAXBEN. We use TAXBEN to calculate the effects of fiscal reforms on each household in the survey and estimate the overall costs of reforms. But to estimate the effects of the options discussed in this chapter, we need to decide on a 'base' integrated child credit with which we can compare the options. This will separate the impact of moving to an integrated child credit - which is really just a structural reform - from the impact of discretionary parameter changes.

\subsubsection{O ur 'base' integrated child credit}

O ur 'base' integrated child credit takes account of the government's announcements and shows an integrated child credit if it were introduced in April 2001. But, as relatively few details have been announced, we still had to choose many parameters (which the government will also need to choose). In doing this, we tried to replicate the current system of financial support for children as closely as possible whilst avoiding large numbers of losers at the bottom of the income distribution ${ }^{3.9}$ The parameters we settled on are shown in Table 5.4.

The three most important implications of this reform are:

- The integrated child credit has lower child rates and a smaller family premium than income support. But because child benefit is now disregarded in income support, all families on income support gain by $£ 4.05 / £ 4.80$ for the first/ subsequent child. This is a direct consequence of creating a seamless system of financial support for children, because, as Table 5.2 showed, families on income support currently receive less for each child than some families on WFTC (Figure 5.3 makes this clear, by showing just financial support for the first child identified in Figures 2.2 and 2.3). Without some change to the level of employment tax credit, this will also have a negative impact on work incentives, as it increases out-of-work income without increasing in-work income.

- Some couple families at the top of the income distribution will be worse off because the family premium of the integrated child credit is withdrawn against net family income and the children's tax credit will be withdrawn only against the higher income in a couple.

- Capital limits are abolished for the integrated child credit and employment tax credit (but retained on the adult component of income support and other means-tested benefits), and a constant definition of income is used throughout, which includes non-earned income. This represents a change for families currently on income

38 Full details are available from the authors. 


\section{Table 5.4. The parameters for our 'base' integrated child credit}

\begin{tabular}{l|l}
\hline \hline Value of credit & $\begin{array}{l}\text { 'Family premium' of £8.50 a week. Child rates of £26 a week for children } \\
\text { under 16 (£26.75 for dependent children aged 16 and over). Child benefit } \\
\text { disregarded in the calculation of the adult component of income support. }\end{array}$ \\
Capital limits & No capital limits for the integrated child credit or employment tax credit. \\
income & $\begin{array}{l}\text { Entitlement is assessed on joint family income after tax and National } \\
\text { Insurance. The income tax definition of income is used, so income includes } \\
\text { savings and investment income. }\end{array}$ \\
$\begin{array}{l}\text { Lower } \\
\text { threshold and } \\
\text { taper }\end{array}$ & $\begin{array}{l}\text { The full integrated child credit award starts to be withdrawn as soon as } \\
\text { employment tax credit has been fully withdrawn. The new employment tax } \\
\text { credit is assumed equal to the basic credit in WFTC, so the integrated child } \\
\text { credit starts to be withdrawn when net family income reaches £212 a week. } \\
\text { This taper continues until the child credits have been fully withdrawn, leaving } \\
\text { families with just the 'family premium' part of the integrated child credit. }\end{array}$ \\
$\begin{array}{l}\text { Higher } \\
\text { threshold and } \\
\text { taper }\end{array}$ & $\begin{array}{l}\text { Beyond net family income of } £ \text { 483 a week, the 'family premium' of the } \\
\text { integrated child credit is withdrawn at 11.1 per cent. This exactly replicates the } \\
\text { children's tax credit for a single-earner family paying the full employee rate of } \\
\text { National Insurance, but the parameters are different as our integrated child } \\
\text { credit is assessed on net income and the children's tax credit is assessed on } \\
\text { gross, taxable income. }\end{array}$ \\
$\begin{array}{l}\text { Interactions } \\
\text { with other } \\
\text { benefits }\end{array}$ & $\begin{array}{l}\text { The parameters of housing benefit and council tax benefit are adjusted so that } \\
\text { none of the change in generosity of the integrated child credit is offset by } \\
\text { changes in housing benefit or council tax benefit. }\end{array}$ \\
\hline \hline
\end{tabular}

\section{Figure 5.3. 'Levelling up' financial support for the first child to create a seamless system}

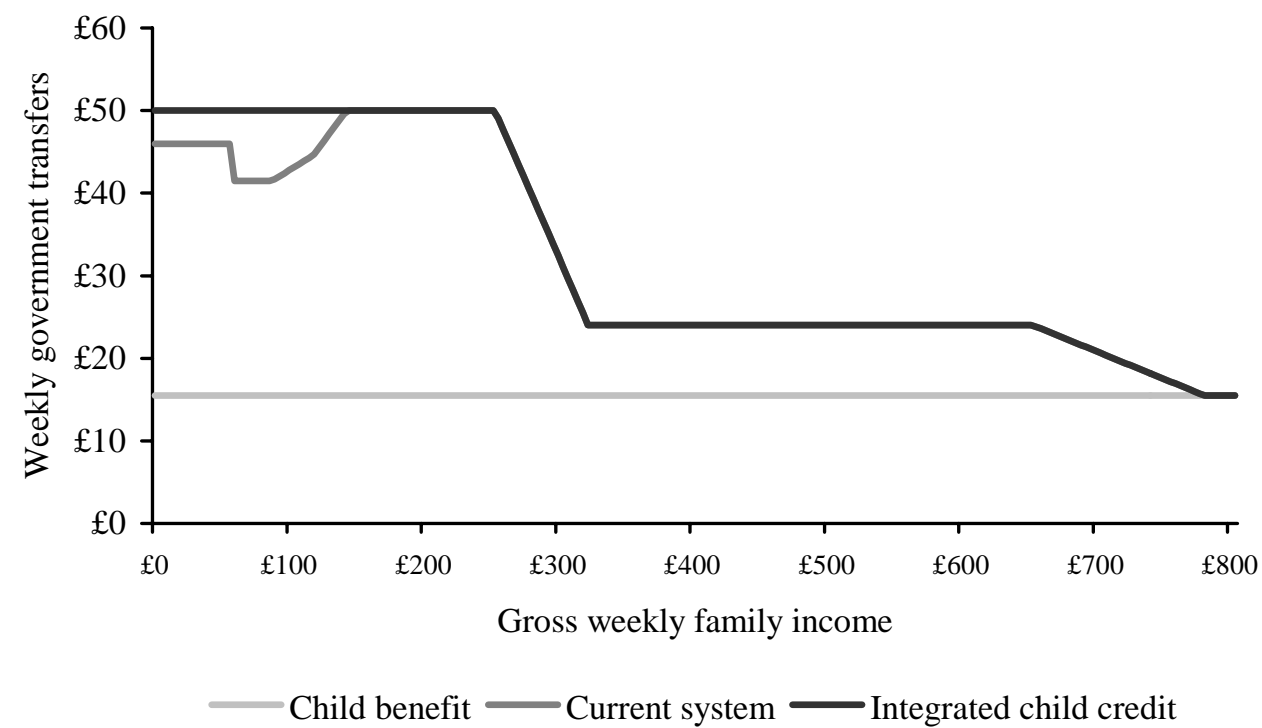

Sourc: Authors' calculations from the IFS tax and benefit model, TAXBEN. The figure assumes that the family qualifies for WFTC at a weekly wage of $£ 59.20$, corresponding to 16 hours of work at the national minimum wage. 
support and WFTC. Families who currently cannot claim WFTC or income support because they have too much capital will gain, but those who are currently claiming WFTC or income support and have some non-earned income may lose.

Figure 5.4 shows the average gains for families in each decile from the introduction of our base integrated child credit and from a system that ensures that no family loses because of the move to joint assessment. Even though the structure of our integrated child credit is very much like the current system, there are a large number of winners and losers. Families in the bottom deciles gain most - families in the bottom decile gain by an average of 4.8 per cent - while families in the top three deciles lose slightly through the change to full joint assessment. It is possible to create a system where no family loses because of the move to joint assessment. This requires doubling the higher threshold to $£ 966$ a week of net family income. All deciles of the income distribution gain, on average, through this reform.

Figure 5.4. Average gains from our 'base' integrated child credit and from a system where no family loses because of the move to joint assessment

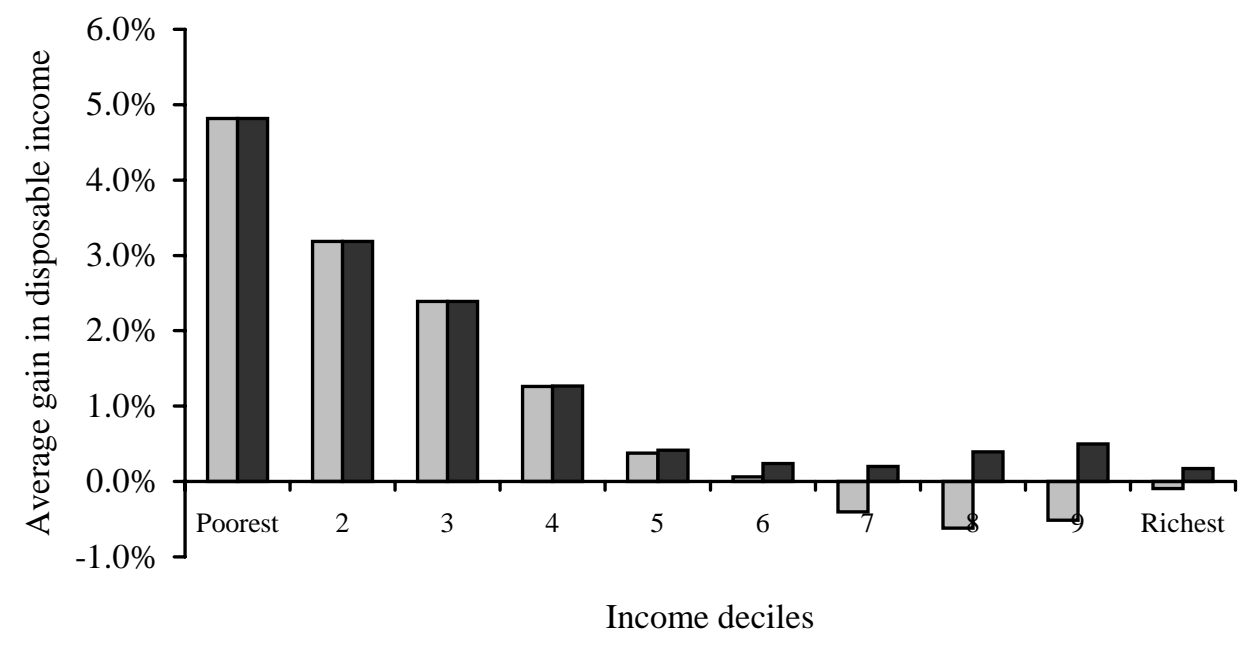

$\square$ Our 'base' integrated child credit

$\square$ No losers from joint assessment

$N$ otes: See text for full details of the reforms.

O ur integrated child credit is by no means a revenue-neutral reform: relative to the current system, the base integrated child credit outlined above would cost around $£ 950$ million a year, and it would cost a further $£ 650$ million a year to ensure that there were no losers through joint assessment. The base integrated child credit would represent around $£ 9.5$ billion of financial support and would go to around 80 per cent of families with children (the government estimates that child benefit will cost $€ 8.8$ billion in 200102, going to 7.07 million families in Great Britain). assessment' integrated child credit would go to 97 per cent of families with children.

39 D epartment of Social Security, 2000d. 


\subsubsection{F urther reforms to the integrated child credit}

We now model the effect of a few reforms to the integrated child credit that would move the structure away from the current system of financial support for children, as discussed earlier in this chapter. Table 5.5 lists the reforms and their aggregate cost. Figures 5.5 and 5.6 show the distributional effects of these reforms compared with our base integrated child credit.

Table 5.5. Some integrated child credit options

\begin{tabular}{l|c}
\hline \hline D escription & Gain/ cost to the government \\
\hline Changing the lower taper & $+£ 200 \mathrm{~m}$ \\
1. Increase the lower taper to $70 \%$ & $-£ 380 \mathrm{~m}$ \\
2. Reduce the lower taper to $40 \%$ & \\
Changing the credits & $-£ 446 \mathrm{~m}$ \\
3. Increase the family premium to $£ 10$ & $-£ 1,970 \mathrm{~m}$ \\
4. Increase the family premium to $£ 15$ & $-£ 650 \mathrm{~m}$ \\
5. Increase the child credit by $£ 2$ & \\
\hline
\end{tabular}

\section{Changing the lower taper}

The government may want to change the lower taper on the integrated child credit, as we discussed in Section 5.2.1. A reduction in the taper reduces the marginal deduction rates faced by some families and increases the number of families who receive more than just the family premium of the integrated child credit and are therefore on a taper. A reduction to 40 per cent would increase the number of families facing marginal deduction rates of 50 per cent or more by 200,000 and reduce the number facing rates of 60 per cent or more by 580,000. The reverse is true for an increase in the taper: an increase in the lower taper to 70 per cent would reduce the number of families facing

Figure 5.5. Average gains or losses from changes in the lower taper of an integrated child credit

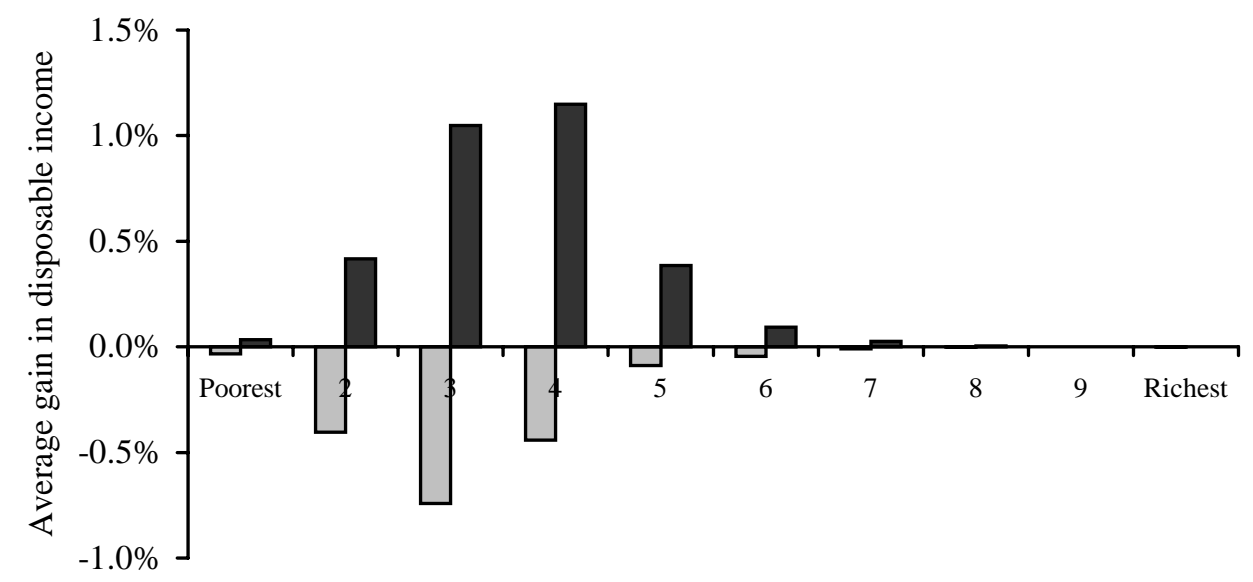

Income deciles

$\square$ Option 1: lower taper $70 \%$

$\square$ Option 2: lower taper $40 \%$

$N$ otes: See text for full details of the reforms. 
marginal deduction rates of 60 per cent or more by 90,000 but increase the number facing rates of 70 per cent or more by 500,000. The distributional results are shown in Figure 5.5.

\section{Changing the credits in the integrated child credit}

Figure 5.6 shows the effects of three options that increase the generosity of our integrated child credit. Option 3 shows what would happen to an integrated child credit if the suggested increase in the children's tax credit to $£ 520$ a year were matched in an integrated child credit. Option 4 goes further than this, increasing the family premium to $£ 15$ a week (or $€ 780$ a year). Option 5 increases the child credits instead, providing a greater increase to large families, as discussed in Section 5.1.

Figure 5.6. Average gains or losses from changes in the family premium and child credits

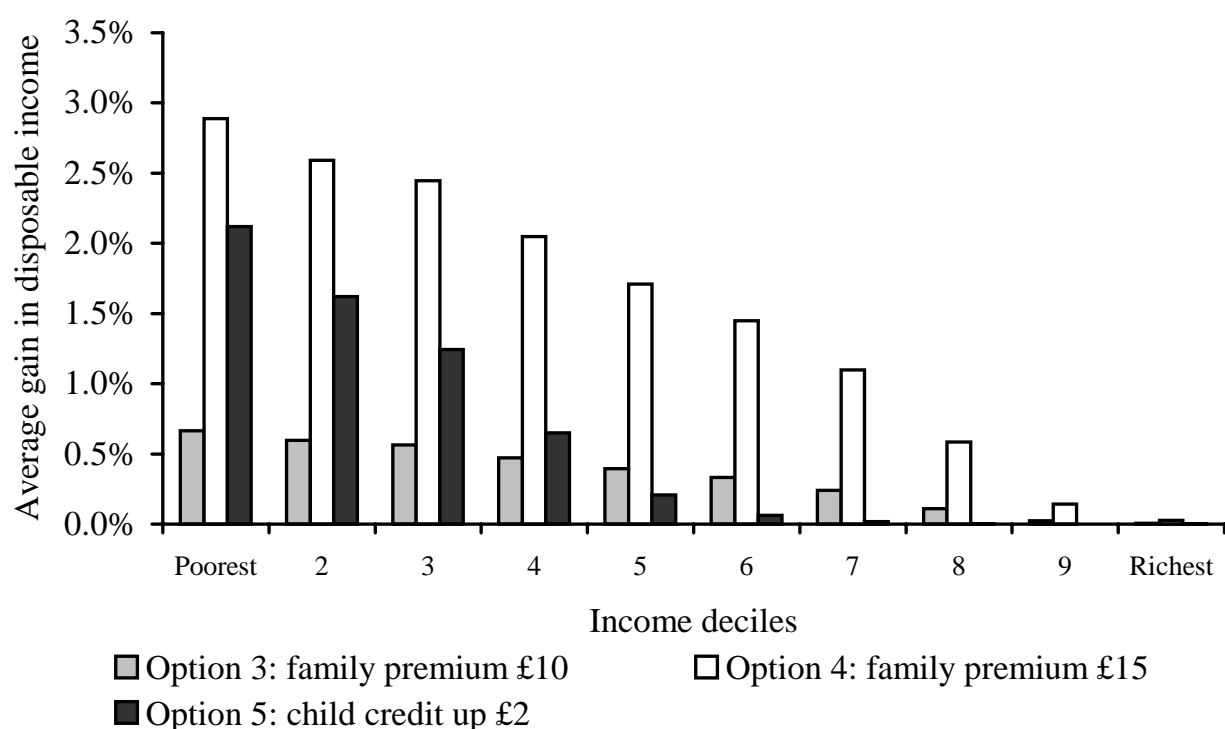

N otes: See text for full details of the reforms.

There is a clear difference in the effect of the reforms: increases in the child credits are more progressive than changes in the family premium. There are two reasons for this. First, higher-income families only receive the family premium part of the integrated child credit. Second, the equivalisation process tends to place larger families in lower deciles, and larger families will gain from the increase in child credits by more than smaller families.

There are many other options that could be explored, but we have shown the important implications of moving to a seamless system of support and of moving to full joint assessment throughout the integrated child credit. 


\section{The administration of an integrated child credit}

Whether the government achieves the objectives for the integrated child credit set out in Chapter 4 will depend not only on the structure of the credit, but also on the administration of the transfer payments. In this chapter, we look at some evidence on the dynamics of family structure and family incomes, and, in the light of this, discuss the principles of the administrative design of the integrated child credit. At present, there are major differences in the principles of administration of income support, WFTC and the children's tax credit, such as whether the system is cumulative or non-cumulative, the period of eligibility assessment, the period of award, frequency of payments and method of payment. In integrating the three elements of the current system, these principles will have to be unified into one coherent mechanism. We discuss the characteristics of the administrative design for the new transfer and then suggest a number of possible ways in which administration of the integrated child credit could be organised.

\subsection{Dynamics of family structure and incomes}

In very general terms, the importance of the mechanism for assessing and paying the integrated child credit will be higher, the greater is the extent of changes in income and family status. For example, if families' incomes changed very little during the year, then an annual eligibility assessment could be sufficient for deciding the appropriate level of integrated child credit payments. This, however, is not the case. Within given family structures, there is a substantial degree of income mobility, particularly amongst those on low incomes, and there are also frequent changes in family structures as partnerships separate and form and children are born and grow up; these all have consequences for families' income and needs. The new integrated child credit system will have to take all these transitions into account.

There is no perfect data source that can tell us about the dynamics of incomes and family status, particularly about the short-term (within-year) dynamics. Only panel or longitudinal datasets - those that track particular individuals over time - can tell us about the dynamics of family circumstances. The panel datasets in the UK typically interview respondents annually or quarterly; in general, these surveys can say little about the changes in circumstances between the interviews, and these monthly or weekly changes may be as important for the design of an integrated child credit as annual or quarterly changes.

In the Appendix, we present some evidence from several sources:

- studies of the British Household Panel Survey (BHPS) that look at the dynamics of low-income families with children;

- our analysis of the Labour Force Survey (LFS), which interviews individuals in (up to) five successive quarters but is a much larger dataset than the BHPS;

- results from ongoing work by researchers at IFS on the employment dynamics of women in the BHPS and the Programme of Research into Low-Income Families 
(PRILIF) datasets (the PRILIF study followed around 900 lone parents over a sevenyear period);

- government administrative data on the flows between in-work and out-of-work benefits.

We present evidence on changes in employment status, family income, family state and benefit receipt, and, where possible, the relationship between them. All sources confirm that there is a lot of movement both across the welfare-to-work divide and along the income scale. The tax and benefit system must also take account of family transitions. The key findings are summarised in Table 6.1. For example, after a year, over 1 million parents have a different employment status and over 750,000 have a different partnership status. These are likely to be underestimates of the actual number of employment and partnership status changes, as some people may have the same status at the end of the year having changed it more than once during the period. Administrative data suggest that nearly 1 million families experienced a move onto or off family credit in a 12-month period when the caseload at any one time was around 750,000.

Table 6.1. Summary of the dynamics of family circumstances

\begin{tabular}{|c|c|c|}
\hline & $\begin{array}{l}\text { Couples with } \\
\text { children }\end{array}$ & Lone parents \\
\hline All adults & $10,460,000$ & $1,710,000$ \\
\hline $\begin{array}{l}\text { Adults who have a different employment status: } \\
\text { within three months } \\
\text { within a vear }\end{array}$ & $\begin{array}{l}360,000 \\
840,000\end{array}$ & $\begin{array}{c}90,000 \\
180,000\end{array}$ \\
\hline $\begin{array}{l}\text { Adults who have a different relationship status: } \\
\text { within a year } \\
\text { Families who started or finished a family credit } \\
\text { claim in 1998-99 }\end{array}$ & 550,000 & 207,000 \\
\hline
\end{tabular}

Source: Authors' calculations from estimates presented in the Appendix, grossed up using population estimates from HBAI 1998-99.

One study that attempts to track changes in joint income for families with children 4 shows that there is substantial stability at the two ends of the income distribution. For example, 86 per cent of 'higher-income' couples with children were higher-income couples with children a year later - this group broadly corresponds to parents most likely to be in receipt of the children's tax credit but not WFTC. There is also considerable stability at the other end of the income distribution: 80 per cent of workless lone parents are still workless lone parents a year later. But there seems to be more mobility amongst other family types and, in particular, between categories that at present correspond to being on the taper of WFTC. For example, on average, about a sixth of adults who remain parents change their income or work status in each year. But 47 per cent of lowincome couples with children are no longer low-income couples with children a year later, a much less stable category than the others. Over a longer period, very many families are likely to experience poverty or worklessness. Over a seven-year period, the study estimates that around half of parents will either experience low income or be in a

40 Iacovou and Berthoud, 2000. 
workless family, the two groups likely to be eligible for a full integrated child credit award.

\subsection{The administrative design of taxes and benefits}

This section discusses the implications of various administrative parameters of the tax and benefit system design and their importance in meeting the objectives set for the integrated child credit. We then examine some (admittedly stylised) options for the administration of an integrated child credit.

\subsubsection{C umulative vs. non-aumulative system}

A mechanism is cumulative if each weekly calculation takes account of previous weeks' calculations and non-cumulative if successive weekly calculations are independent. Both liability/ entitlement/ eligibility 19 and payment can be cumulative or non-cumulative (see Box 6.1). In merging the three elements of the tax and benefit system into one transfer, the government will be integrating one system that is non-cumulative on both payment and liability (WFTC), one system that is cumulative on both criteria (the children's tax credit), and one system that is cumulative with respect to payment and non-cumulative with respect to eligibility (income support).

We now discuss the advantages and disadvantages of having systems that have cumulative or non-cumulative payment or eligibility systems.

\section{Cumulative or non-cumulative eligibility?}

O bviously, people whose incomes do not fluctuate will receive the same level of support whether the system has cumulative entitlement or not. For those who do experience income fluctuations, cumulative systems even out the impact of both positive and negative income changes, while non-cumulative systems can react more to sudden income shocks.

Non-cumulative systems developed with very specific objectives in mind, one of which is the provision of the 'safety net'. For example, families with relatively high incomes up to the point of a claim for income support could well be ineligible for the benefit when faced with a negative income shock if entitlement for income support were based on the income over the past year. Only a transfer system with non-cumulative eligibility will ensure that all those who find themselves suddenly on low income receive support at the time they need it. However, non-cumulative systems mean that people whose income fluctuates may have a different level of entitlement over a longer period than people who have a constant level of income, and this could be perceived as unfair.

\section{Cumulative payment}

The basic choice when designing a cumulative payment system is over the time-frame of the assessment. The trade-off is that infrequent assessments reduce administrative costs

41 We use the words interchangeably. 


\section{Box 6.1. Cumulative and non-cumulative elements of the current system}

In the UK, three of four possible combinations of payment and entitlement are observed in practice. Another example is given by income tax in the US.

\begin{tabular}{l|cc}
\hline \hline Payment/ receipt: & \multicolumn{2}{|c}{ Liability/ entitlement: } \\
& Cumulative & Non-cumulative \\
\hline Cumulative & $\begin{array}{c}\text { PAYE system for income tax, } \\
\text { including the children's tax credit }\end{array}$ & Income support, housing benefit \\
Non-cumulative & $\begin{array}{c}\text { Income tax in the US (monthly } \\
\text { payments are a fixed proportion } \\
\text { of annual earnings; refunds and } \\
\text { under-payments are settled at } \\
\text { year-end) }\end{array}$ & National Insurance contributions \\
\hline \hline
\end{tabular}

Payments and liabilities can be cumulated over different periods of time, the usual time interval being a year. In the UK system, however, income support can be classified as a system with cumulative payment because if the level of entitlement falls in the week over which a payment has already been made, then the over-payment can be reclaimed by the Benefits Agency.

The payment of and eligibility for the children's tax credit will be cumulative, as it is an integral part of the PAYE tax system. Thus, if someone is liable to pay more than $£ 442$ in tax (and if income does not exceed the higher tax threshold), then he or she will receive the full amount of the credit, regardless of whether this tax liability has been a result of income received in one week or spread out evenly throughout the year.

Working families' tax credit is non-cumulative on both payment and eligibility. The value of the award is based on past income in a specified period of time. Income outside that period is completely disregarded. O nce the award is set, it is then paid for six months at the same level regardless of changes in circumstances or income.

but allow under- or over-payments to accumulate. More frequent assessments are more costly but prevent accumulation of under- or over-payments. Infrequent assessments may be preferable in situations where temporary under- or over-payments do not present a very serious problem, perhaps because large changes in eligibility are unlikely or because potential under- or over-payments are small relative to overall income (such as the children's tax credit). On the other hand, if we want to avoid under- or overpayments, it will be necessary to have short periods over which payment is accumulated and frequent eligibility assessments. For example, income support is currently paid weekly on the basis of income at the time of claim for an unlimited period of time. If income increases during the time of receipt, and this is not immediately reported to the Benefits Agency so that adjustments can be made to payments, recipients can be liable to return the amount they have been over-paid. Yet because of close monitoring, accumulation of high levels of under- or over-payments should not be possible. 


\section{Non-cumulative payment}

In contrast to cumulative payment mechanisms, non-cumulative payment systems (such as WFTC) prevent accumulation of debts by recipients by simply ignoring them, but they could lead to families receiving awards different from what their current circumstances would suggest. In the case of WFTC, payment is fixed for six months, and receipt of higher income during the six months than that at the time of award assessment, which would reduce eligibility if assessment were continuous, does not reduce the award. If the payment of WFTC were cumulative over the six months of WFTC receipt, families receiving higher income would be liable to repay awards in excess of their eligibility (or would be eligible for extra payments if their incomes fell).

\subsubsection{The period and frequency of assessment and award}

There are three more parameters to discuss. The first is the period of assessment - the period over which entitlement is calculated. In a cumulative system, the assessment period includes the period of payment - this is what defines a cumulative system. ${ }^{42}$ The second parameter is the period of award - a separate parameter from the period of assessment in a non-cumulative system.

The third parameter is the frequency of payment. This can also differ from the period of payment, regardless of the nature of the system. For example, both the children's tax credit and the earned income tax credit in the US have annual payment periods, but the children's tax credit is paid at regular intervals through the PAYE system and the earned income tax credit is a one-off payment at the end of the year.

These parameters are important as they will affect the cost of a system, how well it provides a safety net and people's 'real-time' work incentives (rather than those calculated on a tax and benefit model).

\section{Period of assessment}

The period of assessment is an important parameter for non-cumulative entitlement systems. This is because a system with non-cumulative entitlement looks more like a system with cumulative entitlement the longer we make the assessment period. For example, an award assessed on six-monthly income may lead to a very different outcome from an award assessed on weekly income. Ensuring a safety net, as we discussed above, means that we need a short period of assessment to ensure that families who received high incomes in the past are not disqualified from assistance when faced with a sudden fall in income.

\section{Period of award}

In systems where payment is cumulative, an award with a long period may lead to accumulation of debts, but an award with a long period in a non-cumulative payment system may lead to over- or under-payment through poor targeting. For example, WFTC is assessed once every six months and the award is then paid at a fixed level for six

\footnotetext{
42 For example, income tax is calculated on annual income and payments are adjusted throughout the year to avoid over- or under-payment at year-end.
} 
months. As a result, families whose circumstances change and who would no longer be entitled to a given level of award if WFTC were assessed more often may continue to receive the transfer. It is possible to imagine a system where entitlement is assessed more frequently and the award is fixed for a shorter period (say for three months). The consequence of that would be better targeting of the transfer at the cost of more administration and more hassle for families.

\section{Frequency of payments}

There are important welfare concerns regarding the frequency of payments. If transfers constitute a large proportion of a family's total income, it will make a great difference to the family whether the transfer is paid weekly or annually. But families for whom transfers represent a small fraction of total income may be happy to receive transfers less frequently.

\section{' Real-time' work incentives}

As well as affecting how well the system provides a safety net and its cost, the period of award, the frequency of assessment and the frequency of payment will all determine people's 'real-time' work incentives - the actual budget constraint faced by families in the short run. ${ }^{43}$ Theoretical budget constraints - as usually drawn by analysts - tend to assume a constant income stream and ignore the fact that different parts of the tax and benefit system respond with different frequencies. But, for example, if transfers are assessed and paid infrequently, people may not realise how their entitlement is linked to their income, and this may alter the (positive or negative) work incentive aspects of inwork support. Alternatively, payments that are fixed over a long period, such as WFTC, may particularly encourage short-term increases in earnings, as there is no immediate withdrawal of the award as income rises.

\subsection{Some options for an integrated child credit}

Below, we present four options for the administration of an integrated child credit and then assess them in Tables 6.2a \& b against the objectives that we presented in Chapter 4 - both the government's objectives for the reform and the general objectives that we identified for the tax and benefit system. We do not pretend that these are fully-thoughtout - or even sensible - suggestions. But they do help expose the inherent trade-offs.

System 1: A n annually cumulated system

O ne way to administer an integrated child credit would be to structure it along the lines of the earned income tax credit in the US. Entitlement for the transfer could be assessed at the end of the tax year, based on income that year. O ver a year, this would ensure that families get the right amount of support, given their income over a year. If payments were lump-sum and made in arrears, accumulation of debts would not be possible. Moreover, administration of the payments would be relatively simple and inexpensive.

43 The phrase comes from Walker and Wiseman (1997). 
This system would, of course, raise concerns for the UK. Most importantly, if payments were made at the end of the tax year, the system would fail to provide a safety net for those who find themselves on low incomes. Families at the bottom of the income distribution, for whom payments would constitute a high proportion of their income, may need to have payments made on a regular basis, with immediate payments in response to negative income shocks.

System 2: A system with week ly assessment

A system administered on a weekly basis like income support, with weekly assessment and payments, would avoid the weaknesses of the design described above. This form of administration would ensure that payments were made promptly to those in greatest need and would be properly targeted on the poorest families, with immediate reductions in payments in response to increased family incomes. Weekly monitoring of family incomes would ensure that no debts were accumulated.

The system would, of course, have a serious drawback in that it would require almost all the 7 million families with children in the country to report changes in income to the Inland Revenue every week. This would involve a lot of hassle for parents, as well as huge administrative costs for government. For families whose incomes are relatively stable, this type of close monitoring would be unnecessary. The level of hassle and interference could well discourage many families from applying, and hence reduce takeup.

Systems 3 and 4 - common parameters

The two examples given above highlight two important points:

- If provision of the safety net is to be maintained, it must allow for payment of transfers to those who suddenly find themselves on very low income. This excludes the possibility of a system with 'pure' cumulative entitlement.

- To avoid debt accumulation and excessive monitoring, the system must compromise on the precision of targeting by having non-cumulative payments.

The two schemes discussed below are both non-cumulative in terms of eligibility and payment. In these two respects, they are more like WFTC than the children's tax credit.

System 3: Income support / employment tax credit passporting

O ne possibility would be to design the system so that eligibility for income support (IS) or employment tax credit (ETC) would passport individuals onto the maximum integrated child credit award. It might be reasonable to make periods of payment of the credit different depending on whether it were attached to an income support or an employment tax credit award. Like WFTC (and presumably ETC), the ETC-linked integrated child credit could be paid for a period of six months. The length of the awards attached to income support would have to balance the desire to provide - in the government's words - 'a seamless system of financial support for children', which would ask for periods of payment similar to those under employment tax credit, with the 
possibility that some people may suffer a temporary income shock and then move to income levels where they would eligible for less than the full integrated child credit award.4 In these cases, monthly periods of payment of the integrated child credit might limit the possibility of over-payment without significantly affecting the disincentive to take up employment through fear of temporary loss of income.

People not directly passported onto the integrated child credit would be eligible for less than a full integrated child credit award, and might have the award set according to some estimate of annual income. At these income levels, temporary income fluctuations might be of less concern and so the amount paid would not have to react immediately to changes in income.

This still leaves several issues that would have to be addressed. O ne is that if payment of the integrated child credit were to be non-cumulative (to avoid over-payment), the payments would have to be based on a one-off assessment of family income and then set at that level for the whole payment period. In this case, the targeting of the transfers would be less precise than in Systems 1 and 2 .

Another possible disadvantage of this type of administration is that not everyone may claim the income support or the employment tax credit that they are entitled to, especially if their anticipated award is low. This system would also mean that receipt of the integrated child credit by the carer in a couple could be dependent on the claim of income support or employment tax credit by the main earner. There would therefore have to be allowance for separate eligibility assessment not based on IS/ ETC passporting to avoid these situations.

System 4: Separate the integrated child credit from income support and employment tax credit, and have continual assessment of the integrated child credit

Another option is to treat the integrated child credit completely separately from income support and employment tax credit, and to have the Inland Revenue adjust the value of the integrated child credit monthly, as with PAYE at present. This would both avoid the linking of maximum awards of the integrated child credit to claims of income support or employment tax credit, described above, and reduce the administrative burden on families compared with System 2.

Such a system might work as follows. Families claiming the integrated child credit would provide the Inland Revenue with information on their family status. $\mathrm{On}$ the basis of that information, and the Inland Revenue's own information on net incomes, the Revenue could send payments to the main carer, perhaps monthly in arrears. As the credit will be based on family income, the Inland Revenue would have to match income data collected from both parents in couples. Information on their family status would have to be checked or updated at some interval.

${ }^{44}$ Lone parents typically spend a number of years on income support, but unemployed parents often move into work within a number of months (see the Appendix). 
Table 6.2a. Govemment objectives for an integrated child credit and possible administration of the transfer

\begin{tabular}{|c|c|c|c|c|}
\hline Govemment objectives & Annually cumulated system & Weekty assessment & IS/ ETC passporting & ICC separated from IS/ ETC \\
\hline Transparency & $\begin{array}{l}\text { Administration and } \\
\text { application independent of } \\
\text { IS/ ETC. Values clearly } \\
\text { specified for given levels of } \\
\text { annual family income. }\end{array}$ & $\begin{array}{l}\text { Administration and } \\
\text { application independent of } \\
\text { IS/ ETC. Values clearly } \\
\text { specified for given levels of } \\
\text { weekly family income. }\end{array}$ & $\begin{array}{l}\text { Application linked to IS/ ETC } \\
\text { receipt, though the level of } \\
\text { support clearer and constant } \\
\text { whether out of work or in } \\
\text { low-paid work }\end{array}$ & $\begin{array}{l}\text { Administration and application } \\
\text { independent of IS/ ETC. Values } \\
\text { clearly specified for given levels of } \\
\text { monthly family inoome. }\end{array}$ \\
\hline Moving from welfare to work & $\begin{array}{l}\text { Paid at the end of the year so } \\
\text { no change in integrated child } \\
\text { credit at the time of the } \\
\text { employment change. }\end{array}$ & $\begin{array}{l}\text { No temporary loss of inoome } \\
\text { as a result of moving from } \\
\text { welfare to work, as } \\
\text { assessments made frequently } \\
\text { and regularly. }\end{array}$ & $\begin{array}{l}\text { No temporary loss of inoome } \\
\text { as a result of moving from } \\
\text { welfare to work; value in and } \\
\text { out of work the same for } \\
\text { most people. }\end{array}$ & $\begin{array}{l}\text { No temporary loss of income as a } \\
\text { result of moving from welfare to } \\
\text { work; value in and out of work the } \\
\text { same for most people. }\end{array}$ \\
\hline Framework of assessment & $\begin{array}{c}\text { Assessment the same for all } \\
\text { families. }\end{array}$ & $\begin{array}{l}\text { Assessment the same for all } \\
\text { families. }\end{array}$ & $\begin{array}{l}\text { Assessment differs for those } \\
\text { in receipt of IS/ ETC and } \\
\text { others. }\end{array}$ & Assessment the same for all families. \\
\hline Who receives the payment? & \multicolumn{4}{|c|}{ Payment to the main carer } \\
\hline $\begin{array}{l}\text { Government efficiency and } \\
\text { hassle for families }\end{array}$ & $\begin{array}{c}\text { Hassle very limited for all } \\
\text { families - only one application } \\
\text { per year. }\end{array}$ & $\begin{array}{l}\text { System extremely demanding } \\
\text { on both families and } \\
\text { government agencies. }\end{array}$ & $\begin{array}{l}\text { Hassle limited for people who } \\
\text { stay out of work and in low- } \\
\text { paid work. Hassle may } \\
\text { increase for nicher families. }\end{array}$ & $\begin{array}{l}\text { Increased hassle for better-off } \\
\text { families. Substantially more effort } \\
\text { required from employers and the } \\
\text { Inland Revenue. }\end{array}$ \\
\hline
\end{tabular}


Table 62b. General objectives for an integrated child credit and possible administration of the transfer

\begin{tabular}{|c|c|c|c|c|}
\hline General objectives & Annually cumulated system & Weekly assessment & IS/ ETC passporting & ICC separated from IS/ ETC \\
\hline Provision of safety net & $\begin{array}{l}\text { Families on low income will see } \\
\text { woekly income become annual } \\
\text { payment. Safety net only } \\
\text { provided by adult elements of IS } \\
\text { and ETC. }\end{array}$ & $\begin{array}{l}\text { Safety net preserved as inoome } \\
\text { monitored weekly. }\end{array}$ & $\begin{array}{l}\text { Safety net maintained through } \\
\text { the 'passporting' system. }\end{array}$ & $\begin{array}{l}\text { Special arrangements necessary } \\
\text { to avoid monthly delay in } \\
\text { payment when families } \\
\text { experience negative income } \\
\text { shock. }\end{array}$ \\
\hline Preserving work incentives & $\begin{array}{c}\text { No immediate response of } \\
\text { payments to change in } \\
\text { employment. }\end{array}$ & $\begin{array}{c}\text { Immediate response of } \\
\text { payments to changes in } \\
\text { employment. }\end{array}$ & $\begin{array}{l}\text { Response to changes in } \\
\text { employment similar to that of } \\
\text { WFTC. }\end{array}$ & $\begin{array}{l}\text { Monthly lag in response to } \\
\text { changes in employment. }\end{array}$ \\
\hline $\begin{array}{l}\text { Minimising administrative } \\
\text { costs and hassle }\end{array}$ & $\begin{array}{l}\text { Low administrative cost as } \\
\text { information needs to be } \\
\text { collected once a year. }\end{array}$ & $\begin{array}{l}\text { Very high costs and hassle for } \\
\text { families, as information } \\
\text { collected weekly. }\end{array}$ & $\begin{array}{l}\text { Administrative burden similar to } \\
\text { WFTC (so less for those } \\
\text { currently claiming inoome } \\
\text { support, more for those who } \\
\text { will claim the children's tax } \\
\text { credit). }\end{array}$ & $\begin{array}{l}\text { Relatively high administrative } \\
\text { burden, though claims made } \\
\text { only twice a year. Requires } \\
\text { significantly more } \\
\text { administration by employers. }\end{array}$ \\
\hline Targeting of transfer & $\begin{array}{l}\text { Accurate targeting on annual } \\
\text { basis. }\end{array}$ & $\begin{array}{l}\text { Accurate targeting on woekly } \\
\text { basis. }\end{array}$ & $\begin{array}{l}\text { Fixed amount paid for a one- } \\
\text { month or six-month period, so } \\
\text { targeting similar to that of } \\
\text { WFTC. }\end{array}$ & $\begin{array}{l}\text { Aocurate targeting on monthly } \\
\text { basis. }\end{array}$ \\
\hline $\begin{array}{l}\text { Guaranteeing faimess (or } \\
\text { equity) between families of } \\
\text { similar resources and needs }\end{array}$ & $\begin{array}{l}\text { Families with same annual } \\
\text { incomes receive same annual } \\
\text { awards. Equity not ensured over } \\
\text { shorter periods. }\end{array}$ & $\begin{array}{l}\text { Families with same weekly } \\
\text { incomes receive same awards. } \\
\text { Equity not ensured over longer } \\
\text { periods. }\end{array}$ & $\begin{array}{l}\text { Families with same incomes at } \\
\text { time of claim recive same } \\
\text { awards. Equity not ensured over } \\
\text { longer periods. }\end{array}$ & $\begin{array}{l}\text { Families with same monthly } \\
\text { incomes reoeive same monthly } \\
\text { awards. Equity not ensured over } \\
\text { longer periods. }\end{array}$ \\
\hline Avoiding over-payment & $\begin{array}{l}\text { Payments made in arrears, thus } \\
\text { no over-payment. }\end{array}$ & $\begin{array}{l}\text { Weekly payments, thus over- } \\
\text { payment unlikely if changes } \\
\text { reported promptly. }\end{array}$ & $\begin{array}{c}\text { Payments are non-cumulative so } \\
\text { never reclaimed. }\end{array}$ & $\begin{array}{l}\text { Payments made in arrears on } \\
\text { actual income data, so no over- } \\
\text { payment. }\end{array}$ \\
\hline
\end{tabular}


Such a system could be non-cumulative (over a month) in eligibility and payment, it would avoid over-payment, and it would be relatively well targeted, as adjustments to payments would be made on a monthly basis. The system would lower the information requirement made on lower-income families, but it would slightly increase the burden higher up the income scale.

The major drawback with this design, though, is its requirement of rapid and accurate processing of income information by the Inland Revenue and employers. The Revenue currently learns about people's net incomes with a significant lag; under this system, employers would probably have to provide information more regularly than they do now. There would have to be mechanisms to ensure immediate assessment and payment in special cases to provide a safety net. The system would also have to ensure that the Inland Revenue had access to information about the incomes of those out of work.

Tables 6.2a and 6.2b assess these four systems against the objectives in Chapter 4. The conclusions are that none of these systems meets all the objectives that we set for an integrated child credit. But this does help to expose the unavoidable trade-offs that exist when designing the integrated child credit. The eventual credit may have to blend some of the features of all the systems we suggest, trading off increased complexity against greater success in meeting the other objectives.

45 The self-employed, and those with high non-earned income, would not fit neatly into this system. 


\section{Other design issues: joint assessment, wallet-to-purse classification and classifying the integrated child credit}

The previous two chapters have discussed some options for the design of the structure and administration of the integrated child credit. A number of issues do not fit neatly under those two headings, and we discuss those here. In particular, we discuss:

- the implications of and arguments around assessing the integrated child credit on the joint incomes of couples;

- why the government wants to pay the integrated child credit to the main carer;

- whether there should be an employment tax credit for people without children;

- $\quad$ whether the integrated child credit is a tax credit or a benefit, and whether it matters.

\subsection{Joint assessment}

The fact that the integrated child credit is to be based on a family's joint income has been seen as a turning-point in the structure of taxes and benefits, which since 1990 has been based on a principle of individual taxation. But, if anything characterises the design of the tax system for the family in the UK, it is a sense of continuous change: as we discussed in Chapter 3, the history of financial support for children shows that the UK's system of financial support for children was based upon joint income from after the Second World War until 1977, and, even after then, the system of income tax was a joint one until 1990.

It is also important to realise that the supposed introduction of joint assessment for the integrated child credit in 2003 may not represent a substantial change in the current system for many parents. At present, couple families claiming income support or WFTC must make joint claims, giving full details of both partners' incomes, and the awards are assessed on joint incomes. Anyone claiming income support must tell the Benefits Agency immediately of any changes in relationship status: if such a change would reduce the amount of money they are entitled to, then they may be liable to repay all overpayments from the date of the change. From 2001, couple families claiming the children's tax credit will have to tell the Inland Revenue if either of them is a higher-rate taxpayer and, if so, which of them earns the most. They also have to tell the Inland Revenue of any changes in relationship status, and are liable to repay over-payments of the children's tax credit due to changes in relationship status. ${ }^{17}$ So, from April 2001 , the only form of financial support for children that a parent can claim independently of their partner will be child benefit. The only people who will see a change in the method of

\footnotetext{
46 See, for example, Chennells, Dilnot and Emmerson (2000), who also noted that the view that individual taxation was not a good way to tax couples was shared by the Conservative Party, which proposed transferable tax allowances in its 1997 general election manifesto. In fact, the switch to joint assessment of the integrated child credit represents part of a trend under the current government to use families rather than individuals as the unit of assessment. This trend is discussed further in Dilnot, Emmerson and Simpson (forthcoming).

47 For example, if the man in a couple was receiving the children's tax credit and then left his partner and children, he would not be entitled to the children's tax credit from that point on.
} 
assessment between the system after April 2001 and the proposed integrated child credit will be families who are claiming the children's tax credit but not WFTC, where the integrated child credit will be assessed on the joint income of couples rather than being assessed on the higher income (we showed the distributional impact of this in Chapter 5).

There will, though, be a change in the administration of financial support for children, as the integrated child credit will be administered by the Inland Revenue. Its staff will need to learn from the experience of the Benefits Agency in dealing with and reacting to changes in family circumstances among low-income families - changes that are often linked to periods of emotional and financial crisis.

\subsubsection{W hy does the government want to assess the integrated child credit on joint inome?}

The main argument put forward for joint assessment is that it allows the government to target resources better on families who need it most. The implicit view behind this statement is that the well-being of individuals in a family is determined by the combined income of the family, rather than by the income earned by the individual. In addition, in the case of the integrated child credit, the government is implicitly assuming that the well-being of children depends upon the combined income of their parents. One could certainly contest that view, but the only real alternative under a purely individual tax and benefit system - assessing the integrated child credit on a mother's own income - would involve an enormous redistribution of resources from 'poor' to 'rich' households (for example, from families where both the mother and father are low-paid workers to families with one high-paid father and a non-working mother). This does not seem compatible with the direction of the government's reforms to financial support for children to date.

\subsubsection{The implications of joint assessment}

Two arguments are commonly used against joint assessment in the tax and benefit system. One is an economic argument - that joint assessment gives second earners a lower incentive to work than the first earner, and this may exaggerate gender inequalities in work and pay. The other is a more political concern - that adults should not have to share their financial affairs with their partners. Both these arguments apply to the integrated child credit, and we discuss them in turn below.

The first concern - which applies to any tax and benefit reform that increases marginal deduction rates ${ }^{48}$ - is that it may reduce people's incentives to increase earnings. For example, following an increase in marginal deduction rates, individuals out of work might decide that it is not worth entering work, and individuals in work might reduce their hours of work or even stop working. In the long run, people might be less inclined to seek increases in earnings through job progression.

Under joint assessment, second earners may face a higher marginal deduction rate than they would under individual assessment (this is because the deduction rate would be

\footnotetext{
${ }^{48}$ A marginal deduction rate is the proportion of income that is lost in extra taxes paid and benefits withdrawn as income rises by $€ 1$.
} 
determined by the combined income of the couple, making it more likely that income is reduced at a higher rate). This may encourage second earners to reduce their work effort. This would not be a concern if we thought that all income was shared within the household and if household composition did not change. But we saw in Chapter 6 that households do change their composition, and so it is argued by some that extending joint assessment will reduce the incentive for women to work (in a couple, the woman is more likely to be the second earner, with lower hourly wages and lower weekly eamings, on average). This could lead to long-term experience and training penalties for women, meaning that they will be more likely to find themselves on a low income if the relationship ends. This result is theoretically possible - for example, one study 49 estimated that some women in couples with children may stop working as a result of WFTC - but there is little evidence yet on how important these concerns are in practice. As we said above, though, the integrated child credit will represent only a small extension of joint assessment for financial support for children, and those families affected by the change - those currently claiming just the children's tax credit - are likely to be on the flat portion of the integrated child credit, where it is not reduced with extra income.

The other argument against joint assessment is a more political concern - that adults should not have to share details of their financial affairs with their partners. This was one of the main arguments used by the then Chancellor, Nigel Lawson, when he announced the move to an individual system of income tax, which began in 1990. However, this argument has usually only been applied to better-off households, as there has not been a widespread call for benefits in the UK to be assessed on an individual's own income.

\subsection{Who should receive financial support for children?}

One of the few details that we do know about the integrated child credit is that the government wants to pay it, like child benefit, to the main carer, almost always the mother in couple families. This will lead to a situation where, from 2003, all financial support for children from the government is paid to the main carer. It will represent the culmination of a long-running process of reforms to how financial support for children is delivered. The trend towards paying financial support to the carer began in 1977, with the replacement of tax allowances (which went to the man in a couple family) with child benefit (which went to the main carer), and continued through the payment of family credit to the main carer. In fact, the only reform since 1977 that has gone in the opposite direction was the introduction of WFTC, where couples can now choose to whom WFTC is paid, so representing a shift (albeit small) from 'purse' to 'wallet'.

7.2.1 W hat effect will the introduction of an integrated child credit have on the distribution of incomes within couples with children?

Table 7.1 shows some illustrative, stylised examples of the redistribution of income between adults in a couple family, assuming that the basic structure and the level of the

\footnotetext{
49 Discussed in Blundell and Reed (2000) and Blundell et al. (2000).

50 As of April 2000, the half a million couple families receiving WFTC have to nominate (jointly) who they want to receive the credit. It does not, therefore, always represent a purse-to-wallet transfer.
} 
integrated child credit mirror the current system of financial support for children. Three sorts of families will be affected by the change to paying integrated child credit to the main carer: families now on income support or jobseeker's allowance; families on WFTC; and families receiving the children's tax credit from April 2001. The most significant impact will be for families currently on income support or jobseeker's allowance where the man currently makes the claim. But where a family is on WFTC and a non-working woman is receiving WFTC direct, the integrated child credit reform will mean that the part of WFTC that becomes employment tax credit will now go to the man.

\section{Table 7.1. Possible redistribution of income within couples under an illustrative integrated child credit}

\begin{tabular}{|c|c|c|c|c|}
\hline & \multicolumn{2}{|c|}{ System from A pril 2001} & \multicolumn{2}{|c|}{$\begin{array}{c}\text { System under integrated child credi } \\
\text { payment rules }\end{array}$} \\
\hline & $\begin{array}{l}\text { Man's } \\
\text { income }\end{array}$ & $\begin{array}{l}\text { Woman's } \\
\text { income }\end{array}$ & $\begin{array}{l}\text { Man's } \\
\text { income }\end{array}$ & $\begin{array}{l}\text { Woman's } \\
\text { income }\end{array}$ \\
\hline $\begin{array}{l}\text { Workless couple on income } \\
\text { support or jobseeker's } \\
\text { allowance, man claims }\end{array}$ & $£ 113.70$ & $£ 15.50$ & $£ 83.25$ & $£ 50.00$ \\
\hline $\begin{array}{l}\text { One-earner couple on } \\
\text { WFTC, man is the earner } \\
\text { (net earnings of } € 137 \text { ) and } \\
\text { claims WFTC }\end{array}$ & $\begin{array}{l}£ 75.70+\text { net } \\
\text { earnings }\end{array}$ & $£ 15.50$ & $\begin{array}{l}£ 41.20+\text { net } \\
\text { earnings }\end{array}$ & $£ 50.00$ \\
\hline $\begin{array}{l}\text { One-earner couple on } \\
\text { WFTC, man is the earner } \\
\text { (net earnings of } £ 137 \text { ), } \\
\text { woman claims WFTC }\end{array}$ & $\begin{array}{l}£ 8.50+\text { net } \\
\text { earnings }\end{array}$ & $£ 82.70$ & $\begin{array}{l}£ 41.20+\text { net } \\
\text { earnings }\end{array}$ & $£ 50.00$ \\
\hline $\begin{array}{l}\text { Couple on the children's tax } \\
\text { credit, woman does not pay } \\
\text { income tax }\end{array}$ & $\begin{array}{l}£ 8.50+\text { net } \\
\text { earnings }\end{array}$ & $£ 15.50$ & $\begin{array}{l}£ 0+\text { net } \\
\text { earnings }\end{array}$ & $£ 24.00$ \\
\hline
\end{tabular}

$\mathrm{N}$ otes: All families have one child. Net family income of $£ 137$ is the minimum income at which earner is benefiting from the full value of the CTC. We assume the new ETC is paid to the earner.

\subsubsection{W hy does the government want to pay financial support for children to women?}

It has been generally believed by policy-makers for a considerable period of time that paying financial support for children to women leads to better outcomes for the children than paying it to men. Some examples of work that shows this include Pahl (1989) and Lundberg, Pollak and Wales (1995). This view also seems to be widely held by the general public. 51

\footnotetext{
51 Bradshaw and Stimson (1997) discuss the results of opinion surveys in 1972 and 1985 which showed very strong public support for paying financial support for children to mothers in couples rather than to fathers.
} 


\subsection{Why an employment tax credit for people without children?}

The government has said that the integrated child credit will be complemented by an employment tax credit paid through the wage packet (see HM Treasury (2000b)). This has been presented as an inevitable consequence of introducing an integrated child credit, but this is not the case. It will be necessary to continue to have an in-work tax credit for families with children to ensure that they do not lose any money from the change to an integrated child credit, which will probably only include the 'child' components of WFTC. But the government has said that it will extend this employment tax credit to people without children as well.

The government's stated aims for an employment tax credit for those without children are to increase work incentives for low-paid workers and to relieve in-work poverty in working households without children.

IFS's 2000 Green Budget discussed some of the implications of introducing an employment tax credit for people without children (Chennells, Dilnot and Emmerson, 2000). It showed that extending the adult component of WFTC - a credit of around £53 a week - to all working adults in low-income families would be very expensive and not well targeted on those with the lowest living standards: the largest gains would go to people in the third quintile of the household income distribution. ${ }^{52}$ Ninety-one per cent of the expenditure would go to single people (living by themselves or with their parents), nearly two-thirds of whom would be under 26 . Because of this profile of potential beneficiaries, the government has suggested that one possibility is the introduction of an employment tax credit with a substantially reduced rate for those under 25 without children (see HM Treasury (2000b, paragraph 3.24)).

But in the light of the integrated child credit reform, it is relevant to ask why the government wants to maintain a continued distinction between in-work and out-of-work benefits for adults when it has decided to remove that distinction for financial support for children. It would certainly be possible to remove the current distinction between being out of work and being in low-paid work. ${ }^{2}$ But the current proposals for employment tax credit imply that people moving into low-paid work and in a lowincome family would have to reapply for financial support from a different source, perhaps administered by a different agency or department. The government has not made it clear why it sees this distinction based on hours of work to be desirable once financial support for children has been turned into a seamless payment across the welfare-to-work divide. O ne possible advantage, though, is that the jobseeker's allowance regime allows the government to impose conditions and sanctions on working-age people receiving benefits, and the government may be unwilling to extend this sort of regime to those already in work.

\footnotetext{
52 This modelling assumed that income is shared between all adults in a household, including in households that consist of a young adult (over 18) living with their parents.

53 This approach is much more common in other countries, where the basic safety-net benefits only depend upon income and not on how many hours people work.
} 


\subsection{Is the integrated child credit a benefit or a tax credit?}

It is not always clear how tax credits should be classified in the public finances or National Accounts. The introduction of WFTC was accompanied by some controversy, as the Treasury classified WFTC in a different way from the European System of Accounts (E SA), used by the O ffice for National Statistics. The Treasury's approach was to count all WFTC awards as negative tax revenues, even though a considerable proportion of families have WFTC awards that are greater than their income tax bills. ${ }^{.4}$ This is a different approach from that used by the previous government, which counted all of family credit as social security spending.

These arguments will apply to the integrated child credit as well. Some of the constituent parts of the integrated child credit currently count as government spending under the ESA classification (for example, the child allowances in income support and that part of WFTC over and above refunds of income tax) and some count as forgone revenue (for example, that part of WFTC that effectively refunds income tax and the children's tax credit). How the integrated child credit is classified in the public finances should make no difference to how people respond to the payments, but it may make a difference to the estimates of the aggregate tax burden (or the proportion of GDP accounted for by government spending). These issues - which are common to the other credits introduced by the current government - will be discussed more in IFS's 2001 G reen Budget (Dilnot, Emmerson and Simpson, forthcoming).

54 Treasury documents allow one to calculate the tax burden using either definition (see, for example, Table B8 in HM Treasury (2000d)), but the government's preferred measure of the tax burden uses the negative tax treatment described above. Other examples of tax credits that are classified as spending include the former mortgage interest tax relief (MIRAS) and the new research and development (R\&D) tax credits. 


\section{Conclusions}

The new integrated child credit is, in our opinion, a radical reform of the tax and benefit system that will affect nearly all of the 7 million families with children in the UK. Given the gradual evolution of the mechanisms that direct financial support to families with children, this represents an ideal time to re-examine the principles on which the current system is based and to remove any anomalies or undesirable features. We have both discussed the economics behind directing financial support to families with children and analysed the objectives for an integrated child credit and some options for achieving those.

Governments all over the world direct extra resources to families, and they do so generally to achieve equity - both horizontal and vertical - and efficiency goals. The horizontal equity argument is not exclusively about children - it is about directing resources towards poor households, taking account of their composition. But if governments do pursue horizontal equity goals, then families with children tend to benefit both because their consumption needs increase compared with those of families without children and because adults' ability to do paid work falls as they become parents. The vertical equity and efficiency arguments, though, both give rationales for directing extra support specifically to families with children, doing more than just reducing the inequality in living standards controlling for the composition of the household.

Equivalence scales help governments make comparisons of living standards in their pursuit of horizontal equity, and should therefore have implications for structuring financial support for children. But we showed that the McClements equivalence scale used by the government when calculating income distribution statistics bears little resemblance to the current structure of financial support for children. This suggests either that the government does not believe the McClements equivalence scale or that it is using the efficiency and vertical equity arguments to go beyond simple redistribution to poor households, particularly in the case of young children.

The government has said that an integrated child credit will provide:

i. a more transparent system of support for children, helping parents understand what they can expect to receive, and facilitating public debate about the appropriate level of support;

ii. a portable and secure income bridge spanning welfare and work;

iii. a common framework for assessment and payment, where all families will be part of the same system;

iv. a system where support for children is paid to the main carer;

v. efficiency gains for Government, and reduced hassle for parents, from moving away from a system where support for children is delivered through four different mechanisms.

Not surprisingly, these are objectives that the current system of financial support for children fails to meet well. But we argued that there are other goals that are met well at 
present, and the integrated child credit should be assessed against these broader objectives too.

To help analyse options for the new integrated child credit, we separated decisions on the credit into those to do with its structure - how the integrated child credit relates to family structure and family income - and those to do with its administration - how entitlement is assessed, the frequency of payments and the period of award.

Ignoring the basic credit of WFTC, weekly financial support for the first child will vary from $€ 15.50$ for the richest families to $€ 45.95$ for the poorest from April 2001. But because the children's tax credit is worth nothing to those who do not pay tax, some families on WFTC will receive $£ 50$ - more than the poorest families. Removing this feature to achieve a seamless system of support for out-of-work and low-paid families means either creating losers in the bottom deciles or spending around £950 million a year. The move to joint assessment in an integrated child credit could also create losers amongst better-off families: an integrated child credit where no family lost through the introduction of full joint assessment could cost a further $€ 650$ million a year. D epending on the exact parameters, the integrated child credit would represent $£ 9-10$ billion a year of financial support to families, and around 6 million families could be entitled to payments.

As the integrated child credit is replacing three very different systems of financial support for children, some administrative parameters will have to change, such as whether the system is cumulative or non-cumulative, the period of assessment for entitlement, the length of award, the frequency of payments and the method of payment. It is therefore unlikely that the government will be able to meet fully the objectives it has set for an integrated child credit without compromising on some of the welcome features of the current system of financial support for children. We presented four possible options for designing an integrated child credit, none of which is perfect - indeed, some of which are far from perfect - but all of which help to expose the trade-offs inherent in designing the integrated child credit. The government will need to decide on which of the many objectives for the integrated child credit it places the most weight, and perhaps accept a system with some rough edges in its design or its effects.

The introduction of the integrated child credit has been seen by some as a significant extension of joint assessment. In fact, it may not represent a substantial change for many parents from the system of financial support for children that will exist in April 2001. Those who will be affected the most are likely to be better-off families. In contrast, the decision to pay the integrated child credit to the main carer - in a couple, usually the mother - may affect the distribution of income between partners in a couple in a large number of families. Evidence suggests that this switch may increase children's well-being too.

There are many issues that we have not discussed in this Commentary, such as how to reform payments for disabled parents or adults with disabled children, what to do with the childcare tax credit and housing benefit and whether to pay the integrated child credit for dependent children over 16. Nor do we pretend to have given full answers. But we hope we have set out a useful framework with which to analyse the integrated child credit and provided information to help promote the debate on its future form. 


\section{Appendix: The dynamics of family circumstances}

There is no perfect data source that can tell us about the dynamics of incomes and family status, particularly about the short-term dynamics (such as changes within the year). D ata on changes in circumstances come from three different types of source:

- Interview-on-interview data from panel survey. For example, the Labour Force Survey (LFS) interviews households in five successive quarters and asks them (amongst other things) about their employment status. The British Household Panel Survey (BHPS) interviews individuals annually and asks them about a range of socioeconomic issues.

- Recalled continuous panel. For example, the BHPS also asks the respondents about their employment status in each of the previous 12 months.

- Recalled spells. For example, the Programme of Research into Low-Income Families (PRILIF) surveys ask respondents for the dates that their family circumstances changed.

Most UK studies of changes in family circumstances use the first type of data from either the BHPS or the LFS. These surveys provide quite full descriptions of people's circumstances at the time of the interview, allowing 'transitions' to be analysed by comparing the information in consecutive interviews. But interview-on-interview panel data can say little about changes in circumstances in the periods between the interviews, and these monthly or weekly changes are just as important for the design of an integrated child credit as annual or quarterly changes.

The integrated child credit will depend upon joint family income and the number of children, so potentially any change in these could affect the value of entitlement. In practice, the most important causes of changes in family income are changes in family status and changes in employment status. This Appendix presents a limited review of recent UK evidence on the extent of changes in or transitions between employment, family state and benefit receipt. It looks at:

- studies of the BHPS (Iacovou and Berthoud (2000) and preliminary results from ongoing work at IFS part-funded by the Inland Revenue), based on up to seven annual observations of around 5,000 households;

- our own and others' (see Gregg, Johnson and Reed (1999)) analysis of the LFS, which interviews around 140,000 individuals in up to five successive quarters;

- results from the Programme of Research into Low-Income Families (PRILIF) study based at the Policy Studies Institute, a long-running study of lone parents in the UK (see Finlayson et al. (2000) for the latest report using these data, and preliminary results from ongoing work at IFS part-funded by the Inland Revenue);

\footnotetext{
55 For example, if a panel survey observes someone in work in one interview and in work in the next, that does not mean that they were continuously employed in between - they may have moved out of work and back into work.
} 
- govemment administrative data on the flows between benefits and tax credits.

Each type of transition is analysed in turn, rather than each data source. Evidence is presented first on the dynamics of employment (Section A.1), then on the dynamics of individuals' claims for means-tested benefits(Section A.2), as changes between in-work and out-of-work benefits should be linked to moves into and out of work. Changes in family status - i.e. between having a partner and being single - are then presented (Section A.3), and these are finally brought together in looking at changes in family income (Section A.4).

O ne obvious but important point that comes out of the analysis is that the longer the time period studied, the more changes there are in family circumstances, so the more likely it is under the present tax and benefit system that a family will have to claim for financial support for children from different transfer mechanisms.

\section{A.1 E mployment transitions}

Tables A.1-A.4 present data from the LFS based on people who began their time in the LFS in spring, summer and autumn of 1998 and who were followed for a year. They show moves into and out of work for adults in couples with children and for lone parents over three and 12 months. There is more change over a 12-month period than over three months: 95 per cent of working lone parents and 98 per cent of working adults in couples with children are in work three months later, while the figures are 91 per cent and 96 per cent respectively after a year. A high proportion of 'inactive' individuals ${ }^{56}$ maintain their status: 89 per cent of inactive parents are inactive three months later and 79 per cent are still inactive after a year (third row of each table). More individuals move from unemployment to employment/ self-employment than move from inactivity: almost 25 per cent of the unemployed adults in couples with children, and 20 per cent of unemployed lone parents, were in work three months later (respectively 46 per cent and 29 per cent after a year).

These row percentages may give a misleading impression of the extent of transitions because, for example, adults in couples with children are much more likely to be working than not. Looking at the aggregate number of transitions, 360,000 adults in couples with children and 90,000 lone parents have a different employment status after three months (respectively 840,000 and 180,000 after 12 months). As highlighted above, this will not capture any movements between the interviews - it is very much a lower bound.

G regg, Johnson and Reed (1999) present a similar analysis by looking at the rate at which out-of-work (both unemployed and inactive) adults moved into work. Their figures suggest that 11 per cent and 7 per cent of out-of-work men and women respectively are in work three months later, rising to 20 per cent and 15 per cent after a year. These are higher than the figures in Tables A.1-A.4 because their figures include adults without children, whom we would expect to show greater labour market mobility.

\footnotetext{
56 'Inactive' is the usual labour-market classification for people who are not in work and not looking for or ready to start work immediately. It may be an unfortunate phrase in this context, as parents who are looking after their children full-time would be classified as 'inactive'.
} 
Table A.1. Q uarterly labour market transitions for adults in couples with children (aged under 55)

\begin{tabular}{l|c|cccc}
\hline \hline Initial labour mark et status & $\begin{array}{c}\text { \% of } \\
\text { population }\end{array}$ & \multicolumn{4}{|c}{ L abour mark et status three months later } \\
& Employed/ & ILO unemployed & Inactive & Total \\
& self-employed & & & \\
\hline Employed/ self-employed & $80.7 \%$ & $98.1 \%$ & $0.7 \%$ & $1.2 \%$ & $100 \%$ \\
ILO unemployed & $3.2 \%$ & $24.2 \%$ & $52.2 \%$ & $23.5 \%$ & $100 \%$ \\
Inactive & $16.1 \%$ & $6.6 \%$ & $4.4 \%$ & $88.9 \%$ & $100 \%$ \\
& $100 \%$ & & & & \\
\hline \hline
\end{tabular}

N ote: Family type measured in first period.

Sourœ: LFS, three waves Spring 1998 to Autumn 1999.

Table A.2. Q uarterly labour market transitions for lone parents (aged under 55)

\begin{tabular}{|c|c|c|c|c|c|}
\hline \multirow[t]{2}{*}{ 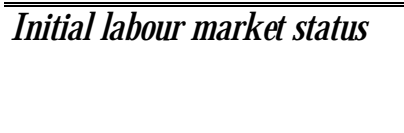 } & \multirow{2}{*}{$\begin{array}{c}\% \text { of } \\
\text { population }\end{array}$} & \multicolumn{4}{|c|}{ L L abour mark et status three months later } \\
\hline & & $\begin{array}{l}\text { Employed/ } \\
\text { self-employed }\end{array}$ & ILO unemployed & Inactive & Total \\
\hline Employed/ self-employed & $49.9 \%$ & $94.9 \%$ & $1.6 \%$ & $3.5 \%$ & $100 \%$ \\
\hline ILO unemployed & $6.7 \%$ & $19.8 \%$ & $48.1 \%$ & $32.1 \%$ & $100 \%$ \\
\hline Inactive & $\begin{array}{l}43.4 \% \\
100 \%\end{array}$ & $3.4 \%$ & $7.9 \%$ & $88.7 \%$ & $100 \%$ \\
\hline
\end{tabular}

N ote: Family type measured in first period.

Sourœ: LFS, three waves Spring 1998 to Autumn 1999.

Table A.3. Annual labour market transitions for adults in couples with children (aged under 55)

\begin{tabular}{l|c|cccc}
\hline \hline Initial labour mark et status & $\begin{array}{c}\text { \% of } \\
\text { population }\end{array}$ & \multicolumn{4}{|c}{ L abour mark et status 12 months later } \\
& & Employed/ & ILO unemployed & Inactive & Total \\
\hline Employed/ self-employed & $80.7 \%$ & $96.2 \%$ & $1.4 \%$ & $2.4 \%$ & $100 \%$ \\
ILO unemployed & $3.2 \%$ & $46.0 \%$ & $30.5 \%$ & $23.5 \%$ & $100 \%$ \\
Inactive & $16.1 \%$ & $16.6 \%$ & $4.6 \%$ & $78.8 \%$ & $100 \%$ \\
& $100 \%$ & & & & \\
\hline \hline
\end{tabular}

N ote: Family type measured in first period.

Souro: LFS, three waves Spring 1998 to Autumn 1999.

Table A.4. Annual labour market transitions for lone parents (aged under 55)

\begin{tabular}{l|c|cccc}
\hline Initial labour mark et status & $\begin{array}{c}\text { \% of } \\
\text { population }\end{array}$ & \multicolumn{4}{|c}{ L abour mark et status 12 months later } \\
& & Employed/ & ILO unemployed & Inactive & Total \\
Employed/ self-employed & $49.9 \%$ & $91.3 \%$ & $3.3 \%$ & $5.4 \%$ & $100 \%$ \\
ILO unemployed & $6.7 \%$ & $28.5 \%$ & $26.9 \%$ & $44.6 \%$ & $100 \%$ \\
Inactive & $43.4 \%$ & $9.8 \%$ & $11.6 \%$ & $78.6 \%$ & $100 \%$ \\
& $100 \%$ & & & & \\
\hline \hline
\end{tabular}

N ote: Family type measured in first period.

Sourœ: LFS, three waves Spring 1998 to Autumn 1999. 
Tables A.5-A.8 focus on lone mothers and report employment transitions for workless lone mothers from two data sources covering periods from 1991 to 1996 or 1997 (PRILIF and BHPS respectively). ${ }^{7}$ The analysis shows the moves into and out of work

Table A.5. E mployment and family credit transitions for women who are lone mothers at consecutive interviews: BHPS

\begin{tabular}{l|rcccc}
\hline \hline $\begin{array}{l}\text { \% of type at initial status in } \\
\text { type after one year }\end{array}$ & \multicolumn{4}{|c}{ E mployment and family credit status after one year } & No work, \\
$\begin{array}{l}\text { Initial employment and family } \\
\text { credit status }\end{array}$ & $\begin{array}{c}\text { No work, } \\
\text { no FC }\end{array}$ & on FC & $\begin{array}{c}\text { Mother } \\
\text { works, } \\
\text { no FC }\end{array}$ & $\begin{array}{c}\text { Mother } \\
\text { works, } \\
\text { on FC }\end{array}$ & Total \\
\hline No work, no FC & $84 \%$ & $0 \%$ & $11 \%$ & $4 \%$ & $100 \%$ \\
No work, on FC & $50 \%$ & $8 \%$ & $25 \%$ & $17 \%$ & $100 \%$ \\
Mother works, no FC & $12 \%$ & $0 \%$ & $79 \%$ & $9 \%$ & $100 \%$ \\
Mother works, on FC & $11 \%$ & $1 \%$ & $18 \%$ & $69 \%$ & $100 \%$ \\
\hline \hline
\end{tabular}

N otes: See footnote 59. There are a few lone mothers on FC and not working, as FC lasts for six months. Sourœ: See footnote 57.

\section{Table A.6. E mployment and family credit transitions for women who are lone} mothers at consecutive interviews: PRILIF

\begin{tabular}{l|ccccc}
\hline \hline $\begin{array}{l}\text { \% of type at initial status in } \\
\text { type after one year }\end{array}$ & \multicolumn{4}{|c}{ E mployment and family credit status after one year } & No work, \\
$\begin{array}{l}\text { Initial employment and family } \\
\text { credit status }\end{array}$ & $\begin{array}{c}\text { No work, } \\
\text { no FC }\end{array}$ & on FC & $\begin{array}{c}\text { Mother } \\
\text { works, } \\
\text { no FC }\end{array}$ & $\begin{array}{c}\text { Mother } \\
\text { works, } \\
\text { on FC }\end{array}$ & Total \\
\hline No work, no FC & $84 \%$ & $1 \%$ & $10 \%$ & $5 \%$ & $100 \%$ \\
No work, on FC & $72 \%$ & $4 \%$ & $12 \%$ & $12 \%$ & $100 \%$ \\
Mother works, no FC & $13 \%$ & $0 \%$ & $72 \%$ & $15 \%$ & $100 \%$ \\
Mother works, on FC & $9 \%$ & $1 \%$ & $15 \%$ & $75 \%$ & $100 \%$ \\
\hline \hline
\end{tabular}

N otes and Source: As Table A.5.

\section{Table A.7. Employment and family credit transitions for lone mothers who partner: BH PS}

\begin{tabular}{|c|c|c|c|c|c|c|c|c|}
\hline \multirow[b]{2}{*}{$\begin{array}{l}\text { \% of type at } \\
\text { initial status in } \\
\text { type after one year } \\
\text { Initial employment } \\
\text { and family credit } \\
\text { status }\end{array}$} & \multicolumn{8}{|c|}{ E mployment and family credit status after one year } \\
\hline & $\begin{array}{c}\text { No } \\
\text { work, } \\
\text { no FC }\end{array}$ & $\begin{array}{c}\text { No } \\
\text { work, } \\
\text { on FC }\end{array}$ & $\begin{array}{c}\text { Mother } \\
\text { only } \\
\text { works, } \\
\text { no FC }\end{array}$ & $\begin{array}{l}\text { Mother } \\
\text { only } \\
\text { works, } \\
\text { on FC }\end{array}$ & $\begin{array}{c}\text { Partner } \\
\text { only } \\
\text { works, } \\
\text { no FC }\end{array}$ & $\begin{array}{l}\text { Partner } \\
\text { only } \\
\text { works, } \\
\text { on FC }\end{array}$ & $\begin{array}{l}\text { Both } \\
\text { work, } \\
\text { no FC }\end{array}$ & $\begin{array}{l}\text { Both } \\
\text { work, } \\
\text { on FC }\end{array}$ \\
\hline No work, no FC & $37 \%$ & $0 \%$ & $3 \%$ & $0 \%$ & $39 \%$ & $3 \%$ & $14 \%$ & $5 \%$ \\
\hline $\begin{array}{l}\text { Mother works, } \\
\text { no FC }\end{array}$ & $6 \%$ & $0 \%$ & $6 \%$ & $2 \%$ & $15 \%$ & $2 \%$ & $67 \%$ & $4 \%$ \\
\hline $\begin{array}{l}\text { Mother works, } \\
\text { on FC }\end{array}$ & $0 \%$ & $0 \%$ & $11 \%$ & $0 \%$ & $11 \%$ & $0 \%$ & $67 \%$ & $11 \%$ \\
\hline
\end{tabular}

$\mathrm{N}$ otes and Source: As Table A.5.

57 These figures are from ongoing work by researchers at IFS investigating the dynamics of employment and family status for lone parents on family credit during the 1990s. See http:// www.ifs.org.uk/ staff/ gillian p.shtml for more details. 
Table A.8. Employment and family credit transitions for lone mothers who partner: PRILIF

\begin{tabular}{|c|c|c|c|c|c|c|c|c|}
\hline \multirow[b]{2}{*}{$\begin{array}{l}\% \text { of type at } \\
\text { initial status in } \\
\text { type after one year } \\
\text { Initial employment } \\
\text { and family credit } \\
\text { status }\end{array}$} & \multicolumn{8}{|c|}{ E mployment and family credit status after one year } \\
\hline & $\begin{array}{c}\text { No } \\
\text { work, } \\
\text { no FC }\end{array}$ & $\begin{array}{c}\text { No } \\
\text { work, } \\
\text { on FC }\end{array}$ & $\begin{array}{c}\text { Mother } \\
\text { only } \\
\text { works, } \\
\text { no FC }\end{array}$ & $\begin{array}{l}\text { Mother } \\
\text { only } \\
\text { works, } \\
\text { on FC }\end{array}$ & $\begin{array}{c}\text { Partner } \\
\text { only } \\
\text { works, } \\
\text { no FC }\end{array}$ & $\begin{array}{c}\text { Partner } \\
\text { only } \\
\text { works, } \\
\text { on FC }\end{array}$ & $\begin{array}{l}\text { Both } \\
\text { work, } \\
\text { no FC }\end{array}$ & $\begin{array}{l}\text { Both } \\
\text { work, } \\
\text { on FC }\end{array}$ \\
\hline No work, no FC & $32 \%$ & $2 \%$ & $8 \%$ & $3 \%$ & $24 \%$ & $15 \%$ & $12 \%$ & $5 \%$ \\
\hline $\begin{array}{l}\text { Mother works, } \\
\text { no FC }\end{array}$ & $2 \%$ & $0 \%$ & $7 \%$ & $5 \%$ & $2 \%$ & $2 \%$ & $79 \%$ & $2 \%$ \\
\hline $\begin{array}{l}\text { Mother works, } \\
\text { on FC }\end{array}$ & $2 \%$ & $7 \%$ & $9 \%$ & $9 \%$ & $7 \%$ & $7 \%$ & $49 \%$ & $9 \%$ \\
\hline
\end{tabular}

N otes and Source: As Table A.5.

(and receipt of family credit) for two groups of women: those who were lone mothers at two consecutive interviews and those who were lone mothers at one interview but had a partner (and a child or children) at the following interview 58

The results for lone mothers who stay lone mothers are similar to those in Table A.4: 84 per cent of lone mothers in the BHPS without work and not on family credit (85 per cent in PRILIF) do not have work a year later, and a similar proportion of lone mothers with work are working a year later (88 per cent in the BHPS and 87-90 per cent in

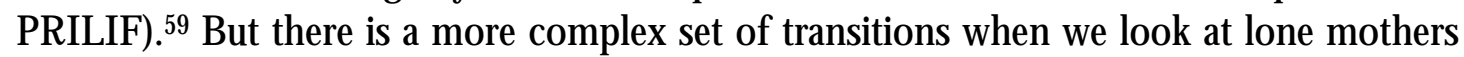
who partner over the course of a year. The general picture is that working lone mothers who partner are more likely to partner a man who works, and are more likely to be in work themselves after partnering, than lone mothers who are not working and then partner. For example, around a third (37 per cent in the BHPS, 34 per cent in PRILIF) of workless lone mothers who partner remain in a workless family (neither they nor their partner are working); a smaller proportion (22 per cent in the BHPS, 28 per cent in PRILIF) start working (the remaining lone mothers are out of work after partnering but have a working partner). But if the lone mother was previously in work before she partnered, she is very likely to continue to work after she partners (less than a quarter stop work, in both surveys) and her partner is very likely to work (around 10-15 per cent are not working in the BHPS, and under 30 per cent in PRILIF).

\section{A.2 Benefit transitions}

Administrative data collected by the Benefits Agency can give a more accurate picture of moves between benefits, as they are able to track claims made by people with the same National Insurance number.

\footnotetext{
${ }^{58}$ Around 84 per cent of lone mothers in these datasets are lone parents in the next interview; 13 per cent in BHPS and 9 per cent in PRILIF have a partner (and a child or children) at the next interview.

59 The intervals between interviews are actually around 14 months in PRILIF and 12 months in the BHPS.
} 
Table A.9. D uration of all family credit awards that started May-N ovember 1997

\begin{tabular}{l|ccc}
\hline \hline Length of award & Number of awards & Cumulative total & Cumulative total (\%) \\
\hline Six months & 119,000 & 119,000 & $44 \%$ \\
12 months & 37,000 & 156,000 & $58 \%$ \\
18 months & 39,000 & 195,000 & $73 \%$ \\
24 months or more & 73,000 & 268,000 & $100 \%$ \\
\hline \hline
\end{tabular}

Souro: Authors' calculations from Department of Social Security Family Credit Q uarterly Statistical E nquiry (various years).

For example, Table A.9 shows the distribution of the length of awards of family credit. It shows that 44 per cent of all new awards lasted for only six months, and only 27 per cent were longer than 18 months.

\section{Figure A.1. Annual transitions onto and off family credit, August 1998 to August 1999}

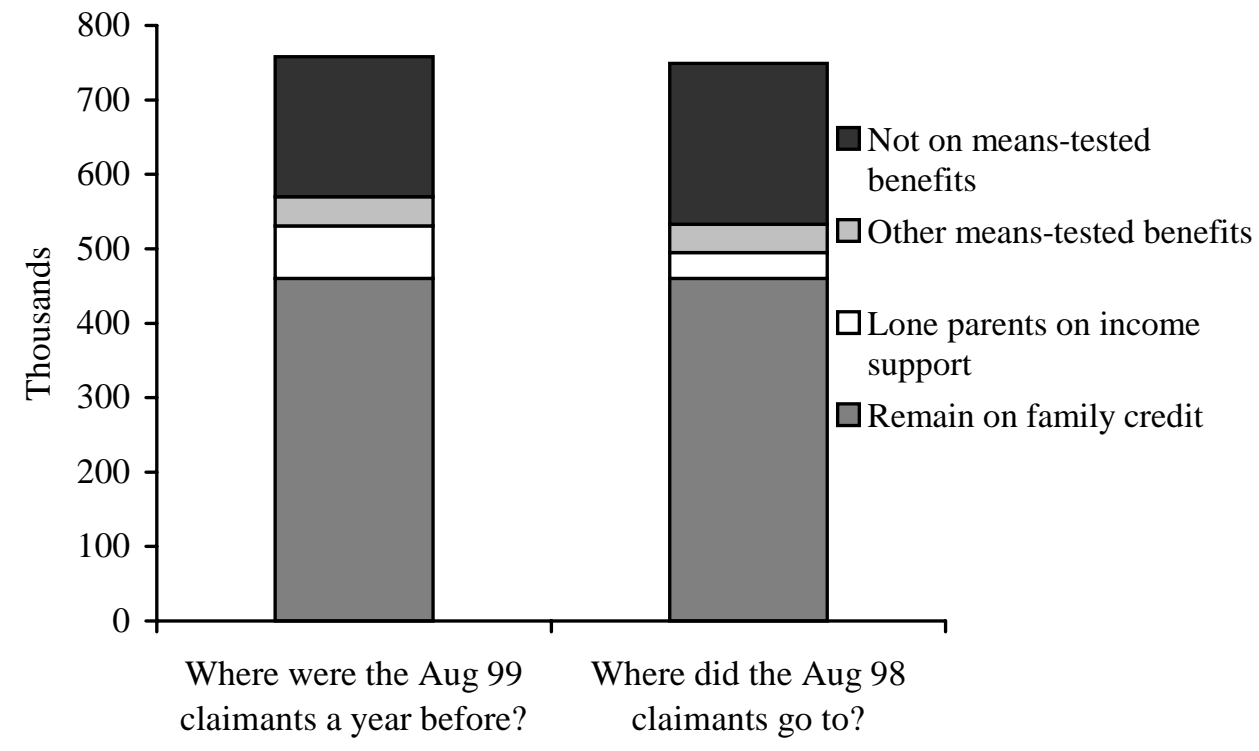

$\mathrm{N}$ otes: The dataset tracks benefit claimants, not families, so a lone mother initially on family credit who stops working and partners with someone claiming an out-of-work benefit would appear in the 'Not on means-tested benefits' category if her partner claims the out-of-work benefit for the couple.

Sourœ: D epartment of Social Security Client G roup A nalysis: W orking A ge, August 1999.

But this does not tell us where families that claimed family credit go to or come from. Figure A.1 takes people claiming family credit in August 1998 or August 1999 and looks at whether they were claiming any other means-tested benefit 12 months after or before respectively. As family credit is available only to low-income working families and the other means-tested benefits only to out-of-work families, this gives another glimpse of

60 D SS administrative data count a continuous award as any award where the family reclaims less than four weeks after the previous award has run out. We have chosen a period where the total family credit caseload was reasonably constant and have not looked at how the introduction of WFTC claims affects the likelihood of staying on in-work benefits.

61 We have again chosen a period that is not affected by the introduction of WFTC. 
moves into and out of work. It also gives an impression of how many parents, under the current system of financial support for children, have to reapply for financial support for their children from a different source because their circumstances have changed.

The total caseload of family credit did not change much over these 12 months (around 750,000), and 460,000 of those claiming family credit in August 1998 were also claiming it a year later (the 'Remain on family credit' portion of the two columns in Figure A.1). This means that around 300,000 families were claiming family credit in August 1999 but not claiming it in August 1998 (i.e. their award started between August 1998 and August 1999) and another 300,000 were claiming family credit in August 1998 but not in August 1999 (i.e. their award stopped between August 1998 and August 1999). Of these 600,000 families whose award started or stopped between August 1998 and August 1999, at least 190,000 moved between family credit and an out-of-work means-tested benefit (or vice versa).

But this is certainly an underestimate of the total number of families with children who move between in-work and out-of-work benefits in a 12-month period, for two reasons:

- some people in the 'Not on means-tested benefits' category may be partners of someone claiming an out-of-work benefit;

- the dataset used in Figure A.1 will not record people who had one six-month family credit spell that started after August 1998 but finished before August 1999.

However, continuous administrative data on family credit awards suggest that nearly 500,000 families started a family credit spell between August 1998 and August 1999 rather than the 300,000 suggested by looking at annual snapshots as in Figure A.1 - and around 45 per cent of these spells lasted only six months. As the total caseload of family credit did not change significantly over the 12 months, this means that 500,000 families' awards must also have stopped over the same period - rather than the 300,000 suggested in Figure A.1 - and that around 85,000 families were on family credit in August 1998 and in August 1999 but not on family credit continuously in between. ${ }^{5}$ All these data indicate that a considerable number of parents have to reapply for financial support for children from a different part of the tax and benefit system within a 12month period because they have crossed the welfare-to-work divide.

Table A.10 gives supporting evidence on the transitions between family credit and income support from the LFS. It shows that around a third of lone parents claiming

\footnotetext{
62 The 45 per cent figure is based upon those who started a family credit spell between August 1998 and February 1999 (D epartment of Social Security F amily C redit Q uarterly Statistical E nquiry, February 1999 and August 1999).

63 D erivation: The annual snapshot of family credit claimants in Figure A.1 suggests 300,000 families were on family credit in August 1999 but not in August 1998. But there were 250,000 new claims in the six months before August 1999, and 137,000 families who started a claim in the six months before February 1999 were still on family credit in August 1999 (137,000 is 55 per cent of the 250,000 who started) - D epartment of Social Security F amily C redit Q uarterly Statistical E nquiry. Together, this makes 387,000 families who were on family credit in August 1999 whose claim started after August 1998, compared with the 300,000 families in Figure A.1 who were on family credit in August 1999 but not in August 1998. This suggests that the difference - around 87,000 families - must have been on family credit in August 1998 and August 1999 but not on family credit continuously in between.
} 
family credit at one point in time do not claim it continuously for the next 12 months. 64 Of those who do not claim it continuously, around a third (or 12 per cent of the original sample) moved from family credit onto income support within 12 months. A third of these (or 4 per cent of the original sample) had a spell on family credit, a spell on income support and another spell on family credit within the 12-month period. Family credit claimants in couples are less likely than lone parents to cycle between these benefits: only 54 per cent of couples who started the panel on family credit claimed it throughout the year, and only 9 per cent of those who left family credit went onto income support. Adults in couples seem less likely to remain on family credit for a further 12 months, but those who do leave family credit are less likely to go onto income support. There is some concern that the LFS under-records benefit receipt. This will affect analysis of changes in benefit receipt if people are more likely to admit to receipt of some benefits than others. But the broad result - that a considerable proportion of lone parents who leave family credit go onto income support - is also found by Bryson and Marsh (1996). They conduct a very detailed study of why people leave family credit and what they go on to do, but our interest is in looking at what proportion of the whole population experience these transitions, so we do not discuss the study further here.

Table A.10. Benefit transitions for family credit recipients

\begin{tabular}{l|cc}
\hline \hline Sample: all those receiving family credit at start of panel & Lone parents & $\begin{array}{c}\text { Couples with } \\
\text { children }\end{array}$ \\
\hline $\begin{array}{l}\text { of whom: proportion who do not receive family credit } \\
\text { throughout the year }\end{array}$ & $35 \%$ & $46 \%$ \\
$\begin{array}{l}\text { of whom: proportion who have at least one spell of income } \\
\text { support throughout the year }\end{array}$ & $36 \%$ & $9 \%$ \\
of whom: proportion who went back to family credit & $35 \%$ & $19 \%$ \\
Above as a proportion of all family credit claimants & $4.4 \%$ & $0.7 \%$ \\
\hline \hline
\end{tabular}

N ote: Family type measured at start of panel.

Sourœ: LFS, individuals starting in Spring 1998 to Autumn 1998.

We can turn these percentages into estimates of aggregate numbers by noting that there were around 350,000 lone parents and a similar number of couples on family credit in 1998-99. This suggests that around 44,000 lone parents claiming family credit at any one time go on to claim income support within 12 months, and 15,000 would have two spells on family credit and one spell on income support within 12 months. O nly 14,000 current couple family credit recipients will claim income support within the next 12 months. These figures are somewhat lower than the estimates from administrative data, but this is probably due to the under-recording of benefit receipt in the LFS.

Another impression of the considerable dynamics of benefit change is given by a study that used the benefits database of a metropolitan authority in north-west England (see Noble, Smith and Cheung (1998a and 1998b)). This dataset was able to track all claims

${ }^{64} \mathrm{At}$ a first glance, this seems to be a higher proportion of claims lasting for a year than suggested by Table A.9. That is because our analysis of family credit claimants in the LFS is a stock sample, and the average duration estimated from a stock of family credit claimants will always be higher than the average duration of a cohort of new family credit claimants. This is because a sample of the stock will over-sample people with longer claim durations (see Lancaster (1990)). 
for housing benefit and council tax benefit in the local authority over a four-year period (July 1993 to July 1997) and, by linking that with DSS administrative data on Family Credit, it was possible to get a complete picture of the dynamics of receipt of the main means-tested benefits (i.e. family credit, income support and housing benefit). Their study showed a remarkable degree of fluidity in the benefit status of families on meanstested benefits. On average over the period, between 80 and 90 per cent of lone mothers on income support were on income support half a year later.5.5.5 After four years, 43 per cent of the original stock of lone mothers on income support were still lone mothers claiming Income Support, but only half of these (i.e. 22 per cent of the original stock) had been lone mothers on income support at each sweep of the data.6.

Lone mothers on family credit showed even less permanence in their benefit status: only 30 per cent of the original sample of lone mothers on family credit were claiming family credit four years later, 16 per cent were claiming income support and 54 per cent were not on income support or family credit (and so had either moved into higher-paid jobs, or partnered and moved into a higher-income family).

\section{A.3 Family-type transitions}

Tables A.11 and A.12 show relationship transitions for adults in different family types between Spring 1998 and Spring 1999, taken from the LFS. The proportion of those changing status is highest among lone parents:67 88 per cent of lone parents in Spring 1998 were lone parents a year later, 7 per cent were living with a partner and 4 per cent were single adults with no dependent children (Table A.11, third row). ' $\mathrm{New}^{\prime}$ lone parents are over four times as likely to have come from a relationship than to have been single without children (Table A.12, fourth column of data).

Tables A.13 and A.14 look at the family-type dynamics of women. Table A.13 is similar to Table A.11 but is taken from the BHPS and shows the family-type changes for women only. Table A.14 is taken from a dataset that followed 900 lone mothers over a four-year period (the PRILIF cohort study). These two datasets reveal slightly more variability in family circumstances than the LFS - for example, 83 per cent of lone parents in the BHPS and 84 per cent in the PRILIF dataset were lone mothers a year later, rather than the 88 per cent suggested by the LFS. This difference may not be significant but could be due to the superior sampling strategy of the BHPS over the LFS. 68

\footnotetext{
65 The study observed claimants in July and February, giving intervals of five and seven months.

${ }^{66}$ Some lone mothers had partnered or seen their children grow up. Including these categories as well suggests that 58 per cent of the original sample of lone mothers on income support were still on income support four years later, 14 per cent were in work and claiming family credit, and 28 per cent were not claiming any means-tested benefits at all.

${ }^{67}$ Although we have not checked whether adults remaining in couples are in the same couple as they were a year ago.

${ }^{68}$ The LFS samples households, so individuals who change addresses are not tracked in subsequent waves, whereas the BHPS and PRILIF attempt to follow individuals as they move about. It is likely that those people who change family type are more likely to change address than those who do not.
} 
Table A.11. Family-type transitions (row percentages)

\begin{tabular}{l|cccccc}
\hline \hline Family type in Spring 1998 & Single & $\begin{array}{c}\text { Couple } \\
\text { without } \\
\text { children }\end{array}$ & $\begin{array}{c}\text { Family type in Spring 1999 } \\
\text { Couple with Lone parent } \\
\text { children }\end{array}$ & $\begin{array}{c}\text { Same-sex } \\
\text { couple }\end{array}$ & Total \\
\hline Single & $98.4 \%$ & $1.1 \%$ & $0.2 \%$ & $0.3 \%$ & $0.0 \%$ & $100 \%$ \\
Couple without children & $2.1 \%$ & $95.7 \%$ & $2.3 \%$ & $0.0 \%$ & $0.0 \%$ & $100 \%$ \\
Couple with children & $0.3 \%$ & $3.9 \%$ & $94.7 \%$ & $1.1 \%$ & $0.0 \%$ & $100 \%$ \\
Lone parent & $4.4 \%$ & $0.7 \%$ & $6.6 \%$ & $87.9 \%$ & $0.3 \%$ & $100 \%$ \\
Same-sex couple & $0.0 \%$ & $0.0 \%$ & $0.0 \%$ & $3.2 \%$ & $96.8 \%$ & $100 \%$ \\
\hline \hline
\end{tabular}

Source: LFS, Spring 1998 to Spring 1999.

Table A.12. Family-type transitions (column percentages)

\begin{tabular}{l|ccccc}
\hline Family type in Spring 1998 & Single & \multicolumn{4}{|c}{ Family type in Spring 1999 } \\
& Couple & $\begin{array}{c}\text { Couple with } \\
\text { without } \\
\text { children }\end{array}$ & Lone parent & Same-sex \\
children & & & couple \\
Single & $96.0 \%$ & $0.7 \%$ & $0.2 \%$ & $1.8 \%$ & $0.0 \%$ \\
Couple without children & $3.1 \%$ & $96.5 \%$ & $3.4 \%$ & $0.0 \%$ & $0.0 \%$ \\
Couple with children & $0.3 \%$ & $2.7 \%$ & $95.5 \%$ & $8.1 \%$ & $0.0 \%$ \\
Lone parent & $0.6 \%$ & $0.1 \%$ & $0.9 \%$ & $89.9 \%$ & $6.3 \%$ \\
Same-sex couple & $0.0 \%$ & $0.0 \%$ & $0.0 \%$ & $0.2 \%$ & $93.8 \%$ \\
Total & $100 \%$ & $100 \%$ & $100 \%$ & $100 \%$ & $100 \%$ \\
\hline \hline
\end{tabular}

Source: LFS, Spring 1998 to Spring 1999.

Table A.13. Family transitions for women: BH PS

\begin{tabular}{l|ccccc}
\hline \% of type at time t in & \multicolumn{5}{|c}{ Family type at time t+1 } \\
$\begin{array}{l}\text { type at time t+1 } \\
\text { (row percentages) }\end{array}$ & $\begin{array}{l}\text { No partner, } \\
\text { no children }\end{array}$ & $\begin{array}{c}\text { No partner, } \\
\text { children }\end{array}$ & $\begin{array}{c}\text { Partner, } \\
\text { no children }\end{array}$ & $\begin{array}{c}\text { Partner, } \\
\text { children }\end{array}$ & Total \\
Family type at time t & & & & & \\
\hline No partner, no children & $90.2 \%$ & $1.0 \%$ & $8.3 \%$ & $0.5 \%$ & $100 \%$ \\
No partner, children & $3.8 \%$ & $83.0 \%$ & $0.5 \%$ & $12.8 \%$ & $100 \%$ \\
Partner, no children & $2.7 \%$ & $0.1 \%$ & $91.9 \%$ & $5.3 \%$ & $100 \%$ \\
Partner, children & $0.1 \%$ & $3.2 \%$ & $4.8 \%$ & $91.9 \%$ & $100 \%$ \\
\hline \hline
\end{tabular}

Sourœ: See footnote 57.

Table A.14. Family transitions for women: PRILIF

\begin{tabular}{l|ccccc}
\hline \hline $\begin{array}{l}\text { \% of type at time t in } \\
\text { type at time t+1 }\end{array}$ & No partner, & $\begin{array}{c}\text { Fo partner, } \\
\text { (row percentages) }\end{array}$ & $\begin{array}{c}\text { Partner, } \\
\text { no children }\end{array}$ & $\begin{array}{c}\text { Partner, } \\
\text { children }\end{array}$ & no children \\
children & Total \\
Family type at time t & & & & & \\
\hline No partner, no children & $82.8 \%$ & $11.2 \%$ & $6.0 \%$ & $0 \%$ & $100 \%$ \\
No partner, children & $6.4 \%$ & $84.3 \%$ & $0.6 \%$ & $8.7 \%$ & $100 \%$ \\
Partner, no children & $15.4 \%$ & $0 \%$ & $84.6 \%$ & $0 \%$ & $100 \%$ \\
Partner, children & $0 \%$ & $12.0 \%$ & $3.2 \%$ & $84.8 \%$ & $100 \%$ \\
\hline \hline
\end{tabular}

Souro: See footnote 57. 


\section{A.4 Changes in family income}

So far, we have looked separately at changes in employment status, benefit status and family-type status, as they are the main components of changes in total family income the variable of interest for the integrated child credit. Few studies have attempted to investigate changes in joint family income, partly because of the complex range of transitions and changes that are possible. One study, though, (Iacovou and Berthoud, 2000) looked at the changing circumstances of low-income families with children in the BHPS. In one part of their study, they place the adults in the survey into one of 12 categories depending on:

- whether they have children;

- whether they have a partner;

- whether they are out of work, are in work but still have a low income, or are in work and do not have a low income ('higher-income').

They then present a transition matrix which shows the probabilities of moving from one category to any other over a 12-month period (reproduced in Table A.15). This matrix captures the main economic and demographic variables that might affect entitlement to an integrated child credit or an employment tax credit (and summarises all of the changes that we have looked at so far in this Appendix). The sample sizes used in the study are small, and the results should not be treated as being precise and accurate estimates. But the study shows that there is substantial stability in some of the categories. For example, 86 per cent of higher-income couples with children were higher-income couples with children a year later. (This group broadly corresponds to parents most likely to be in receipt only of the children's tax credit under the current system of financial support for children.) There is also considerable stability at the other end of the income distribution: 80 per cent of workless lone parents are still workless lone parents a year later.

But it seems that there is considerable mobility amongst other categories of parents and, in particular, between categories that might correspond to being on the taper of an integrated child credit. For example, the study shows that, on average, about a sixth of adults who remain parents change their income or work status in each year. But 47 per cent of low-income couples with children are no longer low-income couples with children a year later, a much less stable category than the others. Much of the movement is at the low end of the income scale, indicative of a low-pay, no-pay cycle: the study finds that workless or low-income working parents who change their status are much more likely to change to the other low-income state than to become a higher-income working family.

\footnotetext{
${ }^{69}$ The 'low-income' category corresponds approximately to a level of income where a family would be eligible for WFTC.

70 The existence of a low-pay, no-pay cycle is investigated by Dickens (1999) and Stewart (1999), but these studies are not limited to families with children.
} 
Table A.15. Changes in family circumstances for families with children overa 12-month period

\begin{tabular}{|c|c|c|c|c|c|c|c|c|c|c|c|c|}
\hline \multirow{3}{*}{$\begin{array}{l}\text { (\% making transitions) } \\
\text { Incomegroup and family type } \\
\text { in first year }\end{array}$} & \multicolumn{12}{|c|}{ Inromegroupand family typein second year } \\
\hline & \multicolumn{4}{|c|}{ Non-norkingfamilies } & \multicolumn{4}{|c|}{ Lowincomenorkingfamilies } & \multicolumn{4}{|c|}{ Higher-incomefamilies } \\
\hline & $\begin{array}{l}\text { Couple, } \\
\text { no kids }\end{array}$ & $\begin{array}{c}\text { Couple, } \\
\text { kids }\end{array}$ & $\begin{array}{c}\text { Single, } \\
\text { kids }\end{array}$ & $\begin{array}{c}\text { Single, } \\
\text { no kids }\end{array}$ & $\begin{array}{l}\text { Couple, } \\
\text { no kids }\end{array}$ & $\begin{array}{c}\text { Couple, } \\
\text { kids }\end{array}$ & $\begin{array}{c}\text { Single, } \\
\text { kids }\end{array}$ & $\begin{array}{c}\text { Single, } \\
\text { no kids }\end{array}$ & $\begin{array}{l}\text { Couple, } \\
\text { no kids }\end{array}$ & $\begin{array}{c}\text { Couple, } \\
\text { kids }\end{array}$ & $\begin{array}{c}\text { Single, } \\
\text { kids }\end{array}$ & $\begin{array}{c}\text { Single, } \\
\text { no kids }\end{array}$ \\
\hline Non-workingfamilies & & & & & & & & & & & & \\
\hline Couple, no kids & 87 & 2 & & 2 & 2 & & & & 7 & & & 1 \\
\hline Couple, kids & 3 & 67 & 3 & 1 & & 16 & & & 1 & 9 & & \\
\hline Single, kids (lone parent) & & 3 & 80 & 3 & & 2 & 7 & & & 3 & 2 & \\
\hline Single, no kids & 1 & & 1 & 74 & 1 & & & 16 & 2 & & & 4 \\
\hline Lovincomeworkingfamilies & & & & & & & & & & & & \\
\hline Couple, no kids & 11 & 3 & & 1 & 36 & 1 & & 2 & 45 & 1 & & 1 \\
\hline Couple, kids & & 8 & 2 & & 1 & 53 & 1 & 1 & 2 & 32 & & \\
\hline Single, kids (lone parent) & & & 15 & 1 & & 1 & 63 & 5 & 1 & 5 & 7 & 2 \\
\hline Single, no kids & & & 1 & 10 & 1 & & & 69 & 7 & & & 12 \\
\hline Higher-incomefamilies & & & & & & & & & & & & \\
\hline Couple, no kids & 4 & & & & 3 & & & 1 & 86 & 5 & & 1 \\
\hline Couple, kids & & 1 & 1 & & & 6 & & & 5 & 86 & & 1 \\
\hline Single, kids (lone parent) & & & 5 & 1 & & & 10 & & & 8 & 63 & 14 \\
\hline Single, no kids & & & & 4 & & & & 10 & 8 & 1 & & 77 \\
\hline Total & 6 & 4 & 3 & 9 & 2 & 5 & 1 & 9 & 28 & 25 & 1 & 8 \\
\hline
\end{tabular}

Nctes Values of less than 0.5 per cent have been shown as blank. Cell sizes are given in Iacovou and Berthoud (2000).

Sarre From Iacovou and Berthoud (2000, Appendix B). 
Relationship changes may be as great a cause of changes in economic circumstances as changes in employment and earnings: the study shows that nearly half of workless lone parents were in a relationship with children immediately before becoming a workless lone parent (as opposed to being a working lone parent who stopped work, for example), and about five times as many lone parents become lone parents because a relationship ended rather than because they were previously single and had a child.

The study also confirms that the longer the time period, the more mobility: of the sample of adults who were parents for all seven years of the survey, only 47 per cent remained in a higher-income family, never experiencing either low incomes or worklessness - the two statuses likely to lead to a full integrated child credit award. 


\section{References}

Banks, J. and Johnson, P. (1993), Children and H ousehold L iving Standards, London: Institute for Fiscal Studies.

- and - (1994), 'Equivalence scale relativities revisited', E conomic Journal, vol. 104, pp. 883-90.

Battle, K. and Mendelson, M. (2001), Benefits for Children: A Four Country Study, O ttawa: Caledon Institute / York, UK: Joseph Rowntree Foundation.

Blundell, R., Duncan, A., McCrae, J. and Meghir, C. (2000), "The labour market impact of the working families' tax credit', Fiscal Studies, vol. 21, pp. 75-103.

- and Reed, H. (2000), The E mployment E ffects of the W orking Families' Tax C redit, Institute for Fiscal Studies, Briefing Note no. 6, http:// www.ifs.org.uk/ labmarket/ wftc bn.pdf.

Bradshaw, J. and Barnes, H. (forthcoming), Poverty: The Outoomes for Children, London: Family Policy Studies Centre.

- and Stimson, C. (1997), U sing Child Benefit in the Family Budget, London: Stationery Office.

Bryson, A. and Marsh, A. (1996), L eaving Family C redit, London: HMSO.

Chennells, L., Dilnot, A. and Emmerson, C. (2000), The IFS G reen Budget: January 2000, Commentary no. 80, London: Institute for Fiscal Studies.

Coulter, F., Cowell, F. and Jenkins, S. (1992), 'Equivalence scale relativities and the extent of inequality and poverty', E conomic Journal, vol. 102, pp. 1067-82.

Department of Social Security (1998), Households Below A verage Income, 1979-1996/7, London: Government Statistical Service.

- (2000a), Households Below A verage Inome, 1994/5-1998/9, London: Government Statistical Service.

- (2000b), O pportunity for A ll - One Y ear 0 n: Making A D ifference, London: Stationery Office.

- (2000c), InomeR elated Benefits E stimates of TakeUp in 1998/ 99, G overnment Statistical Service, http:// www.dss.gov.uk/ asd/ Pub9899v2Elec.pdf.

- (2000d), Social Searity D epartmental Report: The G overnment's E x penditure Plans 2000/ 01 2001/ 02, Cm. 4614, London: Stationery O ffice.

- (various years), Client G roup A nalysis: W orking A ge, London: Government Statistical Service.

- (various years), Child Benefit Quarterly Statistical Enquiry, London: Government Statistical Service. 
- (various years), Family Credit Quarterly Statistical Enquiry, London: Government Statistical Service.

- (various years), Income Support Quarterly Statistical Enquiry, London: Government Statistical Service.

- (various years), Jobseek er's A llowanœ Q uarterly Statistical E nquiry, London: Government Statistical Service.

Dickens, R. (1999), 'Wage mobility in G reat Britain', in P. G regg and J. Wadsworth (eds), The State of W ork ing Britain, Manchester: Manchester University Press.

- and Ellwood, D . (2000), 'Whither poverty in Great Britain and the United States? The determinants of changing poverty and whether work will work', prepared for 'Seeking a Premier League Economy' Conference, London School of Economics, D ecember 2000, http:// www.nber.org/ books/ bcf/ index.html.

Dilnot, A., Emmerson, C. and Simpson, H. (forthcoming), The IF S G ren Budget: January 2001, London: Institute for Fiscal Studies.

Dilnot, A., Kay, J. and Morris, C. (1984), The R eform of Social Seaurity, London: Institute for Fiscal Studies.

Ditch, J., Barnes, H., Bradshaw, J. and Kilkey, M. (1998), A Synthesis of N ational Family Policies 1996, European Commission.

Finlayson, L., Ford, R., Marsh, A., McKay, S. and Mukherjee, A. (2000), The British L one Parent C ohort, 1991 to 1998, D SS Research Report no. 128, London: Corporate D ocument Services.

George, C., Allirajah, D ., D onnelly, C., Fitzpatrick, P., Frobisher, F., Hynes, B., Mitchell, S., Robinson, S., Simmons, D., Stagg, P., Tait, G., Thurley, D. and Turville, P. (2000), W elfare Benefits H andbook 2000/ 2001, London: Child Poverty Action Group.

Gordon, D., Adelman, L., Ashworth, K., Bradshaw, J., Levitas, R., Middleton, S., Pantazis, C., Patsios, D., Payne, S., Townsend, P. and Williams, J. (2000), Poverty and Social E x dusion in Britain, Y ork: Joseph Rowntree Foundation.

Gregg, P., Harkness, S. and Machin, S. (1999), 'Poor kids: trends in child poverty in Britain, 1968-96', Fiscal Studies, vol. 20, pp. 163-87.

- , Johnson, P. and Reed, H. (1999), Entering W ork and the British Tax and Benefit System, London: Institute for Fiscal Studies.

- and Machin, S. (2000a), 'Childhood disadvantage and success in the young adult labour market', in D. Blanchflower and R. Freeman (eds), Y outh E mployment and Joblessness in A dvanoed Countries, Chicago: University of Chicago Press.

- and - (2000b), 'Childhood experiences: educational attainment and adult labour market performance', in K. Vleminckx and T. Smeeding (eds), Child W ell-Being, Child Poverty and Child Policy in M odern N ations: W hat D o W e Know?, Bristol: Policy Press. 
Hill, M. and Jenkins, S. (1999), 'Poverty amongst British children: chronic or transitory?', University of Essex, Institute for Economic and Social Research, Working Paper no. 9923.

Hills, J. (ed.) (1999), Persistent Poverty and L ifetime Inequality: The E vidence, CASE Report no. 5, London: Centre for Analysis of Social Exclusion, London School of Economics.

Hirsch, D . (2000), A C redit to C hildren, York: Joseph Rowntree Foundation.

HM Treasury (1998), W ork Incentives: A Report by Martin Taylor, The Modernisation of Britain's Tax and Benefit System, no. 2.

- (1999), Supporting Children through the Tax and Benefit System, The Modernisation of Britain's Tax and Benefit System, no. 5.

- (2000a), Prudent with a Purpose: W orking for a Stronger and Fairer Britain, HC346, London: Stationery Office.

- (2000b), Tadkling Poverty and Making W ork Pay: Tax Credits for the $21^{\text {st }}$ Century, The Modernisation of Britain's Tax and Benefit System, no. 6.

- (2000c), H elping People to Save, The Modernisation of Britain's Tax and Benefit System, no. 7.

- (2000d), Building L ong-T erm Prosperity for A ll, Cm. 4917, London: Stationery Office.

Hobcraft, J. (1999), 'Intergenerational and life-course transmission of social exclusion: influences of childhood poverty, family disruption and contact with the police', London School of Economics, Centre for Analysis of Social Exclusion, CASE Paper no. 15.

House of Commons Social Security Select Committee (forthcoming), The Integrated Child Credit, London: Stationery O ffice.

Iacovou, M. and Berthoud, R. (2000), Parents and E mployment, Department of Social Security Research Report no. 107.

Inland Revenue (various years), W orking Families' Tax Credit Q uarterly Statistical E nquiry, London: Government Statistical Service.

Lancaster, T. (1990), The E conometric A nalysis of Transition D ata, Cambridge: Cambridge University Press.

Lundberg, S., Pollak, R. and Wales, T. (1995), D o H usbands and W ives Pool Their Resouroes? $\mathrm{E}$ vidence from the $\mathrm{U} \mathrm{K}$ Child Benefit, University of Washington, mimeo.

McClements, L. (1977), 'Equivalence scales for children', Journal of Public E conomics, vol. 8, no. 2 .

- (1979), 'Muellbauer on equivalence scales', Journal of Public E conomics, vol. 12, no. 2.

Middleton, S., Ashworth, K. and Braithwaite, I. (1997), Small Fortunes: Spending on Children, Childhood Poverty and Parental Sacrifice, York: Joseph Rowntree Foundation. 
MISSO C (1999), Social Protection in the Member States of the E U, Luxembourg: Office for Official Publications of the EC.

Muellbauer, J. (1979a), 'McClements on equivalence scales for children', Journal of Public E conomics, vol. 12, no. 2.

- (1979b), 'Reply to McClements', Journal of Public E conomics, vol. 12, no. 2.

Myck, M. (2000), Fiscal Reforms Since May 1997, Institute for Fiscal Studies, Briefing Note no. 14, http:// www.ifs.org.uk/ taxben/ fiscalreform.pdf.

Noble, M., Smith, G. and Cheung, Sin Yi (1998a), 'Origins and destinations: social security claimant dynamics', Journal of Social Policy, vol. 27, pp. 351-70.

— , - and - (1998b), L one M others M oving In and O ut of Benefits, York: Joseph Rowntree Foundation.

Pahl, J. (1989), M oney and Marriage, London: Macmillan.

Parker, H. (ed.) (1999), L ow Cost but A coeptable - A M inimum Income Standard for the U K: Families with Y oung C hildren, Bristol: Policy Press.

Paull, G., Walker, I. and Zhu, Y. (2000), 'Child support reform: some analysis of the 1999 White Paper', Fiscal Studies, vol. 21, pp. 105-40.

Piachaud, D. and Sutherland, H. (2000), 'How effective is the British government's attempt to reduce child poverty?', London School of Economics, Centre for Analysis of Social Exclusion, CASE Paper no. 38.

Rake, K. (ed.) (2000), W omen's Incomes over the Lifetime: Explaining the Female Forfeit, London: Women's Unit.

Rathbone, E. (1940), The Case for Family A llowanœs, Middlesex:: Penguin.

Stewart, M. (1999), 'Low pay in Britain', in P. Gregg and J. Wadsworth (eds), The State of W ork ing Britain, Manchester: Manchester University Press.

Tolley's (2000), Inome Tax 2000/ 01, London: Tolley's.

UNICEF (2000), A L eague Table of Child Poverty in Rich Nations, Florence, Innocenti Report Card Issue 1, http:// www.unicef-icdc.org/ pdf/ poverty.pdf.

Walker, R. and Wiseman, M. (1997), "The possibility of a British earned income tax credit', Fiscal Studies, vol. 18, pp. 401-25. 